Oxidation behavior and chlorination treatment to improve oxidation resistance of Nb-Mo-Si-B alloys

by

\title{
Vikas Behrani
}

\author{
A thesis submitted to the graduate faculty \\ in partial fulfillment of the requirements for the degree of \\ MASTER OF SCIENCE
}
Major: Materials Science and Engineering
Program of Study Committee:
Mufit Akinc, Co-major Professor
Matthew J. Kramer, Co-major Professor
Kurt R. Hebert

Iowa State University

Ames, Iowa 


\section{Graduate College \\ Iowa State University}

This is to certify that the master's thesis of

\section{Vikas Behrani}

has met the thesis requirements of Iowa State University

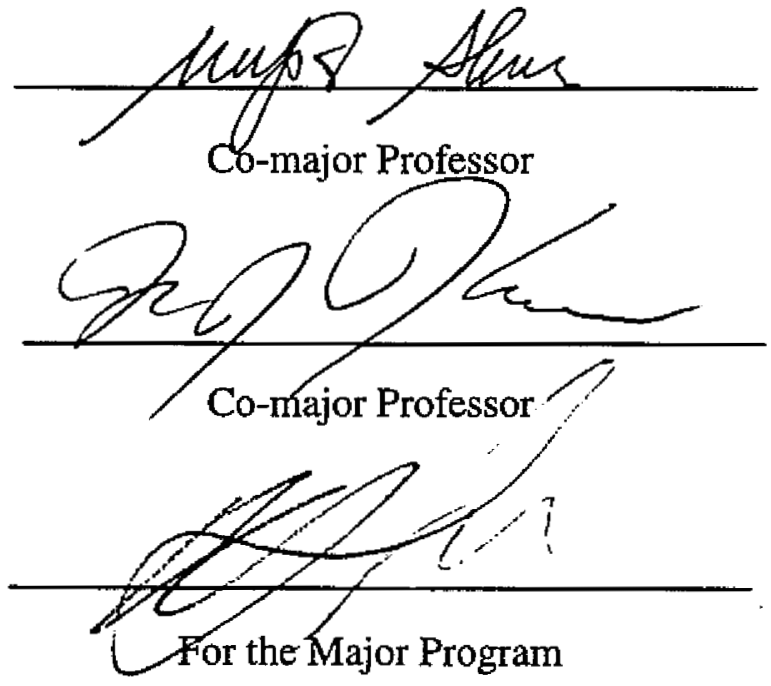




\section{TABLE OF CONTENTS}

CHAPTER 1:GENERAL INTRODUCTION

Literature Review

References

CHAPTER 2:MICROSTRUCTURE AND OXIDATION BEHAVIOR OF

$\mathrm{Nb}-\mathrm{Mo}-\mathrm{Si}-\mathrm{B}$ ALLOYS

$\begin{array}{lr}\text { Abstract } & 23 \\ \text { I. Introduction } & 24 \\ \text { I. Experimental } & 26 \\ \text { III. Results and Discussion } & 27 \\ \text { IV. Summary } & 34 \\ \text { Acknowledgement } & 35 \\ \text { References } & 35 \\ \text { Tables and Figures } & 37 \\ \text { Figure Captions } & 51\end{array}$

CHAPTER 3:CHLORINATION TREATMENT TO IMPROVE OXIDATION 54

RESISTANCE OF Nb-Mo-Si-B ALLOYS

Abstract

54

I. Introduction $\quad 55$

II. Experimental Procedure $\quad 57$

III. Results and Discussion $\quad 58$

IV. Summary 63

Acknowledgement 64

References $\quad 64$

Tables and Figures $\quad 66$

$\begin{array}{ll}\text { Figure Captions } & 77\end{array}$

CHAPTER 4:GENERAL CONCLUSIONS $\quad 79$

$\begin{array}{ll}\text { References } & 81\end{array}$

$\begin{array}{ll}\text { ACKNOWLEDGEMENTS } & 82\end{array}$ 


\section{CHAPTER 1}

\section{GENERAL INTRODUCTION}

This thesis is written in an alternate format. The thesis is composed of a general introduction, two original manuscripts, and a general conclusion. References cited within each chapter are given at the end of each chapter. The general introduction starts with the driving force behind this research, and gives an overview of previous work on boron doped molybdenum silicides, $\mathrm{Nb} / \mathrm{Nb}_{5} \mathrm{Si}_{3}$ composites, boron modified niobium silicides and molybdenum niobium silicides. Chapter 2 focuses on the oxidation behavior of $\mathrm{Nb}-\mathrm{Mo}-\mathrm{Si}-\mathrm{B}$ alloys. Chapter 3 contains studies on a novel chlorination technique to improve the oxidation resistance of Nb-Mo-Si-B alloys. Chapter 4 summarizes the important results in this study.

\section{Literature Review}

For civilian and military applications, there is an increasing need for materials, which can be used at high temperature to improve energy efficiency. Potential uses for high temperature materials include industrial furnace elements, power generation components, aircraft turbine engine hot section components such as blades, combustors, nozzles, and so on. In terms of candidate materials for high temperature structural application, there is a temperature cut off at $\sim 1000^{\circ} \mathrm{C}$ [1]. Below this temperature, it is possible to use nickel and cobalt-base superalloys and aluminide intermetallics. However, above $1000^{\circ} \mathrm{C}$, for oxidation and strength reasons, one must shift to the silicon-based ceramics, advanced intermetallics, and silicidebased materials. Transition metal silicides show good potential for use as structural materials in excess of $1000^{\circ} \mathrm{C}$. Silicides can provide exceptional high-temperature corrosion resistance under oxidizing and sulfidizing conditions characteristic of many fossil energy environments and thus are potential candidate materials for protective coatings. Especially, $\mathrm{M}_{5} \mathrm{Si}_{3}$ type compounds are attractive due to their high melting temperature, relatively low density and good creep resistance [2]. Drawbacks of single phase $\mathrm{M}_{5} \mathrm{Si}_{3}$ include brittle fracture at ambient temperature. However, some of these silicides can be equilibrium with the terminal refractory metal (or alloy) phase, and therefore offer the potential for ductile phase toughing 
by forming $\mathrm{M}_{3} \mathrm{M}_{5} \mathrm{Si}_{3}$ composite. Extensive studies [3,4] have demonstrated that two-phase $\mathrm{Nb} / \mathrm{NbSi}_{3}$ alloys have a good balance of low temperature toughness and high temperature strength. However, $\mathrm{Nb} / \mathrm{Nb}_{5} \mathrm{Si}_{3}$ alloys still suffer from catastrophic oxidation upon exposure to air at temperature above $500^{\circ} \mathrm{C}$.

It was previously reported that the addition of boron to $\mathrm{Mo}_{5} \mathrm{Si}_{3}$ results in substantial improvement in high-temperature oxidation resistance [5,6]. Boron doped molybdenum silicides provide good oxidation resistance and high strength at elevated temperature, but low fracture toughness limits its use as the high temperature structural material.

$\mathrm{Nb}-\mathrm{Si}-\mathrm{B}$ ternary phase diagram suggests a large phase field, which offers a possibility of ductile-phase toughening of the brittle niobium silicide; however, past research in this group as well as elsewhere showed that boron modified niobium silicide does not have a good oxidation resistance at high temperature [8,9]. Because of the complete solid solubility between $\mathrm{Nb}$ and $\mathrm{Mo}$, two-phase structure, $(\mathrm{Nb}, \mathrm{Mo}$ ) metal plus boron modified ( $\mathrm{Nb}, \mathrm{Mo}$ ) silicide, may exist and combine the good properties of low temperature toughness and high temperature oxidation resistance. Past work [8] on Nb-Mo-Si-B alloys showed that the quaternary system is not oxidation resistant as Mo-Si-B system. The difference in oxidation resistance between boron-doped $\mathrm{Mo}-\mathrm{Si}$ and $\mathrm{Nb}-\mathrm{Si}$ may be interpreted in terms of the volatility of oxide. $\mathrm{MoO}_{3}$ volatize forming pores and way for glass to flow and make protective glass layer but $\mathrm{Nb}_{2} \mathrm{O}_{5}$ does not volatilize and thus a thin protective borosilicate layer does not form[9]. It was thought that if $\mathrm{Nb}_{2} \mathrm{O}_{5}$ that form during exposure to air atmosphere is volatilized by gas phase reactions, the scale may behave like Mo-Si-B intermetallic and hence can be rendered oxidation resistant. This led us to chlorination process to selectively remove $\mathrm{Nb}_{2} \mathrm{O}_{5}$ from the oxide layer and study microstructure and oxidation behavior after chlorination.

\section{Mo-Si-B System}

Mo-Si-B system intermetallics have been attracting attention as promising candidate materials for high temperature applications, especially materials containing $\mathrm{Mo}_{5} \mathrm{Si}_{3}\left(\mathrm{~T}_{1}\right)$ phase. The Mo-Si-B phase diagram was first investigated by Nowotny [10] in the 1950's. The isothermal section of the phase diagram at $1600^{\circ} \mathrm{C}$ is shown in Figure 1. The crystal 
structure of impurity-free $\mathrm{Mo}_{5} \mathrm{Si}_{3}$ is tetragonal $\mathrm{W}_{5} \mathrm{Si}_{3}$ having the space group I4/mcm. The $\mathrm{Mo}_{5} \mathrm{Si}_{3}$ unit cell is very large and complex, and contains four formula units. The homogeneity ( $\sim 2.5$ at $\%$ silicon) of $\mathrm{Mo}_{5} \mathrm{Si}_{3}$ makes the production of a single-phase material much easier compared to the line compounds $\mathrm{Mo}_{3} \mathrm{Si}$ and $\mathrm{MoSi}_{2}$.

Because of the stability of $\mathrm{Mo}_{3} \mathrm{Si}$, terminal solid solution Mo can not co-exist with the brittle $\mathrm{Mo}_{5} \mathrm{Si}_{3}$ in thermodynamic equilibrium. Small amount of boron is incorporated into the $\mathrm{Mo}_{5} \mathrm{Si}_{3}$ and yields a ternary phase, $\mathrm{T}_{1}$, with the tetragonal $\mathrm{W}_{5} \mathrm{Si}_{3}$-type structure. Nowotny reported that $\mathrm{T}_{1}\left(\mathrm{Mo}_{5} \mathrm{Si}_{3} \mathrm{~B}_{\mathrm{x}}\right)$ has a maximum solubility of 4.5 at.\% boron, but recent work performed by Huebsch[11] suggests that the boron solubility is much lower, approximately 2 at\%. Nowotny also reported another ternary phase, $\mathrm{T}_{2}$, with higher boron content $\left(\mathrm{Mo}_{5} \mathrm{SiB}_{2}\right)$. The structure was determined to be tetragonal $\mathrm{Cr}_{5} \mathrm{~B}_{3}$-type. Oxidation of $\mathrm{Mo}_{5} \mathrm{Si}_{3}$ is characterized by porous scale formation and active oxidation below about $1650^{\circ} \mathrm{C}$.

Scale porosity allows oxygen transport via a short circuit path to the underlying silicide, allowing faster oxidation than would be expected from a diffusion-controlled process.

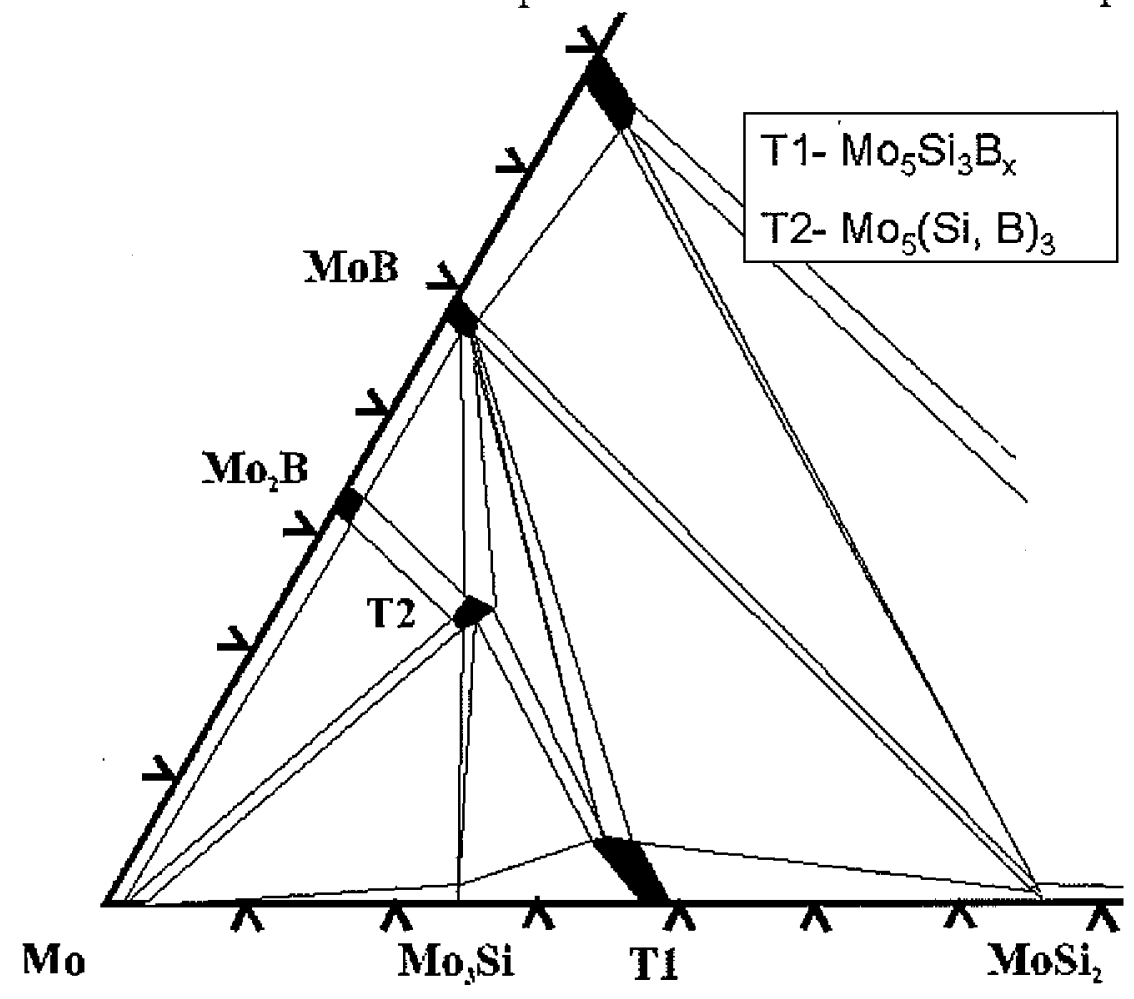

Figure 1 Isothermal cut of the Mo-Si-B ternary phase diagram at $1600{ }^{\circ} \mathrm{C}$ 
Bartlett et al explained the oxidation of Mo by the partial pressure of oxygen at the oxidation interface [12]. The model is based on the premise that, in order to maintain $\mathrm{P}_{\mathrm{O} 2}$ at the level thermodynamically indicated by $\mathrm{Si} / \mathrm{SiO}_{2}$ equilibria, the rate of $\mathrm{Si}$ supply to the oxidation interface must be faster than the rate of $\mathrm{Si}$ consumption due to reaction with $\mathrm{O}_{2}$. If the $\mathrm{Si}$ supply rate is slower than Si consumption rate, the oxidation interface become silicondepleted and oxygen partial pressure at interface increases. An increasing in $\mathrm{P}_{\mathrm{O} 2}$ will lead to oxidation and volatilization of Mo, causing the scale to rupture and become non-passivating . When temperature is higher, Si diffusion rate is sufficiently high and no Mo is oxidized. A protective $\mathrm{SiO}_{2}$ layer is formed [12].

It has been shown by Meyer et al [5,6] that doping $\mathrm{Mo}_{5} \mathrm{Si}_{3}$ 1-2 wt\% boron significantly improves the oxidation resistance of $\mathrm{Mo}_{5} \mathrm{Si}_{3}$ by several orders of magnitude [5]. Mechanism of high oxidation resistance of boron-doped $\mathrm{Mo}_{5} \mathrm{Si}_{3}$ is also explained by Meyer et al. At $600^{\circ} \mathrm{C}$, the scale is composed of three distinct areas: small pockets of borosilicate glass and almost pure $\mathrm{MoO}_{3}$ are surrounded by a matrix of mixed molybdenum and silicon oxides. At $633^{\circ} \mathrm{C}$, Iarger $\mathrm{MoO}_{3}$ crystals begin to form around "pure" $\mathrm{MoO}_{3}$. At $750^{\circ} \mathrm{C}, \mathrm{MoO}_{3}$ begins to sublime, which leads to the decrease of both number and size of $\mathrm{MoO}_{3}$ crystals. Viscous flow starts at $1000^{\circ} \mathrm{C}$ and then a coherent protective layer is formed.

Oxygen pressure at oxidation interface, porosity and viscosity are the keys for forming a protective layer. If oxidation is limited by oxygen diffusion, oxygen partial pressure will be fixed by the $\mathrm{Si} / \mathrm{SiO}_{2}$ equilibria. $\mathrm{SiO}_{2}$ has a much lower free energy of formation than any molybdenum oxide. The dominant oxidation reaction will be:

$$
\mathrm{Mo}_{5} \mathrm{Si}_{3}+3 \mathrm{O}_{2} \rightarrow 5 \mathrm{Mo}+3 \mathrm{SiO}_{2}
$$

A silicon depleted and molybdenum rich interlayer will thus form.

On the other hand, if the partial pressure of oxygen at the interface is high enough to oxide molybdenum, oxidation will be:

$$
2 \mathrm{Mo}_{5} \mathrm{Si}_{3}+21 \mathrm{O}_{2} \rightarrow 10 \mathrm{MoO}_{3}(\text { volatile })+6 \mathrm{SiO}_{2}
$$

It predicts a mass loss due to volatilization of $\mathrm{MoO}_{3}$. A metallic Mo interlayer will not form $[5]$. 
When viscous flow doesn't close pores, porosity of the layer determines the steady state oxidation rate. When viscous flow forms a coherent layer, oxidation is controlled by diffusion rate of oxygen through the layer $[5,6]$.

Boron doping of $\mathrm{Mo}_{5} \mathrm{Si}_{3}$ does not appear to decrease the high creep strength of $\mathrm{Mo}_{5} \mathrm{Si}_{3}$ due to the complex unit cell. The creep rate for a three-phase microstructure consisting of $T_{1}$ matrix and $\mathrm{Mo}_{3} \mathrm{Si}$ and $\mathrm{T}_{2}$ is $1.1 \times 10^{-6} \mathrm{~s}^{-1}$ at $1300^{\circ} \mathrm{C}$ under $140 \mathrm{MPa}$. No dislocation motion was observed in $\mathrm{T}_{1}$ phase. Only a few dislocations were noted in $\mathrm{T}_{2}$. The average activation energy was determined to be $\sim 400 \mathrm{~kJ} / \mathrm{mol}$. [5]

$\mathrm{Mo}_{5} \mathrm{Si}_{3}$ single crystal has significant thermal expansion anisotropy along the a and $c$ directions. The measured thermal expansion coefficient of $\mathrm{Mo}_{5} \mathrm{Si}_{3}$ single crystal is: $\alpha_{a}=5.2 \times 10^{-6}{ }^{\circ} \mathrm{C}^{-1}, \alpha_{c}=11.5 \times 10^{-6}{ }^{\circ} \mathrm{C}^{-1}$ and $\alpha_{a} / \alpha_{c}=2.2$ [13]. This can result in a substantially high residual thermal stresses, up to $1.8 \mathrm{GPa}$, due to thermal expansion mismatch between different grains in the polycrystalline $\mathrm{Mo}_{5} \mathrm{Si}_{3}$ materials. These large stresses can fracture weakly bonded grain boundaries in cooling processes during fabrication, resulting in grain boundary cracking.

Recent study in this group $[13,14]$ indicates the addition of boron or change of the Mo:Si ratio have minor effects on the thermal expansion anisotropy behavior of $\mathrm{T} 1$ phase. This was the motivation of recent studies $[8,15]$ to incorporate $\mathrm{Nb}$ into $\mathrm{Mo}-\mathrm{Si}-\mathrm{B}$ system to improve mechanical properties while retaining oxidation resistance. 


\section{Nb-Si System}

Niobium silicide base alloys have a strong potential as high temperature structural materials due to their high melting point over $2000^{\circ} \mathrm{C}$ and excellent strength [16] even at temperature above $1200^{\circ} \mathrm{C}$. There are three silicides of Niobium: $\mathrm{Nb}_{3} \mathrm{Si}$, which is only stable between $1765^{\circ} \mathrm{C}$ and $1975^{\circ} \mathrm{C} ; \mathrm{NbSi}_{2}$ and $\mathrm{Nb}_{5} \mathrm{Si}_{3}$, with the highest melting point in the $\mathrm{Nb}-\mathrm{Si}$ system[17].

\section{$\mathrm{Nb}_{5} \mathrm{Si}_{3}$}

The correct stoichiometry of $\mathrm{Nb}_{5} \mathrm{Si}_{3}$ was first identified by Knapton [18] in 1955. The latest

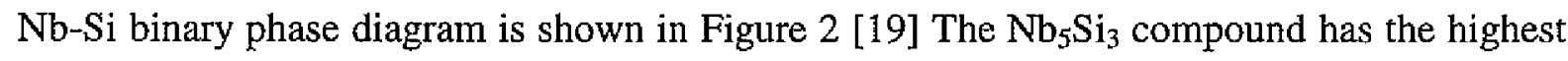
melting temperature of $2515^{\circ} \mathrm{C}$ in Nb-Si system and low density $\left(7.11 \mathrm{gm} / \mathrm{cm}^{3}\right)$ [16]. $\mathrm{Nb}_{5} \mathrm{Si}_{3}$ has very limited range of solubility in with niobium and $\mathrm{NbSi}_{2}$. It has two tetragonal equilibrium phases with a transition at $1940^{\circ} \mathrm{C} . \alpha-\mathrm{Nb}_{5} \mathrm{Si}_{3}$ is stable below $1935^{\circ} \mathrm{C}$, while $\beta$ $\mathrm{Nb}_{5} \mathrm{Si}_{3}$ is stable above $1645^{\circ} \mathrm{C}$. Owing to their complex crystal structures, plastic deformation of monolithic $\mathrm{Nb}_{5} \mathrm{Si}_{3}$ will be limited even in the high temperature range. An incorporation of a ductile phase to brittle $\mathrm{Nb}_{5} \mathrm{Si}_{3}$ phase resulting in two-phase silicide alloy will be one way to improve room temperature deformability.

$\mathrm{Nb}_{5} \mathrm{Si}_{3}$ shows brittle fracture behavior at low temperatures. However, from $\mathrm{Nb}-\mathrm{Si}$ phase diagram, the terminal niobium solid solution and $\mathrm{Nb}_{5} \mathrm{Si}_{3}$ coexist up to temperature of $1645^{\circ} \mathrm{C}$. So the $\mathrm{Nb}-\mathrm{Si}$ system offers a possibility of ductile-phase toughing of the brittle $\mathrm{Nb}_{5} \mathrm{Si}_{3}$ with the niobium solid solution. This concept has led to alloy development efforts oriented toward two-phase/multi-phase systems, wherein the goal is to achieve a balance of properties for structural use such as high melting temperatures, high stiffness, low densities, and good hightemperature strength/creep resistance. 


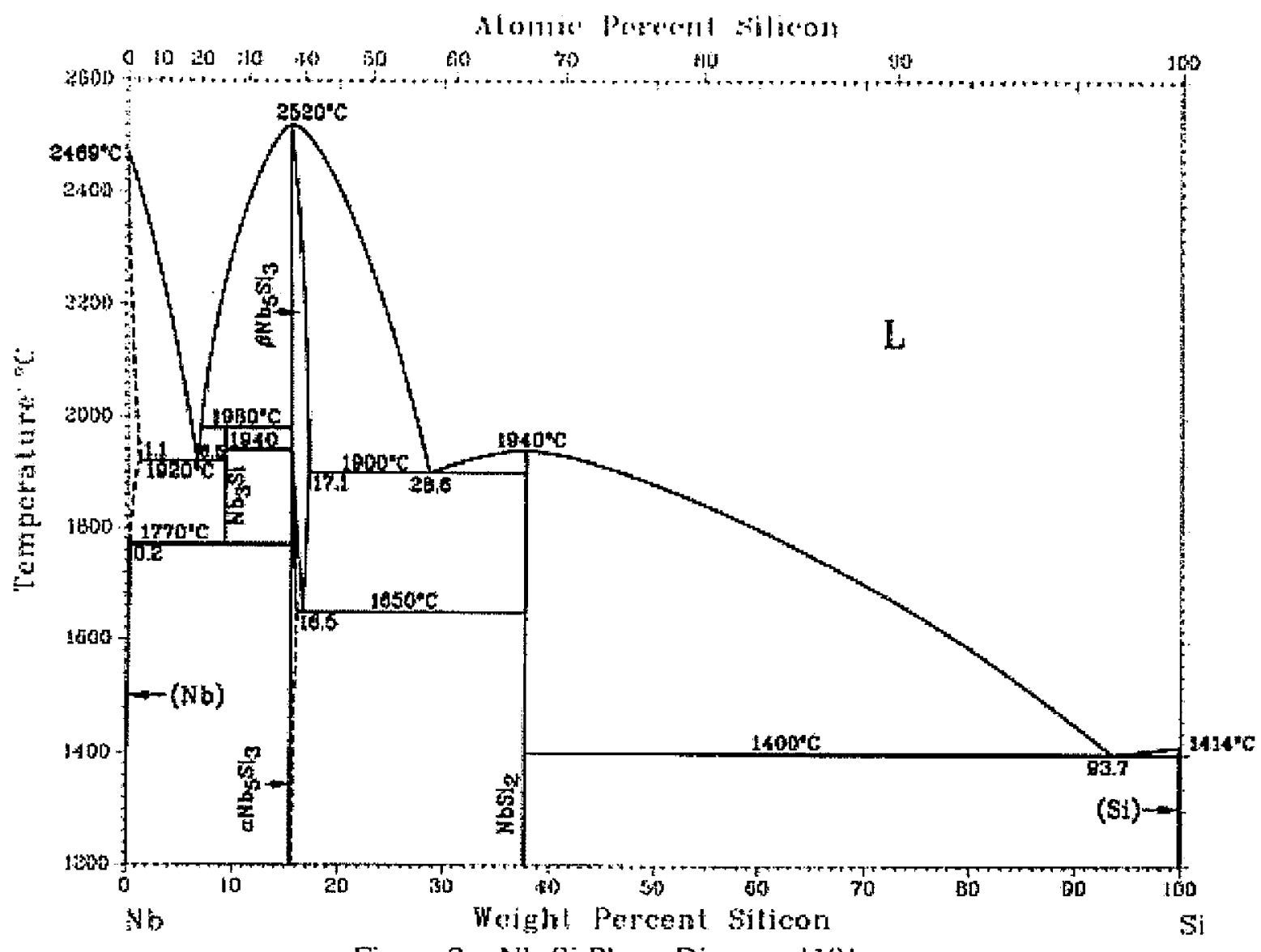

Figure 2 Nb-Si Phase Diagram [19] 


\section{$\mathrm{Nb} / \mathrm{Nb}_{5} \mathrm{Si}_{3}$ composites}

Niobium silicide in-situ composites have been extensively studied for high temperature applications. Its properties are discussed in brief as follows:

\section{Creep Behavior}

There have been several recent studies on the creep resistance of Nb-Si in-situ composites $[16,20,21,22,23,24,25]$. In a series of papers [22, 23, 24, 25], Henshall and co-workers investigated the primary and steady state creep response of ductile-phase toughened $\mathrm{Nb}_{5} \mathrm{Si}_{3} / \mathrm{Nb}$ in-situ composites through a combination of analytical modeling and numerical simulation, using experimental data generated by Subramanian et al. [16,20]. These studies, which treated the $\mathrm{Nb}_{5} \mathrm{Si}_{3}$ as the continuous phase, demonstrated that the creep behavior of the in-situ composites is dominated by the silicide phase, which is stronger and bears a higher load than the weaker $\mathrm{Nb}$ solid solution. At a given stress, the steady state creep rate of the niobium silicide in-situ composites $[20,21]$ is significantly lower than that of the $\mathrm{Nb}_{s s}$ phase, even though it is higher than that exhibited by monolithic silicides [16]. The creep exponent of the in-situ composite is about 2 [20,21], compared with $\approx 1$ for $\mathrm{Nb}_{5} \mathrm{Si}_{3}$ [16] and 5.8 for $\mathrm{Nb}$ $[22,23]$ or $\mathrm{Nb}(\mathrm{Si})$ solid solution [25].

\section{Thermal expansion}

The thermal expansion coefficients of niobium $\left(7 \times 10^{-6} / \mathrm{C}\right.$ for pure $\left.\mathrm{Nb}\right)$ and niobium silicide $\left(\mathrm{Nb}_{5} \mathrm{Si}_{3}\right)\left(6.2 \times 10^{-6} / \mathrm{C}\right)$ are not appreciably different [3], so the interface between composite phases will not suffer excess stress during thermal cycling.

\section{Strength}

The strength increases and ductility decreases for $\mathrm{Nb} / \mathrm{Nb}_{5} \mathrm{Si}_{3}$ with increasing $\mathrm{Si}$ content in the $\mathrm{Nb}-10$ to $16 \mathrm{Si}$ range[28]. In the as-cast + heat-treated alloys, a high level of strength is retained in the temperature range of $1400^{\circ} \mathrm{C}$ to $1600^{\circ} \mathrm{C}$, even though these alloys are totally brittle at temperature below $1000^{\circ} \mathrm{C}$. 


\section{Fracture toughness}

The room temperature fracture toughness of the $\mathrm{Nb}$-Si system ranged from $13 \mathrm{MPam}^{1 / 2}$ for a $\mathrm{Nb}-16.5 \mathrm{Si}$ alloy to about $21 \mathrm{MPam}^{1 / 2}$ for a $\mathrm{Nb}-10 \mathrm{Si}$ alloy [29]. However, we know the monolithic $\mathrm{Nb}_{5} \mathrm{Si}_{3}$ intermetallic shows a room temperature fracture toughness of only $\rightarrow 3$ $\mathrm{MPam}^{1 / 2}$. The results show that the room temperature fracture toughness of the composite is considerably greater than that of the intermetallic and that the toughness of the composite can be affected by the way it is processed.

\section{Oxidation Resistance}

It is well recognized that all $\mathrm{Nb}$-based alloys suffer from catastrophic oxidation and oxygen penetration embrittlement upon exposure to air at temperatures above $500^{\circ} \mathrm{C}$. [28] High metal recession rates, spalling, and general structural disintegration typically characterize the hightemperature oxidation behavior of the $\mathrm{Nb}-\mathrm{Nb}_{5} \mathrm{Si}_{3}$ alloys. Further, the fast diffusion of oxygen throughout the oxide layers or through the grain boundaries, followed by dissolution of oxygen within the $\mathrm{Nb}$ phase, results in substantial hardening and embrittlement of the $\mathrm{Nb}$ phase. The oxidation of $\alpha-\mathrm{Nb}_{5} \mathrm{Si}_{3}$ crystal was measured by Okada [30] with TG and DTA . The oxidation begins to proceed in the temperature range of about $430^{\circ} \mathrm{C}$. The oxidation product was found to be $\mathrm{Nb}_{2} \mathrm{O}_{5}$. Although a $\mathrm{SiO}_{2}$ was not detected in his experiment, he suggested the noncrystalline or amorphous $\mathrm{SiO}_{2}$ was probably formed during the oxidation reaction. Jackson et al [31] also reported the single phase $\mathrm{Nb}_{5} \mathrm{Si}_{3}$ oxidized rapidly, and formed a very voluminous, thick scale. The oxidative instability of $\mathrm{Nb}-\mathrm{Si}$ alloys led researchers $[7,8,9]$ to add small amount of boron in Nb-Si alloys as to imitate the Mo-Si-B system to form a protective borosilicate glass layer 


\section{Nb-Si-B System}

Nowotny[32] determined the isothermal section of $\mathrm{Nb}-\mathrm{Si}-\mathrm{B}$ at $1600^{\circ} \mathrm{C}$ (Figure 3). He reported the boron will be interstitially built into $\mathrm{Nb}_{5} \mathrm{Si}_{3}$ and form $\mathrm{Nb}_{5} \mathrm{Si}_{3}(\mathrm{~B})$ with $\mathrm{D} 8_{8}$ structure ( $\mathrm{Mn}_{5} \mathrm{Si}_{3}$-type, hexagonal). The lattice parameters for 5 at. \% boron [33] are: $\mathrm{a}=7.54$, $\mathrm{c}=5.25$. When $\mathrm{B} / \mathrm{Si}$ substitution takes places, $\mathrm{Nb}_{5}(\mathrm{Si}, \mathrm{B})_{3}$ is formed. $\mathrm{Nb}_{5}(\mathrm{Si}, \mathrm{B})_{3}$ has a bodycentered tetragonal $\mathrm{Cr}_{5} \mathrm{~B}_{3}$-type structure which is called $\mathrm{T}_{2}$ phase by Nowotny. The lattice parameters of $\mathrm{Nb}_{5}(\mathrm{Si}, \mathrm{B})_{3}$ for 5 at. \% boron are: $\mathrm{a}=6.46, \mathrm{c}=11.75 \AA$.

Murakami et al [9] studied the microstructure, mechanical properties and oxidation behavior of powder compacts, prepared by spark plasma sintering, of the $\mathrm{Nb}-\mathrm{Si}-\mathrm{B}$ system in the $\mathrm{Nb}_{5} \mathrm{Si}_{3}-\mathrm{NbB}_{2}-\mathrm{NbSi}_{2}$ triangle, which contains ternary phase $\mathrm{D} 8_{8}$ (Figure 4)

Compacts of the system was found to consist of two or three of $\mathrm{NbB}_{2}, \mathrm{Nb}_{5} \mathrm{Si}_{3}, \mathrm{Nb}_{5} \mathrm{Si}_{3} \mathrm{~B}_{2}$ and $\mathrm{NbSi}_{2}$ phases depending on the composition unless a large amount of silicon is consumed by forming $\mathrm{SiO}_{2}$. It was found that compacts with compositions on the line of $\mathrm{Nb}_{5} \mathrm{Si}_{3}-\mathrm{Nb}_{5} \mathrm{Si}_{3} \mathrm{~B}_{2}-\mathrm{NbB}_{2}$ generally exhibit high micro vickers hardness ( 1.5-2.0KHv) at room temperature and a high compressive strength at high temperatures $\left(-1700^{\circ} \mathrm{C}\right)$. The oxidation results (Figure 6) showed that oxidation resistance increases in the sequence $\mathrm{NbB}_{2}, \mathrm{Nb}_{5} \mathrm{Si}_{3}$, $\mathrm{D}_{88}(56 \mathrm{Nb}-34 \mathrm{Si}-10 \mathrm{~B})$ and $\mathrm{NbSi}_{2}$. The oxide layer of $\mathrm{D}_{88}(56 \mathrm{Nb}-34 \mathrm{Si}-10 \mathrm{~B})$ is as thick as 230 $\mu \mathrm{m}$ after exposing to air at $1250^{\circ} \mathrm{C}$ for 5 hours, and is composed of $\mathrm{Nb}_{2} \mathrm{O}_{5}, \mathrm{SiO}_{2}$ and a large number of pores. The oxidation resistance of $\mathrm{Nb}_{5} \mathrm{Si}_{3} \mathrm{~B}_{2}$ is found to be better than that of $\mathrm{Nb}_{5} \mathrm{Si}_{3}$ for the short duration oxidation experiment, but not as good as that of $\mathrm{NbSi}_{2}$ by the boron addition responsible for the formation of $\mathrm{Nb}_{5} \mathrm{Si}_{3} \mathrm{~B}_{2}$. Figure 5 shows the oxidation induced mass change for compositions studied by Murakami et al [9].

Liu et al $[7,8]$ studied the oxidation behavior of $\mathrm{Nb}-\mathrm{Si}-\mathrm{B}$ compacts at $1000^{\circ} \mathrm{C}$ (Figure 6 ). Boron-containing phases, $\mathrm{T}_{2}$ and $\mathrm{D} 8_{8}$, showed better oxidation resistance than $\mathrm{Nb}_{5} \mathrm{Si}_{3}$, but they are still extremely poor compared to boron-modified $\mathrm{Mo}_{5} \mathrm{Si}_{3}$. The oxide scale was composed of a fine mixture of $\mathrm{Nb}_{2} \mathrm{O}_{5}$ and borosilicate glass. The inferior oxidation resistance of $\mathrm{Nb}_{5} \mathrm{Si}_{3} \mathrm{~B}_{\mathrm{x}}$ against boron-doped $\mathrm{Mo}_{5} \mathrm{Si}_{3}$ may be attributed to the fact that contrary to $\mathrm{MoO}_{3}$, $\mathrm{Nb}_{2} \mathrm{O}_{5}$ does not volatilize and thus a thin protective borosilicate layer does not form on $\mathrm{Nb}_{5} \mathrm{Si}_{3} \mathrm{~B}_{2}[7,8,9]$. 


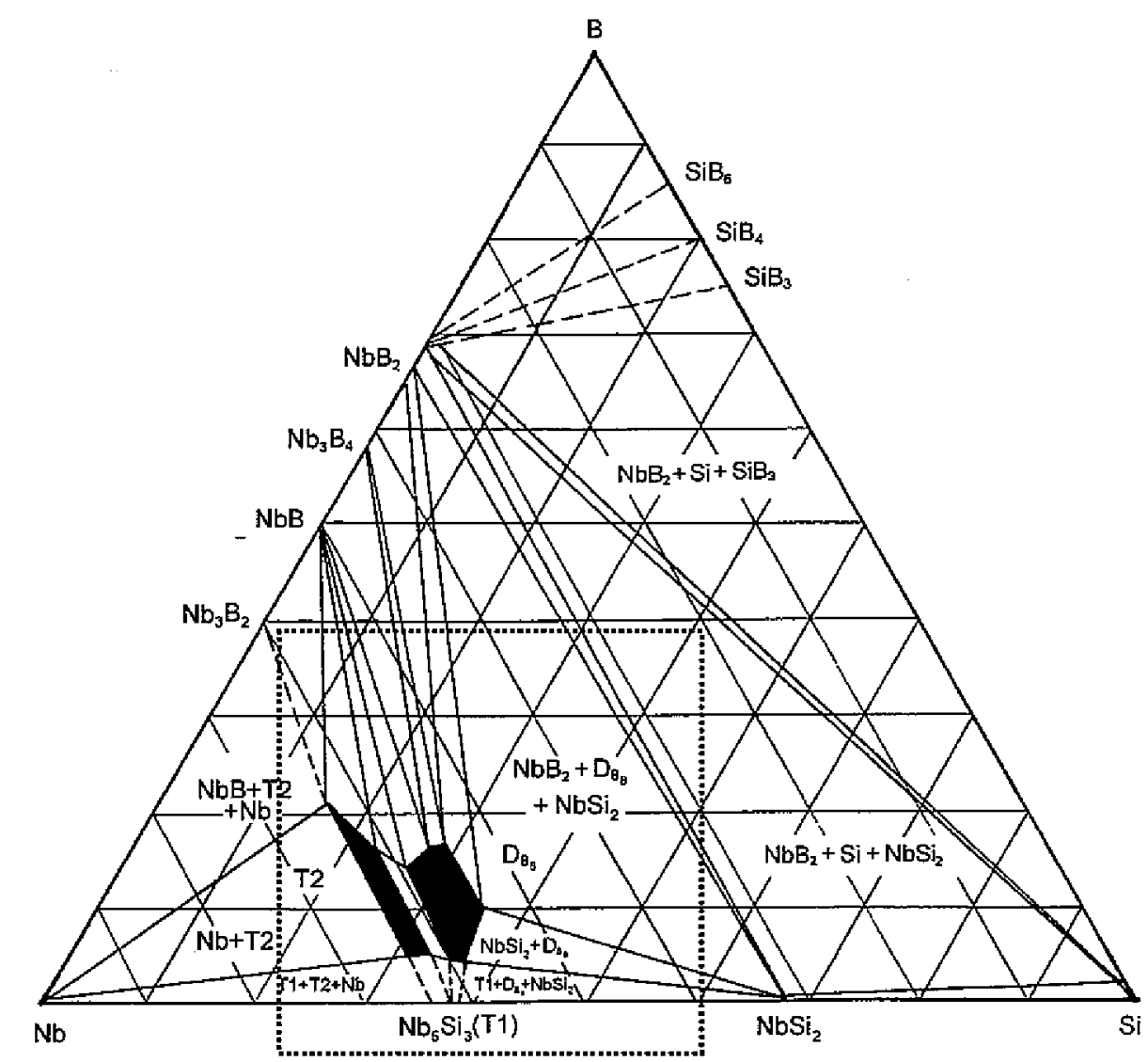

Figure 3 Isothermal section of Nb-Si-B Phase diagram at $1600^{\circ} \mathrm{C}$ [32]

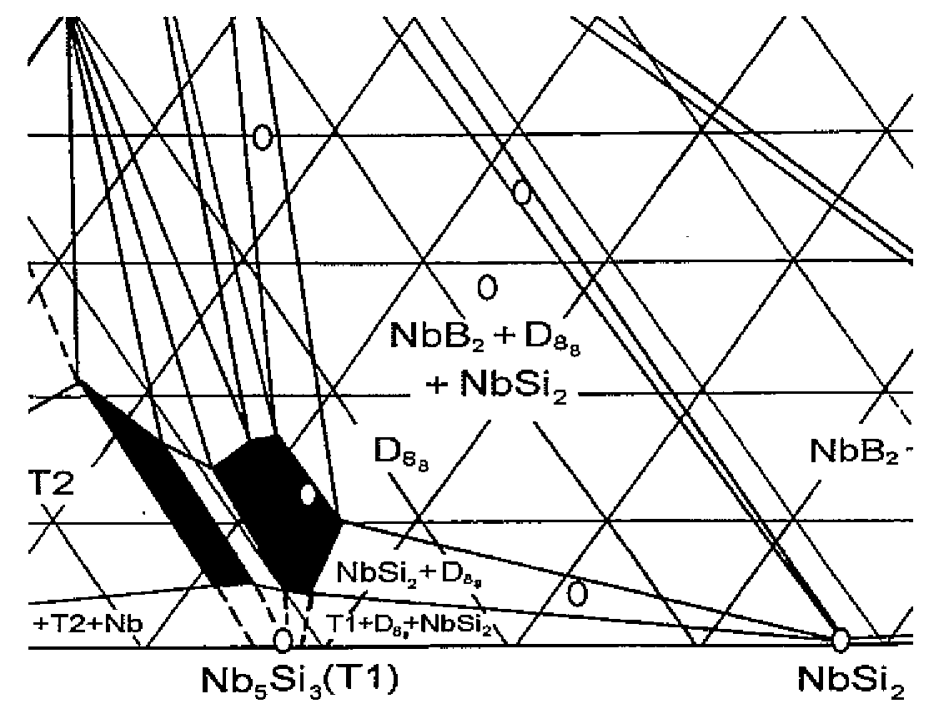

Figure 4 Compositions of $\mathrm{Nb}-\mathrm{Si}-\mathrm{B}$ compacts investigated by Murakami et al (open circles)[9] 


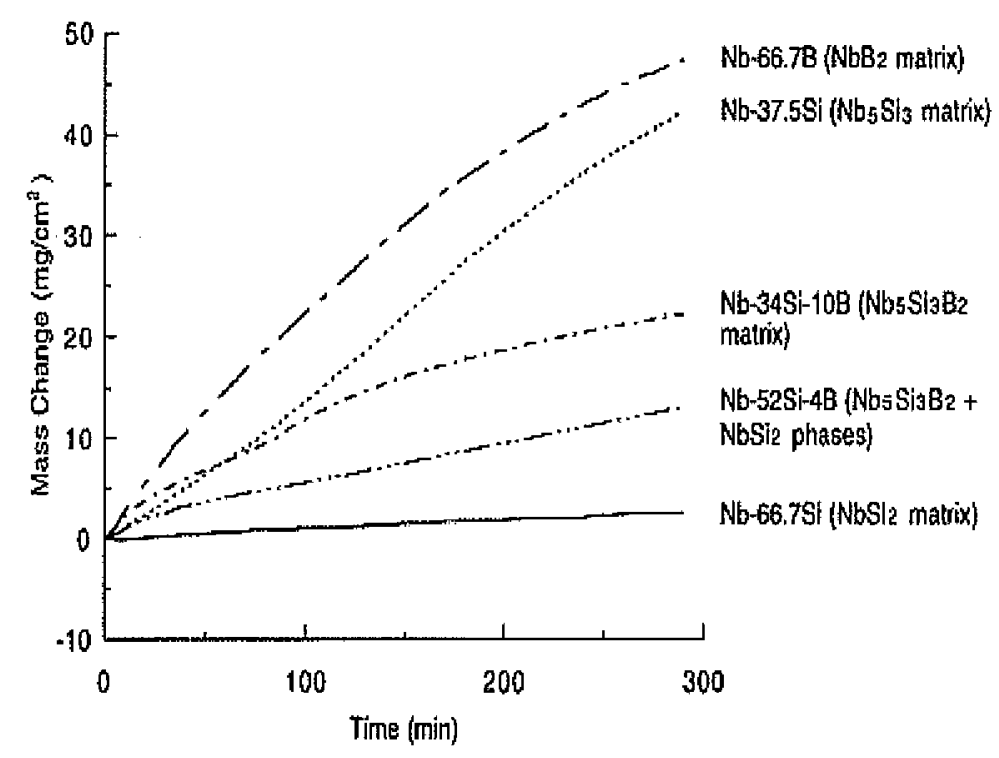

Figure 5 Oxidation-induced mass change of $\mathrm{Nb}$-Si-B powder compacts with five different compositions at $1250^{\circ} \mathrm{C}$ in air as a function of time[9]

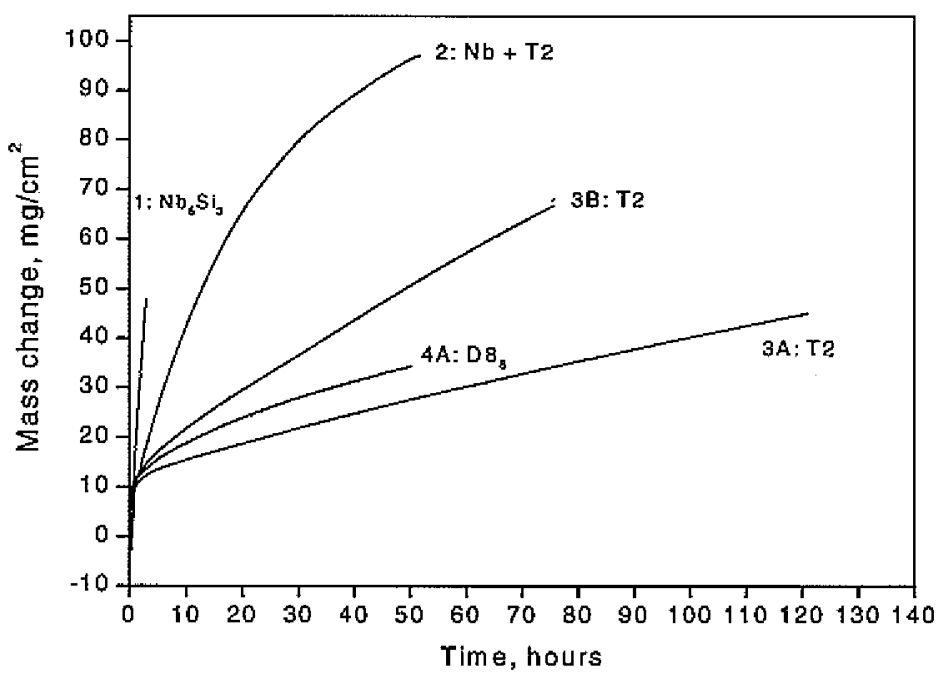

Figure 6 Oxidation-induced mass change of Nb-Si-B arc melted powder compacts different compositions at $1000^{\circ} \mathrm{C}$ in air as a function of time[7,8] 


\section{Nb-Mo-Si-B System}

As discussed earlier, Mo-Si-B system offers a good combination of properties for high temperature application. But its low fracture toughness and thermal expansion anisotropy need to be improved before they can find practical applications. This is the motivation of a recent study to incorporate $\mathrm{Nb}$ into $\mathrm{Mo}-\mathrm{Si}-\mathrm{B}$ system to improve mechanical properties while retaining good oxidation resistance. $\mathrm{Nb}-\mathrm{Si}$ system offers possibility of ductile phase toughening and $\mathrm{Nb}$ metal can coexist in equilibrium with boron containing silicides. Since there is a complete solubility between $\mathrm{Nb}$ and $\mathrm{Mo}$ (Figure 7), the $\mathrm{Nb} / \mathrm{Mo}$ substitution may avoid the formation of $\mathrm{Mo}_{3} \mathrm{Si}$ and then improve the toughness of $\mathrm{T}_{1}\left(\mathrm{Mo}_{5} \mathrm{Si}_{3} \mathrm{~B}_{\mathrm{x}}\right)$ by ductile phase toughening. In addition, $\mathrm{Nb} / \mathrm{Mo}$ substitution may change the lattice parameter of $\mathrm{T} 1$ and subsequently affect the thermal expansion behavior of $\mathrm{T}_{1}$. Thermal expansion anisotropy of Nb-Mo-Si alloys has been studied by Fu et al [34]. They found that the CTE (coefficient of thermal expansion) anisotropy of $\mathrm{Mo}_{5} \mathrm{Si}_{3}$ can be significantly reduced through ternary alloying additions that alter interatomic distance and bonding strength along the atom chains in the $c$-direction. $\mathrm{Nb}$ was found to reduce $\mathrm{CTE}(c) / \mathrm{CTE}(a)$ ratio to a value of 1.5 for $\mathrm{MoNb}_{4} \mathrm{Si}_{3}$ from the 2.2 for $\mathrm{Mo}_{5} \mathrm{Si}_{3}$ as reported previously [35,36,37]. Isothermal oxidation behavior and microstructure of $\mathrm{Nb}-\mathrm{Mo}-\mathrm{Si}-\mathrm{B}$ intermetallic compacts with different compositions and at different temperatures has been studied recently by Liu et al [8] (Figure 8). Desired compositions were prepared by arc melting process and compacts were obtained by grinding followed by pressing and sintering. It is reported that that when metal content $(\mathrm{Nb}+\mathrm{Mo})$ is fixed, the relative density increases as the Mo content increases. In addition, the relative density also increases with the metal content when $\mathrm{Nb} / \mathrm{Mo}$ is fixed. The microstructure depends on the $\mathrm{Nb} / \mathrm{Mo}$ ratio. The co-existence of $\mathrm{T}_{2}$ or $\mathrm{T}_{1}$ with metal phase was obtained in $53 \mathrm{Nb}-17 \mathrm{Mo}-23 \mathrm{Si}-7 \mathrm{~B}$ and $35 \mathrm{Nb}-35 \mathrm{Mo}-23 \mathrm{Si}-7 \mathrm{~b}$ systems. The lattice dimensions reported for $\mathrm{T}_{1}, \mathrm{~T}_{2}$ and $\mathrm{D} 8_{8}$ increased linearly with $\mathrm{Nb} / \mathrm{Mo}$ ratio. Also formation of the $\mathrm{M}_{3} \mathrm{Si}$ was suppressed by substitution of $\mathrm{Nb}$ for Mo. Oxidation studies of Nb-Mo-Si-B alloys with nominal compositions of $\mathrm{Nb} / \mathrm{Mo}=1 / 3,1$ and 3 show that alloys with $\mathrm{Nb} / \mathrm{Mo}=3$ gained mass at a very rapid rate and eventually converted to powder when exposed to air. On the other hand alloys with $\mathrm{Nb} / \mathrm{Mo}=1 / 3$ lost mass due to $\mathrm{MoO}_{3}$ vaporization. $\mathrm{Nb}_{2} \mathrm{O}_{5}$ was present in scale of all alloy compositions. Large oxidation rate constants suggest that Nb-Mo- 
Si-B alloys are not oxidative stable as confirmed by absence of continuous protective glass layer. Formation of non-volatile $\mathrm{Nb}_{2} \mathrm{O}_{5}$ is speculated to be the primary reason behind the oxidative instability of $\mathrm{Nb}-\mathrm{Mo}-\mathrm{Si}-\mathrm{B}$ alloys. Selective removal of $\mathrm{Nb}_{2} \mathrm{O}_{5}$ that forms during initial stages of oxidation was thought to result in improved oxidation resistance by forming continuous glass layer as oxide scale would behave life Mo-Si-B alloys. The idea led us to design the chlorination process to selectively remove $\mathrm{Nb}_{2} \mathrm{O}_{5}$ as volatile $\mathrm{NbCl}_{5}$.

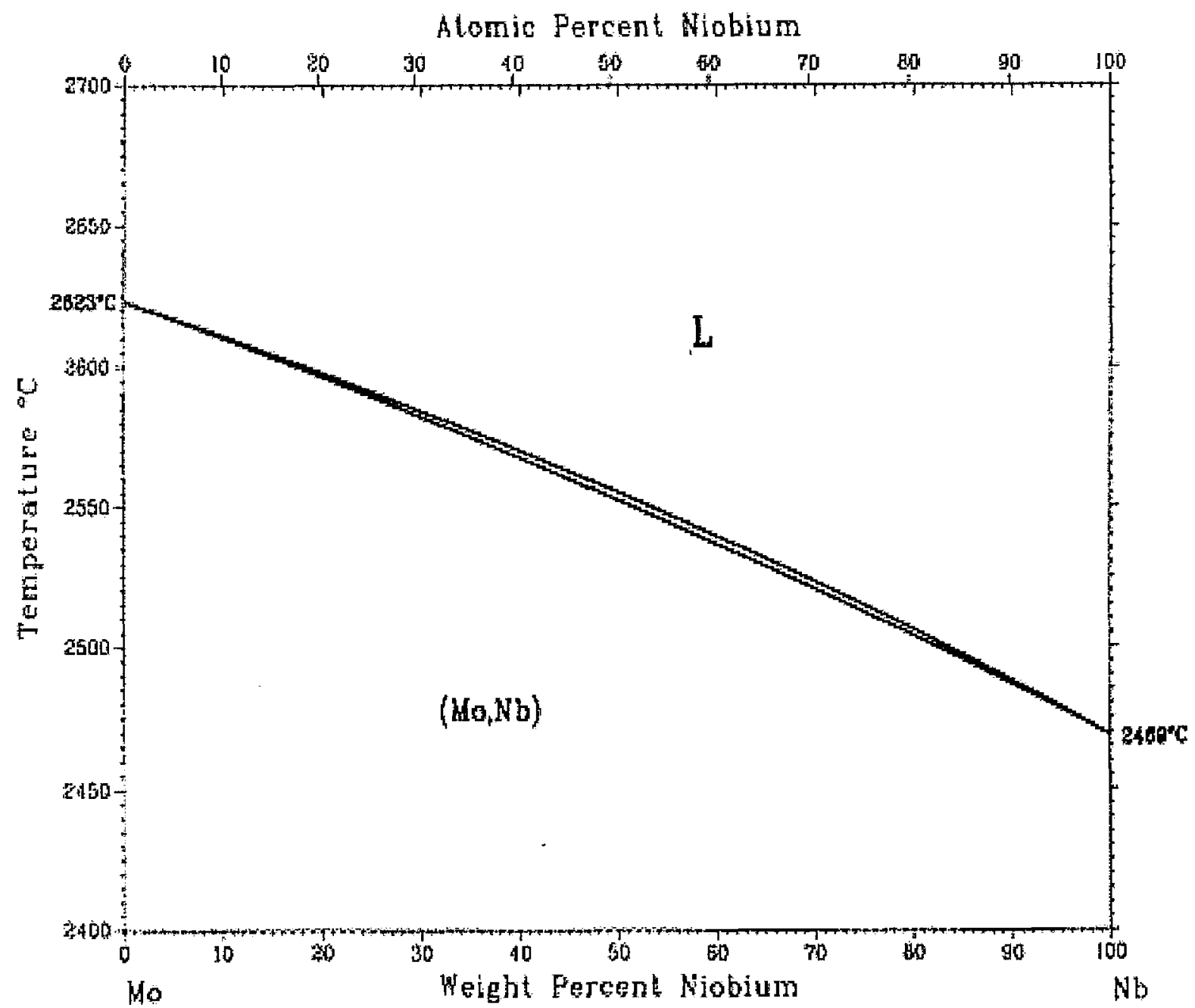

Figure 7 Nb-Mo phase diagram 


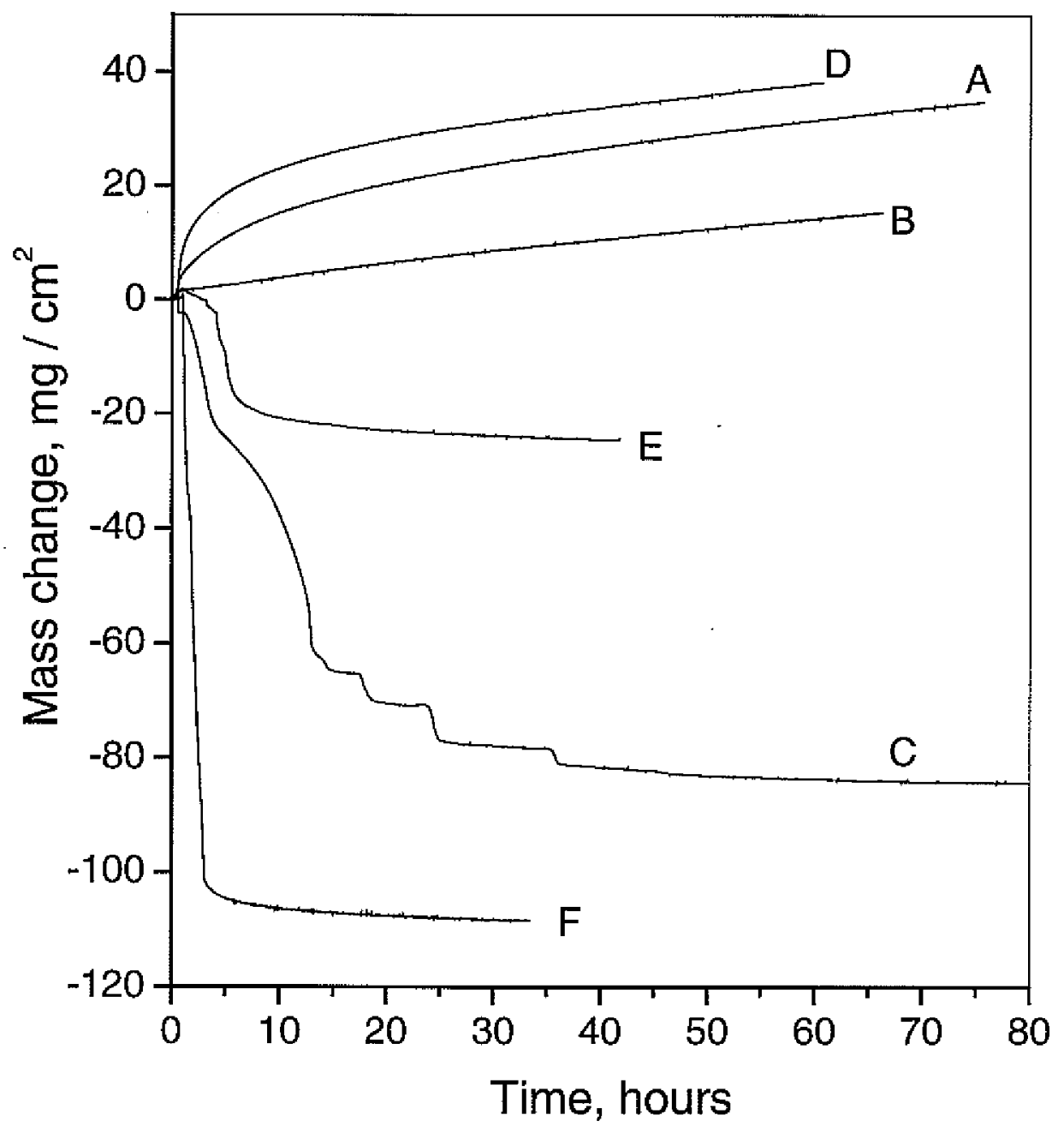

Figure 8 Oxidation induced mass change of Nb-Mo-Si-B powder compacts at $1000^{\circ} \mathrm{C}$ in air as a function of time [8] 


\section{Chlorination}

\section{Statement of Problem}

The non-volatile $\mathrm{Nb}_{2} \mathrm{O}_{5}$, which is one of the oxidation products during oxidation of Nb-MoSi-B alloys, seems to be the main reason for its poor oxidation resistance. In Mo-Si-B system, $\mathrm{MoO}_{3}$ volatilization leads to formation of pores which in turn gets healed by the viscous flow of borosilicate glass and leading to formation of the protective layer or barrier to oxygen diffusion and prevents further oxidation of alloy. But in Nb-Mo-Si-B system, non-

volatile $\mathrm{Nb}_{2} \mathrm{O}_{5}$ grains not only increase the viscosity of the borosilicate glass but also possibly allows oxygen to diffuse through grains and grain boundaries and further oxidizes the alloy.

\section{Hypothesis}

If we can design a procedure to selectively volatilize the $\mathrm{Nb}$ component from the scale and enrich the scale of the quaternary alloy in borosilicate glass, it may be possible to affect oxidation resistance that is on par with the Mo-Si-B alloys.

\section{Approach}

To test the hypothesis stated above, the following will be attempted in Nb-Mo-Si-B system:

1. Pre-oxidize alloy to form an oxide layer containing $\mathrm{Nb}_{2} \mathrm{O}_{5}$ embedded in borosilicate glass layer.

2. Convert the $\mathrm{Nb}_{2} \mathrm{O}_{5}$ formed during oxidation to a volatile phase and remove from the scale leaving behind a borosilicate glass which would flow on heat treatment and form a protective layer.

Review of literature indicates that halides and oxyhalides of Niobium are volatile. The primary purpose of the present study is to design an experimental setup to selectively remove $\mathrm{Nb}_{2} \mathrm{O}_{5}$ by converting to a halide and study the oxidation behavior of the treated material.

Although all the halides of niobium are volatile at ambient temperature, niobium pentachloride is the best choice as it is easy to form. Formation of niobium iodide requires 
iodine vapors at high pressure and temperature $\left(1300-1600^{\circ} \mathrm{C}\right)$ for complete reaction [38]. No method for preparing pentabromides from pentoxides was found in literature. Niobium pentafluoride reacts readily with silica or glass (which is present in system) to form niobium oxyflouride and silicon tetrafluoride.

$$
\mathrm{SiO}_{2}+\mathrm{NbF}_{5} \rightarrow \mathrm{NbO}_{2} \mathrm{~F}+\mathrm{SiF}_{4}
$$

This reaction is undesirable as it removes the protective $\mathrm{SiO}_{2}$ from the scale. Considering these factors, niobium pentachloride appears to be composition of choice to convert niobium pentoxide to volatile niobium compound.

The melting point of niobium pentachloride as reported range between $205-210^{\circ} \mathrm{C}[39,40,41]$. The boiling point of $\mathrm{NbCl}_{5}$ was reported to be $254^{\circ} \mathrm{C}$ [39] .

\section{Chlorination of $\mathrm{Nb}_{2} \mathrm{O}_{5}$}

Conversion of $\mathrm{Nb}_{2} \mathrm{O}_{5}$ to $\mathrm{NbCl}_{5}$ can be accomplished by one of several ways as briefly described below:

1. By heating pentoxide in Carbon tetrachloride $\left(\mathrm{CCl}_{4}\right)$ as illustrated by the following chemical reaction,

$$
\mathrm{Nb}_{2} \mathrm{O}_{5}(\mathrm{~s})+\frac{5}{2} \mathrm{CCl}_{4}(\mathrm{~g}) \rightarrow 2 \mathrm{NbCl}_{5}(\mathrm{~g})+\frac{5}{2} \mathrm{CO}_{2}(\mathrm{~g})
$$

2. By introducing carbon in the samples during processing. Then heating the sample in chlorine gas to convert niobium pentoxide to niobium pentachloride as shown by the following reaction,

$$
2 \mathrm{Nb}_{2} \mathrm{O}_{5}(s)+5 \mathrm{C}(s)+10 \mathrm{Cl}_{2}(\mathrm{~g}) \rightarrow 4 \mathrm{NbCl}_{5}(\mathrm{~g})+5 \mathrm{CO}_{2}(\mathrm{~g})
$$

3. By flowing a mixture of carbon monoxide and chlorine through the $\mathrm{Nb}_{2} \mathrm{O}_{5}$ at elevated temperature. It undergoes a reaction of the type:

$$
\mathrm{Nb}_{2} \mathrm{O}_{5}(\mathrm{~s})+5 \mathrm{Cl}_{2}(\mathrm{~g})+5 \mathrm{CO}(\mathrm{g}) \rightarrow 2 \mathrm{NbCl}_{5}(\mathrm{~g})+5 \mathrm{CO}_{2}(\mathrm{~g})
$$

Although all three methods have been used to convert non-volatile $\mathrm{Nb}_{2} \mathrm{O}_{5}$ to volatile $\mathrm{NbCl}_{5}$, thermodynamic calculations have been performed on possible reactions and reactants to select the best method for conversion. From the calculations (Figure 9), all 
three reactions are possible at the test temperature, but third method is preferred, as it is the most recent method used for chlorination of pentoxide to pentachloride. Moreover, this method does not involve introduction of any fourth element (i.e. as Carbon in second method) to the Nb-Mo-Si-B system to form the undesirable phases in alloy to alter its properties. Also, the formation of carbon tetrachloride in gaseous form at test temperature is thermodynamically not favored $\left(\Delta \mathrm{G}_{\mathrm{f}}>0\right.$ at $\mathrm{T}>700^{\circ} \mathrm{C}$ ). Other two methods (using carbon and carbon tetrachloride) are low temperature methods $\left(300-400^{\circ} \mathrm{C}\right.$ ), so there is possibility of formation of other non-volatile compounds of niobium at that temperature range $\left(\mathrm{NbOCl}_{3}\right)$, which may further dissociate back to form pentoxide and chlorine. Considering these factors, third method using carbon monoxide and chlorine mixture was chosen for this study.

\section{References}

1. J. J. Petrovic and A. K. Vasudevan, "Key developments in high temperature structural silicides", Materials Science and Engineering, A 261, 1-5 (1999)

2. D. M. Shah, Superalloys. ed. S. D. Antolovich et al. The Mineral, Metals and Materials Society, Warrendate, PA, 409 (1992)

3. R. M. Nekkanti and D. M. Dimiduk, "Ductile-phase toughening in niobium-niobium silicide powder processed composites", Mat. Res. Soc. Symp. Proc. 194, 175-182 (1990)

4. M. G. Mendiratta, J. J. Lewandowski and D. M. Dimiduk, "Strength and ductile phase toughening in the two phase Nb/Nb5Si3 alloys", Metall. Trans, 22A, $1573-$ $1583(1991)$

5. M. K. Meyer, A. J. Thom and M. Akinc, "Oxide scale formation and isothermal oxidation behavior of Mo-Si-B intermetallics at $600-1000^{\circ} \mathrm{C}$ ", Intermetallics, 7, 153 $162(1999)$ 
6. A. J. Thom, M. K. Meyer, J. J. Williams and M. Akinc, "Improved oxidation . resistance of $\mathrm{A}_{5} \mathrm{Si}_{3}$ ( $\mathrm{A}=$ transition metal) silicides by small atom doping" Processing and Fabrication of Advanced Materials IV, 139-49 (1996)

7. Y. H. Liu, A. J. Thom, M. J. Kramer, and M. Akinc, "Processing and oxidation behavior of Nb-Si-B intermetallics" Processing and Fabrication of Advanced Materials-XI, edited by T. S. Srivatsan and V. A. Ravi, ASM International, 258-271 (2003)

8. Y. H. Liu, "Microstructure and oxidation behavior of Nb-Si-B and Nb-Mo-Si-B intermetallics", MS thesis, Iowa State University, Ames, Iowa (2001).

9. T. Murakami, C. N. Xu, A. Kithara, M. Kawahara, Y. Takahashi, H. Inui, M. Yamaguchi, "Microstructure, mechanical properties and oxidation behavior of powder compacts of the Nb-Si-B system prepared by spark plasma sintering" Intermetallics 7, 1043-1048 (1999)

10. H. Nowotny, E. Dimakopoulu, H. Kudielka., "Ternary systems, molybdenum-siliconboron, and tungsten-silicon-boron, and the system VSi ${ }_{2}-\mathrm{TaSi}_{2}$ " Monatsh. Chem., 88 180-192 (1957)

11. J. Huebsch, "Solubility of boron in $\mathrm{Mo}_{5+\mathrm{y}} \mathrm{Si}_{3-\mathrm{y}}$ and related mechanical and oxidation properties", M.S. thesis, Iowa State University, Ames (1997)

12. R. W. Bartlett, J. W. McCamont, and P. R. Gage, "Structure and chemistry of oxide films thermally grown on molybdenum silicides", J. Am. Ceram. Soc., 48, No.11, $551-58$ (1965)

13. H. L. Zhao,'Thermal Expansion behavior of Mo-Si-B intermetallics", M.S Thesis, Iowa State university, Ames, IA (2001)

14. H. L. Zhao, M. J. Kramer and M. Akinc, "Thermal expansion behavior of intermetallic compounds is the Mo-Si-B system" (Accepted in Intermetallics)

15. K. Ito, M. Kumagai, T. Hayashi and M. Yamaguchi , "Room temperature fracture toughness and high temperature strength of $\mathrm{T} 2 / \mathrm{Mo}_{s s}$ and $(\mathrm{Mo}, \mathrm{Nb})_{s s} / \mathrm{T} 1 / \mathrm{T} 2$ eutectic alloys in the Mo-Si-B system", Scripta Materialia, 49, Issue 4, 285-290 (2003) 
16. P. R. Subramanian, T. A. Parthasarathy, M. G. Mendiratta, and D. M. Dimiduk, "Compressive creep behavior of $\mathrm{Nb}_{5} \mathrm{Si}_{3}$ ", Scripta Metall. 32(8), 1227-1232 (1995)

17. E. M.Carrillo-Heian, C. Unuvar, J. C. Gibeling,G. H. Paulino and Z. A. Munir, "Simultaneous synthesis and densification of niobium silicide/niobium composites" Scripta Materialia 45, 405-412 (2001)

18. A. G. Knapton, "The system niobium-silicon and the effect of carbon on the structures of certain silicides", Nature, 175, 730 (1955)

19. M. E. Schlesinger, H. Okamoto, A. B Gokhale and R. Abbaschian, "The Nb-Si system", J. Phase Equilibria, 14(4), 502-509 (1993)

20. P. R. Subramanian, T. A. Parthasarathy, M. G. Mendiratta, D. M. Dimiduk, paper presented at the 1994 MRS Symposium on High Temperature Ordered Intermetallic Alloys--VI, Boston, MA (1994)

21. B. P. Bewlay, P. W. Whiting, A. W. Davis and C. L. Briant, "On the formation of silicide precipitates in niobium-silicide based composites", MRS Symposium Proceedings, 552, KK6.11.1-KK6.11.5 (1999)

22. G. A. Henshall and M. J. Strum, "Simulations of creep in dictile-phase toughned $\mathrm{Nb}_{5} \mathrm{Si}_{3} / \mathrm{Nb}$ in-situ composites" MRS Symposium Proceedings 364, 937-942 (1995)

23. G. A. Henshall, M. J. Strum, P. R. Subramanian and M. G. Mendiratta, "Simulations of deformation in composites with two steady-state creeping phases", Scripta Metall. et Mater. 30(7), 845-850 (1994)

24. G. A. Henshall and M. J. Strum, "Continuum predictions of deformation in composites with two creeping phases-I. Model systems", Acta Mater. 44(8), 3249-3257 (1996)

25. G. A. Henshall, P. R. Subramanian, M. J. Strum and M. G. Mendiratta, "Continuum predictions of deformation in composites with two creeping phases- $\Pi$. $\mathrm{Nb}_{5} \mathrm{Si}_{3} / \mathrm{Nb}$ composites", Acta Mater. 45(8), 3135-3142 (1997)

26. P. R. Subramanian, M. G. Mendiratta, D. M. Dimiduk and M. A. Stucke, "Advanced intermetallic alloys-beyond gamma titanium aluminides", Mater. Sci. Eng. A 239-340, 1-13 (1997) 
27. Kwai S. Chan, "Modeling creep behavior of niobium silicide in-situ composites", Materials Science and Engineering A 337, 59-66 (2002)

28. P.R. Subramanian, M.G. Mendiratta, and D.M. Dimiduk, "Microstructures and mechanical behavior of Nb-Ti base beta + silicide alloys", Mat. Res. Soc. Symp. Proc. 322, 491-502 (1994)

29. P. R. Subramanian, M. G. Mendiratta, and D. M. Dimiduk, “ The development of Nbbased advanced intermetallic alloys for structural applications", JOM, 48(1), 33-38 (1996)

30. Shigeru Okada, Keisuke Okita, Kenya Hamano and Torsten Lundstrom, "Growth Conditions of $\mathrm{Nb}_{3} \mathrm{Si}_{1} \mathrm{Nb}_{5} \mathrm{Si}_{3}$ and $\mathrm{NbSi}_{2}$ Single Crystals from High-Temperature Metal Solutions and Properties of the Crystals", High temperature materials and processes, 13(4), 311-318 (1994)

31. M. R. Jackson, R. G. Rowe and D. W.Skelly, " Oxidation of some intermetallic compounds and intermetallic matrix composites", Mat. Res. Soc. Symp. Proc. 364, 1339-1344 (1995)

32. H. Nowotny, F. Benesovsky, E. Rudy and A. Wittmann, " Aufban und Zunderverhalten von Noib-Bor-Silicium Legierungen", Monatch. Chem., 91, 975-990 (1960)

33. H. Nowotny, B. Lux und H. Kudielka, "The effect of carbon, nitrogen, oxygen, and boron on silicides of transition elements", Monatch. Chem., 87, 447-470 (1956)

34. C. L. Fu, J. H. Schneibel, "Reducing the thermal expansion anisotropy in $\mathrm{Mo}_{5} \mathrm{Si}_{3}$ by $\mathrm{Nb}$ and V additions: theory and experiment", Acta Materialia 51, 5083-5092 (2003)

35. C. L. Fu, X. Wang, "Thermal Expansion Coefficients of Mo-Si Compounds by FirstPrinciples Calculations", Philos Mag Lett 80, 683. (2000)

36. J. H. Schneibel, C. J. Rawn, T. R. Watkins, E. A. Payzant, "Thermal Expansion Anisotropy of Temary Molybdenum Silicides Based on $\mathrm{Mo}_{5} \mathrm{Si}_{3}{ }^{\prime \prime}$, Phys Rev B, 65, 134112 (2002)

37. F. Chu, D. J. Thoma, K. McClellan, P. Peralta, Y. He, "Synthesis and properties of $\mathrm{Mo}_{5} \mathrm{Si}_{3}$ single crystals", Intermetallics, 7, 611 (1999) 
38. F. Fairbrother, "The chemistry of Niobium and Tantalum", 115-120 (1967)

39. K. M. Alexander and F. Fairbrother, "The halides of columbium and tantalum: The vapor pressures of columbium and tantalum pentachlorides and pentabromides" $J$. Chem. Soc., S 223 (1949)

40. H. Schäfer and C. Pietruck, "Chemistry of niobium and tantalum. VII. Note on the binary system niobium pentachloride-tantalum pentachloride" Z. Anorg. Allgem. Chem., 267, 174-80 (1951).

41. H. Schäfer, L. Bayer, and H. Lehmann, "Chemistry of the elements niobium and tantalum. IX. Equilibrium pressure of the decomposition of niobium tetrachloride", $Z$. Anorg. Allgem. Chem., 268, 268-278 (1952) 


\title{
CHAPTER 2
}

\section{MICROSTRUCTURE AND OXIDATION BEHAVIOR OF Nb-Mo-Si-B ALLOYS}

\author{
Vikas Behrani, Andrew J Thom, Matthew J Kramer and Mufit Akinc \\ Department of Materials Science and Engineering and Ames Laboratory \\ Iowa State University, Ames IA 50011 \\ (To be submitted to Intermetallics)
}

\section{Abstract}

Microstructure and oxidation behavior of sintered $\mathrm{M}-\mathrm{Si}-\mathrm{B}$ alloys, where $\mathrm{M}=\mathrm{Nb}$, Mo and $(\mathrm{Nb}, \mathrm{Mo})$ with phase assemblies $\mathrm{T}_{1}\left(\mathrm{Mo}_{5} \mathrm{Si}_{3} \mathrm{~B}_{\mathrm{x}}\right)-\mathrm{MoSi} \mathrm{i}_{2}-\mathrm{MoB}, \mathrm{T}_{1}-\mathrm{T}_{2}\left(\mathrm{Mo}_{5} \mathrm{SiB}_{2}\right)-\mathrm{Mo}_{3} \mathrm{Si}$, Mo$\mathrm{T}_{2}-\mathrm{Mo}_{3} \mathrm{Si}$ in Mo-Si-B system, $\mathrm{T}_{2}\left(\mathrm{Nb}_{5}(\mathrm{Si}, \mathrm{B})_{3}\right), \mathrm{D}_{8}\left(\mathrm{Nb}_{5} \mathrm{Si}_{3} \mathrm{~B}_{\mathrm{x}}\right)$ in Nb-Si-B system, and $\mathrm{T}_{1^{-}}$ $\mathrm{T}_{2}-\mathrm{D} 8_{8}$ in $(\mathrm{Nb}, \mathrm{Mo})-\mathrm{Si}-\mathrm{B}$ system were investigated. Alloys were oxidized at $1000^{\circ} \mathrm{C}$ in flowing dry air. In Mo-Si-B compositions, alloys showed excellent oxidation stability and initial mass loss of alloy varied according to Mo content. Minor quantities of $\mathrm{MoO}_{2}$ were observed in Mo-Si-B scales. Nb-Si-B and Nb-Mo-Si-B alloys displayed large parabolic rate constants (in the range of $0.5-120 \mathrm{mgs}^{2} / \mathrm{cm}^{4} . \mathrm{hr}$ ) indicating that these systems are not as oxidatively stable as Mo-Si-B alloys. Oxidation kinetics was significantly dependent on initial heating atmosphere. In the $\mathrm{Nb}-\mathrm{Si}-\mathrm{B}$ system $\mathrm{T}_{2}$ and $\mathrm{D} 8_{8}$ alloys were more resistant to oxidation when heated to test temperature in ultra high pure argon. Quaternary Nb-Mo-Si-B alloy containing less $\mathrm{D} 8_{8}$ phase was more oxidation resistant than that containing more D8 8 phase. Scales on the order of 20-80 $\mu \mathrm{m}$ were observed on Mo-Si-B alloys and relatively thicker scales (on the order of $200-600 \mu \mathrm{m}$ ) were observed on $\mathrm{Nb}-\mathrm{Si}-\mathrm{B}$ and $\mathrm{Nb}-\mathrm{Mo}-\mathrm{Si}-\mathrm{B}$ alloys. Initial heating in argon resulted in denser scale and reduced the parabolic rate constants of ternary alloys by $\sim 17-22 \%$ and quaternary compositions by $\sim 30-40 \%$. 


\section{Introduction}

For civilian and military applications, there is an increasing need for materials, which can be used at high temperature to improve energy efficiency. Among the current materials for high temperature structural application, there is a temperature cut off at $\sim 1000^{\circ} \mathrm{C}$ [1]. Below this temperature, nickel and cobalt-base superalloys and aluminide intermetallics are being used. However, above $1000^{\circ} \mathrm{C}$, one must shift to other materials systems such as silicon-based ceramics and advanced intermetallics to meet oxidation and strength requirements. Transition metal silicides show good potential for use as structural materials above $1000^{\circ} \mathrm{C}$. Silicides can provide exceptional high-temperature corrosion resistance under oxidizing and sulfidizing conditions characteristic of many fossil fuel environments and thus are potential candidate materials for protective coatings. Especially, $\mathrm{M}_{5} \mathrm{Si}_{3}$ type compounds are attractive due to their high melting temperature and good creep resistance [2]. The creep rate of $\mathrm{Mo}_{5} \mathrm{Si}_{3}$ is lower than that of even whisker reinforced $\mathrm{MoSi}_{2}$ at high stress level [3]. Recently Mo-rich multiphase alloys have received considerable attention [4-10]. Drawbacks of single-phase $\mathrm{M}_{5} \mathrm{Si}_{3}$ materials included brittle fracture at ambient temperature and poor oxidation resistance at elevated temperature. Some of these silicides coexist with the terminal refractory metal solid solution phase, and therefore offer the potential for ductile phase toughing by forming $\mathrm{M}-\mathrm{M}_{5} \mathrm{Si}_{3}$ composite. It was previously reported that the addition of boron to $\mathrm{Mo}_{5} \mathrm{Si}_{3}$ results in substantial improvement in high-temperature oxidation resistance [11, 12]. The oxide scale is $\sim 50 \mu \mathrm{m}$ thick for undoped $\mathrm{Mo}_{5} \mathrm{Si}_{3}$ oxidized at $1000^{\circ} \mathrm{C}$ for 80 hours, whereas the boron-doped $\mathrm{Mo}_{5} \mathrm{Si}_{3}$ forms a continuous, non-porous scale that is less than $10 \mu \mathrm{m}$ thick after 400 hours exposure at $1000^{\circ} \mathrm{C}$. Boron doping of $\mathrm{Mo}_{5} \mathrm{Si}_{3}$ does not appear to decrease the high creep strength of $\mathrm{Mo}_{5} \mathrm{Si}_{3}$ due to the complex unit cell. The creep rate for a three-phase microstructure consisting of $\mathrm{T}_{1}$ matrix and $\mathrm{Mo}_{3} \mathrm{Si}$ and $\mathrm{T}_{2}$ was found to be $1.1 \times 10^{-6} \mathrm{~s}^{-1}$ at $1300^{\circ} \mathrm{C}$ under $140 \mathrm{MPa}$. No dislocation motion was evident in $\mathrm{T}_{1}$ phase and only a few dislocations were noted in $T_{2}$. The average activation energy of creep was $\sim 400 \mathrm{~kJ} / \mathrm{mol}$ [13]. Recently Choe et al [14] studied the fracture toughness and fatigue crack behavior in Mo$\mathrm{Mo}_{3} \mathrm{Si}-\mathrm{T}_{2}$ alloys at ambient and elevated temperatures. They found that micro cracking and extensive crack trapping by the primary $\alpha$-Mo phase are the principal mechanisms of toughening. Moreover, the fatigue crack growth resistance of $\mathrm{Mo}-\mathrm{Mo}_{3} \mathrm{Si}-\mathrm{T}_{2}$ alloy was found 
to be superior to monolithic $\mathrm{MoSi}_{2}$ at ambient temperature. Figure 1(a) shows the isothermal section of $\mathrm{Mo}-\mathrm{Si}-\mathrm{B}$ phase diagram at $1600^{\circ} \mathrm{C}$ [15] for the area of interest. Boron doped molybdenum silicides provide good oxidation resistance and high strength at elevated temperature, but low fracture toughness limits its potential use as a high temperature structural material.

Extensive studies [16, 17] have demonstrated that two phase $\mathrm{Nb}-\mathrm{NbSi}_{3}$ alloys have a good balance of low temperature toughness and high temperature strength. The toughness of Nb$\mathrm{Nb}_{5} \mathrm{Si}_{3}$ composites increases with $\mathrm{Nb}$ content [16]. However, $\mathrm{Nb}-\mathrm{Nb}_{5} \mathrm{Si}_{3}$ alloys still suffer from catastrophic oxidation upon exposure to air at temperature above $500^{\circ} \mathrm{C} . \mathrm{Nb}-\mathrm{Nb}_{5} \mathrm{Si}_{3}$ alloys oxidize mainly by oxygen diffusion, with the rapid formation of stratified and porous layers which spall off easily [18].

Addition of boron to the $\mathrm{Nb}-\mathrm{Si}$ system results in two ternary phases with large homogeneity regions, $\mathrm{T}_{2}\left(\mathrm{Nb}_{5}(\mathrm{Si}, \mathrm{B})_{3}\right)$ and $\mathrm{D} 8_{8}\left(\mathrm{Nb}_{5} \mathrm{Si}_{3} \mathrm{~B}_{\mathrm{x}}\right)$, as shown in the isothermal section of $\mathrm{Nb}-\mathrm{Si}-\mathrm{B}$ phase diagram (Figure 1(b)) at $1600^{\circ} \mathrm{C}$ [19]. This diagram suggests that Nb-rich boundary of the $\mathrm{T}_{2}$ phase varies over a large $\mathrm{B} / \mathrm{Si}$ range but nearly constant $\mathrm{Nb}$ concentration, whereas $\mathrm{D} 8_{8}$ phase shows a broader compositional variability with respect to niobium. Recently Murakami and Yamaguchi [20] studied the oxidation behavior of compositions in the $\mathrm{Nb}_{5} \mathrm{Si}_{3}-\mathrm{NbB}_{2}-\mathrm{NbSi}_{2}$ phase triangle containing D8. Oxidation resistance of $\mathrm{D} 8_{8}$ at $1250^{\circ} \mathrm{C}$ in air was found to be poor compared to $\mathrm{NbSi}_{2}$, but superior to $\mathrm{Nb}_{5} \mathrm{Si}_{3}$. The scale microstructure is consisted of $\mathrm{Nb}_{2} \mathrm{O}_{5}, \mathrm{SiO}_{2}$ and large number of pores. No continuous glass layer was observed. Liu et al [21] also studied the microstructure and oxidation behavior of single phase $\mathrm{Nb}_{5} \mathrm{Si}_{3}, \mathrm{~T}_{2}\left(\mathrm{Nb}_{5}(\mathrm{Si}, \mathrm{B})_{3}\right)$ and $\mathrm{D} 8_{8}\left(\mathrm{Nb}_{5} \mathrm{Si}_{3} \mathrm{~B}_{\mathrm{x}}\right)$ alloys in $\mathrm{Nb}-\mathrm{Si}-\mathrm{B}$ system. They reported that oxidation behavior of $\mathrm{Nb}-\mathrm{Si}-\mathrm{B}$ system is inferior to that of Mo-Si-B.

Because of the complete solid solubility between $\mathrm{Nb}$ and Mo, one can reasonably expect the existence of $(\mathrm{Nb}, \mathrm{Mo})$ alloy with boron modified $(\mathrm{Nb}, \mathrm{Mo})$ silicide. Such a composite may be designed to possess the desired properties of low temperature toughness and high temperature oxidation resistance. The free substitution of $\mathrm{Nb}$ for Mo may suppress the formation of $\mathrm{Mo}_{3} \mathrm{Si}$ (Figure 1) and thereby improve the fracture toughness of $\mathrm{T}_{1}\left(\mathrm{Mo}_{5} \mathrm{Si}_{3} \mathrm{~B}_{\mathrm{x}}\right.$ ) by ductile $\mathrm{Nb} / \mathrm{Mo}$ phase toughening. In addition, $\mathrm{Nb} / \mathrm{Mo}$ substitution may change the metalmetal and metal-silicon bonding of $T_{1}$ and subsequently affect the thermal expansion 
behavior of $T_{1}$ phase. This concept has led to alloy development efforts with the goal of achieving an acceptable balance of mechanical properties and environmental resistance.

As proposed [20,21], the dominant factor for low oxidative stability of Nb-Si-B alloys appears to be formation of non-volatile $\mathrm{Nb}_{2} \mathrm{O}_{5}$ and high porosity on exposure to air. The motivation behind this work is to reduce the porosity in the oxide scale by initially heating alloys in an inert atmosphere to by-pass the "pesting region" and investigate the oxidation behavior and scale formation at $1000^{\circ} \mathrm{C}$, and study the oxidation behavior of $\mathrm{Nb}-\mathrm{Mo}-\mathrm{Si}-\mathrm{B}$ alloys to develop possibility of alloys with acceptable mechanical properties. Specifically, we studied the oxidation resistance of boron modified molybdenum silicides, niobium silicides and molybdenum-niobium silicides in order to better evaluate the Nb-Mo-Si-B quaternary silicides as high temperature material.

\section{Experimental Procedure}

Three compositions in the Mo-Si-B system, two compositions in Nb-Si-B system and two quaternary $\mathrm{Nb}-\mathrm{Mo}-\mathrm{Si}-\mathrm{B}$ compositions were chosen for study (Table 1). Starting materials used for Mo-Si-B samples were powders of desired composition provided by Exotherm Corporation (Camden, NJ) and for Nb-Si-B samples were 99.8\% niobium rod (MPC of Ames Laboratory, Ames, IA), $99.99 \%$ lump silicon (Alpha Chemicals, Danvers, MA) and $99.5 \%$ lump boron (AESAR, Ward Hill, MA). All processing operations were carried out under ultra high purity argon atmosphere. Nb-Si-B and Nb-Mo-Si-B samples were prepared by arc melting the starting materials on a copper hearth with a tungsten electrode. Each sample was melted at least three times to ensure homogeneity. Powders were ground in a tungsten carbide lined container (Model 8000 Mixer/Mill, SPEX Industries, Edison, NJ) with 0.2 0.3 wt\% stearic acid. Powders were sieved through a -635 mesh stainless steel sieve, with a nominal opening size of $20 \mu \mathrm{m}$, and uniaxially dry pressed into $0.95 \mathrm{~cm}$ diameter pellets at $186 \mathrm{MPa}$ using stearic acid as Iubricant. The samples were heated in a tube furnace at $550^{\circ} \mathrm{C}$ to remove the stearic acid. Pellets were then sintered at $1900^{\circ} \mathrm{C}$ for 2 hours in a high temperature furnace with tungsten heating elements (Model M60, Centorr/Vacuum Industries, Nashua, $\mathrm{NH}$ ). The furnace was heated at a rate of $20^{\circ} \mathrm{C} / \mathrm{min}$ and cooled at a rate of $5^{\circ} \mathrm{C} / \mathrm{min}$. Phase identification and microstructure characterization were performed using $\mathrm{X}$ - 
ray diffraction (XRD, Scintag XDS 2000,Cupertino,CA), scanning electron microscopy (SEM, JEOL, JSM 6100,Peabody,MA) and energy dispersive spectroscopy (EDS, Oxford Instruments, Valley,CA). Rietveld refinement of XRD patterns was performed using Rietica (Lucas Height Research Laboratory, Menai, Australia) to determine the lattice parameters and fraction of phases present. Peak profile coefficients, thermal parameters, specific atom sites, and lattice parameters were varied to obtain the best numerical fit for the $\mathrm{X}$-ray data.

The oxidation coupons $(\sim 0.8 \mathrm{~cm}$ in diameter and $\sim 0.1 \mathrm{~cm}$ in thickness) were polished (final polish with $0.05 \mu \mathrm{m} \mathrm{Al}_{2} \mathrm{O}_{3}$ ). A $0.18 \mathrm{~mm}$ diameter hole was drilled through coupons prior to polishing from which the coupons were suspended from a sapphire wire in a vertical tube thermo-gravimetric analyzer using an electrobalance accurate to $0.01 \mathrm{mg}$ (Cahn-2000, Cahn Instruments,Inc., Cerritos,CA).

Samples were haeted to the test temperature either in argon or compressed breathing air and subsequently oxidized in breathing air at $1000^{\circ} \mathrm{C}$. All gas flow were set at $100 \mathrm{ml} / \mathrm{min}$. Specimen temperature was increased at a rate of $20^{\circ} \mathrm{C} / \mathrm{min}$ to $1000^{\circ} \mathrm{C}$ and held up to 100 hours for Mo-Si-B alloys, and for 5-7 hours for Nb-Si-B and Nb-Mo-Si-B alloys. The oxidation-induced mass changes were continuously recorded as a function of time. The oxide scale was characterized using XRD, SEM and EDS.

\section{Results and Discussion}

\section{(a) Microstructure analysis}

Phase characterization was performed to confirm the composition of sintered alloys. Samples $\mathrm{A}, \mathrm{B}$ and $\mathrm{C}$ formed the expected composition as predicted by the Mo-Si-B phase diagram (Figure 1(a)) with densities greater than 95\%. Table 2 summarizes the phase composition of alloys from Reitveld refinement with the error in the range of $\pm 2 \%$. BSE images of alloy cross sections are shown in Figure 2. Microstructure of alloy A shows connected grains of $T_{1}$ with isolated grains of $\mathrm{MoB}$ and $\mathrm{MoSi}_{2}$ within the matrix. Similarly, alloy B shows connected grains of $\mathrm{T}_{1}$ matrix with dispersed $\mathrm{Mo}_{3} \mathrm{Si}$ and $\mathrm{T}_{2}$. Alloy $\mathrm{C}$ shows microstructure of connected network of Mo grains with $\mathrm{Mo}_{3} \mathrm{Si}$ and $\mathrm{T}_{2}$. Although $\mathrm{T}_{1}$ and Mo phases are clearly visible in 
backscattered electron images but it is difficult to distinguish between $\mathrm{Mo}_{3} \mathrm{Si}$ and $\mathrm{T}_{2}$ phases as they have similar contrast. Some grain pullouts occurred during the preparation of metallographic samples. Small pores, grain pullouts and/or silica packets are visible as dark circles.

Alloys $\mathrm{D}$ and $\mathrm{E}$ were intended to form single phase $\mathrm{T}_{2}$ and $\mathrm{D} 8_{8}$ respectively as shown in $\mathrm{Nb}$ Si-B phase diagram (Figure 1(b)). Alloy $\mathrm{D}$ contains $\sim 3-5 \% \mathrm{Nb}$ metal phase in $\mathrm{T}_{2}$ matrix. Alloy $\mathrm{E}$ is nearly single phase $\mathrm{D} 88$ with minor $\mathrm{NbB}$ (3-5\%) phase. Alloy $\mathrm{D}$ was $95 \%$ dense whereas $\mathrm{E}$ was only $85 \%$ dense. Unlike Mo-Si-B alloys, which can be sintered to near theoretical density at $1800^{\circ} \mathrm{C}$ [22], the densities of $\mathrm{Nb}-\mathrm{Si}-\mathrm{B}$ samples were low, even after sintering at $1900^{\circ} \mathrm{C}$ for 2 hours. The difference in sintering behavior can be attributed to the high melting temperature of $\mathrm{Nb}-\mathrm{Si}-\mathrm{B}$ alloys. Single phase $\mathrm{Mo}_{5} \mathrm{Si}_{3}$ melts at $2180^{\circ} \mathrm{C}$ whereas $\mathrm{Nb}_{5} \mathrm{Si}_{3}$ melts at $2515^{\circ} \mathrm{C}$. Slower diffusion is expected from niobium silicides. Fitzer [23] reported that silicon diffusion in $\mathrm{Mo}_{5} \mathrm{Si}_{3}$ is 1000 times higher than in $\mathrm{Nb}_{5} \mathrm{Si}_{3}$ at $1700 \mathrm{C}$. On the other hand Liu et al [21] reported that $\mathrm{Nb}-\mathrm{Si}-\mathrm{B}$ alloys are denser than boron free- $\mathrm{Nb}_{5} \mathrm{Si}_{3}$ and they suggested that diffusion in boron-containing $T_{2}$ phase is faster because $B$ is smaller than Si.

Sample $F$ and $G$ showed very similar microstructure with mixture of $T_{1}, T_{2}$ and $D 8_{8}$ phases. Sample $\mathrm{F}$ is richer in $\mathrm{D} 8_{8}\left((\mathrm{Nb}, \mathrm{Mo})_{5} \mathrm{Si}_{3}, \mathrm{~B}_{\mathrm{x}}\right)$ phase $(\sim 20 \%)$ than sample $\mathrm{G}(\sim 11 \%)$. Absence of the $\mathrm{M}_{3} \mathrm{Si}$ phase in quaternary Nb-Mo-Si-B compositions shows that the appropriate substitution of $\mathrm{Nb}$ for Mo suppresses the formation of $\mathrm{M}_{3} \mathrm{Si}$ phase. The reduction in the amount of $\mathrm{M}_{3} \mathrm{Si}$ phase is attributed to the expansion of two-phase field by $\mathrm{Nb}$ substitution. In particular, the Nb substitution results in a shift in $\mathrm{T}_{2}$ composition towards Nb-Mo-Si side or to regions with lower $\mathrm{B}$ to Si ratio in the quatemary system. X-ray diffraction data clearly points to the expansion of the lattice dimensions of the $T_{1}$ and $T_{2}$ phases as suggested by the shift in corresponding peaks lower angles. Table 3 shows lattice parameters of constituent phases of Nb-Mo-Si-B alloys along with the published data $[15,19,24-27]$ of ternary Mo or $\mathrm{Nb} \mathrm{T}_{1}$ and $\mathrm{T}_{2}$ phases. Reitveld analysis confirmed that in both samples, $\mathrm{Nb}$ substitution for Mo in Mo-Si-B causes lattice expansion. This is to be expected based on the larger atomic radius of $\mathrm{Nb}$. Quaternary $\mathrm{D} 8_{8}$ lattice parameters are in agreement with that of $\mathrm{D} 8_{8}$ phase of $\mathrm{Nb}-\mathrm{Si}-\mathrm{B}$ system implying that $\mathrm{D} 8_{8}$ phase in $\mathrm{Nb}-\mathrm{Mo}-\mathrm{Si}-\mathrm{B}$ alloys is $\mathrm{Nb}$ rich. This is consistent 
with the observation that the existence of a large homogeneity region for the hexagonal D $8_{8}$ in $\mathrm{Nb}-\mathrm{Si}-\mathrm{B}$ system and absence of a D8 8 type phase in Mo-Si-B system. Results show that lattice parameters of $\mathrm{T}_{1}$ and $\mathrm{T}_{2}$ phases after substitution of $\mathrm{Nb}$ for Mo vary between the values of single phase $\mathrm{Mo}$ and $\mathrm{Nb}$ free $\mathrm{T}_{1}$ and $\mathrm{T}_{2}$ compositions respectively. Isolated porosity was observed in all compositions.

\section{(b) Isothermal oxidation}

\section{Mo-Si-B}

Oxidation behavior of Mo-Si-B alloys represented as change in mass as a function of time is shown in Figure 3(a). Results show that oxidation of Mo-Si-B occurs in three distinct stages. Stage I refers to the initial uptake of oxygen and formation of oxide layer containing Mo oxide, $\mathrm{B}_{2} \mathrm{O}_{3}$ and $\mathrm{SiO}_{2}$ (Fig. 3(b)). During this stage the temperature is lower than the vaporization temperature of $\mathrm{MoO}_{3}$. As temperature reaches vaporization temperature of $\mathrm{MoO}_{3}$, a sharp drop in mass was observed, which is referred as stage II. [11]

In the stage $\mathrm{II}$ mass change with time slows down considerably. In this stage the oxidation is diffusion controlled. Oxidation kinetics in this stage was reported in detail by Meyer et al (REF) and found to be limited by diffusion of $\mathrm{MoO}_{3}$ through the scale. The scale after 100 hours of oxidation ranges between 10 and $20 \mu \mathrm{m}$ depending upon the alloy composition. During stage $\Pi$, mass loss due to $\mathrm{MoO}_{3}$ volatilization increases as Mo content of the sample increases. Alloy $C$ lost $\sim 40 \mathrm{mg} / \mathrm{cm}^{2}$ compared to $A$ and $B$ which lost 1 and $3 \mathrm{mg} / \mathrm{cm}^{2}$ respectively. These mass losses correlate, at least qualitatively, with the Mo contents of the samples (Table 1). Parabolic oxidation behavior in the steady state (Stage III) oxidation is illustrated in Figure 3(c). Parabolic rate constant, $\mathrm{K}_{\mathrm{p}}$, for stage $\mathrm{II}$ has been calculated from the slope of straight line on the plot of $(\Delta \mathrm{m} / \mathrm{A})^{2}$ vs time.

$$
\left(\frac{\Delta m}{A}\right)^{2}=K_{p} t+C
$$

where, $\mathrm{A}$ is surface area of sample and $\mathrm{C}$ is a constant. Rate constant and correlation coefficients $\left(\mathrm{R}^{2}\right)$ are given in Table 4 . 
Linear oxidation rate constants on the order of $10^{-5} \mathrm{~kg}^{2} / \mathrm{m}^{4} \mathrm{hr}$ are in agreement with the values reported previously $[11,12$, and 22]. Figure 4 shows the secondary electron images of oxide layer on Mo-Si-B alloys after 100 hours of oxidation in dry air. Energy dispersive spectroscopy detected presence of Mo along with Si. X-ray diffraction patterns of the scale after 100 hours of oxidation in flowing air at $1000^{\circ} \mathrm{C}$ is shown in Figure 5. All the three Mo$\mathrm{Si}-\mathrm{B}$ composition showed presence of $\mathrm{MoO}_{2}$ in the scale. This is believed to be $\mathrm{MoO}_{2}$ trapped in borosilicate glass layer. After formation of glass layer, oxygen partial pressure at oxide/alloy interface must be reduced to a level that only partial oxidation of Mo occurs forming $\mathrm{MoO}_{2}$. Its content in the scale varies with the phase composition of alloy. Comparing the relative intensities of $\mathrm{MoO}_{2}$ peaks, alloy $\mathrm{C}$ forms more $\mathrm{MoO}_{2}$ than alloy $\mathrm{A}$ and alloy $\mathrm{B}$ forms least amount of $\mathrm{MoO}_{2}$. This observation is evident from the SEM analysis of scale. Presence of base alloy silicide peaks in the XRD patterns also indicative of a thin scale in alloy A. Silicide peak intensities were low for alloy B and almost negligible for alloy C, showing that alloy $C$ forms a thicker scale than alloy $B$. XRD also detected Mo element in the oxide scales of alloy A and B. Intensities of Mo peaks in alloy B is stronger than that of A Probable oxidation reactions for the formation of $\mathrm{MoO}_{2}$ and Mo for alloy $\mathrm{A}$ and $\mathrm{B}$ which contains significant amount of $T_{1}$ phases are:

$$
\begin{gathered}
4 \mathrm{Mo}_{5} \mathrm{Si}_{3} \mathrm{~B}+25 \mathrm{O}_{2} \rightarrow 10 \mathrm{Mo}+10 \mathrm{MoO}_{2}+12 \mathrm{SiO}_{2}+2 \mathrm{~B}_{2} \mathrm{O}_{3} \\
2 \mathrm{Mo}_{3} \mathrm{Si}+5 \mathrm{O}_{2} \rightarrow 3 \mathrm{Mo}+3 \mathrm{MoO}_{2}+2 \mathrm{SiO}_{2} \\
4 \mathrm{Mo}_{5} \mathrm{Si}_{3} \mathrm{~B}+15 \mathrm{O}_{2} \rightarrow 20 \mathrm{Mo}+12 \mathrm{SiO}_{2}+2 \mathrm{~B}_{2} \mathrm{O}_{3}
\end{gathered}
$$

Obviously, overall oxidation reaction involves formation of both $\mathrm{MoO}_{2}$ and $\mathrm{Mo}$, relative amounts of which depends on the partial pressure of oxygen at the scale/alloy interface. For alloy $\mathrm{C}$, two Mo bearing phases, and in particular $\mathrm{T}_{2}$ phase must be involved in oxidation:

$$
\begin{gathered}
2 \mathrm{Mo}_{5} \mathrm{Si}_{3} \mathrm{~B}_{2}+19 \mathrm{O}_{2} \rightarrow 10 \mathrm{MoO}_{2}+6 \mathrm{SiO}_{2}+2 \mathrm{~B}_{2} \mathrm{O}_{3} \\
\mathrm{Mo}+\mathrm{O}_{2} \rightarrow \mathrm{MoO}_{2}
\end{gathered}
$$


Very low rate constants indicated the tendency for all alloys to undergo either a small steady state mass gain or mass loss. For alloy $\mathrm{C}$ with highest molybdenum content, large $\mathrm{MoO}_{2}$ peaks coupled with absence of Mo peaks implies that the oxygen partial pressure at the interface is large enough to convert all Mo into $\mathrm{MoO}_{2}$ and $\mathrm{MoO}_{3}$.

\section{Nb-Si-B}

Oxidation induced mass change for $\mathrm{Nb}-\mathrm{Si}-\mathrm{B}$ compositions exposed to air at $1000^{\circ} \mathrm{C}$ are shown in Figure 6. Figure 6(a) shows mass gain as a function of time when samples were initially heated to the test temperature in flowing air and 6(b) shows the same in argon. Both $\mathrm{Nb}$-Si-B compositions (i.e. $\mathrm{T}_{2}$ and $\mathrm{D} 8_{8}$ ) showed mass gain irrespective of initial heating atmosphere. The curves were fitted to a parabolic model, and the fit of the model. Rate constants, $\mathrm{K}_{\mathrm{p}}$, along with correlation coefficient, $\mathrm{R}^{2}$, are summarized in Table 5. The large parabolic rate constants compared to Mo-Si-B system indicates that the scale formed was not protective in nature. Figure 7(c), (d) and (e) shows the microstructure of oxide scale formed on $\mathrm{Nb}-\mathrm{Si}-\mathrm{B}$ alloys after oxidation at $1000^{\circ} \mathrm{C}$ when heated in flowing air and Figure 8(c),(d) and (e) shows the same when heated in pure argon. T2 showed more resistance to oxidation than D88 under same conditions irrespective of initial heating atmosphere. This can be attributed to the denser microstructure of $\mathrm{T}_{2}$ (95\% theoretical density) then $\mathrm{D} 88_{8}$ (85\% theoretical density). Porosity of the alloys has significant effect on the oxidation behavior and oxide scale microstructure. Similarity of the pore size within the scale and base alloy indicates that the pores in the oxide are predominantly those from the base alloy after oxidation. One can expect improvement in oxidation resistance by reducing the porosity of the base alloys. Plausible methods may be to form dense alloys using processing techniques like HIP (Hot isostatic pressing) and plasma spray sintering. Yamaguchi et al reported [20] densities greater than $90 \%$ of theoretical density by plasma spray sintering between $1500^{\circ} \mathrm{C}$ and $1800^{\circ} \mathrm{C}$. XRD detected $\mathrm{Nb}_{2} \mathrm{O}_{5}$ in the scale. The mixed oxide product very likely formed by the simultaneous oxidation of $\mathrm{Nb}, \mathrm{Si}$ and $\mathrm{B}$ since these three elements have similar standard free energies of formation [28]. $\mathrm{T}_{2}$ and $\mathrm{D} 8_{8}$ alloys showed more resistance to oxidation when heated to test temperature in argon atmosphere. When samples are heated to test temperature parabolic rate constant was reduced by $17-22 \%$. The scale formed on Nb-Si- 
B alloys was porous and spalled off easily when heated in air. Exposure of alloys to inert atmosphere (i.e. argon) during heating by-passes the "pesting" region (i.e. $650-850^{\circ} \mathrm{C}$ ) and the scale forms is less porous and thin as evident in Figure 8(c),(d) and (e). However, it has been shown that $\mathrm{T}_{2}$ and $\mathrm{D} 88$ have much better oxidation resistance than binary $\mathrm{Nb}_{5} \mathrm{Si}_{3}$ [21], suggesting that addition of boron can improve oxidation resistance, although only modestly in comparison to the Mo-Si-B system. The difference in oxidation resistance between boron modified $\mathrm{Mo}_{5} \mathrm{Si}_{3}$ and boron modified $\mathrm{Nb}_{5} \mathrm{Si}_{3}$ is most likely due to the formation of nonvolatile $\mathrm{Nb}_{2} \mathrm{O}_{5}$ and the high porosity of oxide scale observed in the latter. The presence of $\mathrm{Nb}_{2} \mathrm{O}_{5}$ impedes flow of borosilicate glass. As a result a continuous protective glass layer does not form on the alloy surface. Moreover, the non-volatile $\mathrm{Nb}_{2} \mathrm{O}_{5}$ facilitates the diffusion of air to scale/alloy interface through grain boundaries. The coefficient of oxygen diffusion in $\mathrm{Nb}_{2} \mathrm{O}_{5}\left(8.7 \times 10^{-11} \mathrm{~cm}^{2} / \mathrm{sec}\right)$ is almost 1000 times higher than in silica glass $\left(1.8 \times 10^{-14}\right.$ $\left.\mathrm{cm}^{2} / \mathrm{sec}\right)$ at $1000^{\circ} \mathrm{C}[29,30,31]$.

\section{Nb-Mo-Si-B}

Oxidation behavior of Nb-Mo-Si-B compositions (sample F and G) is shown in Figure 6. Sample $G$ was more resistant to oxidation than sample $F$ irrespective of initial heating atmosphere, which is due to presence of more $\mathrm{D} 88$ phase in composition $\mathrm{F}(20 \%)$ than in composition $\mathrm{G}(11 \%)$. There is no $\mathrm{D}_{8}$ phase in Mo-Si-B system, therefore it is believed that D8 8 phase present in Nb-Mo-Si-B compositions is essentially $\mathrm{Nb}$ rich, thus on exposure to air it forms more non-volatile $\mathrm{Nb}_{2} \mathrm{O}_{5}$ and increases the oxidation rate. Porosity in scale is mainly left behind pores from the base alloy. Mostly scale was consisted of connected network of $\mathrm{Nb}_{2} \mathrm{O}_{5}$ particles in glass. This connected matrix of $\mathrm{Nb}_{2} \mathrm{O}_{5}$ is expected to diffuse oxygen to the alloy surface.

The initial heating atmosphere significantly affected scale microstructure. When heated in air, sample $F$ and $G$ formed a four-layered scale microstructure as shown in Figure 7(d,e). Layer 1 consists of $\mathrm{Nb}_{2} \mathrm{O}_{5}$ with a small amount $\mathrm{SiO}_{2}$. Layer 2 is mainly the coarse $\mathrm{Nb}_{2} \mathrm{O}_{5}$, silica glass and some large pores. EDS detected Mo-element in layer 3. This is believed to be condensed $\mathrm{MoO}_{3}$ in the scale. This implies that layer 2 may act as a diffusion barrier for volatile MoO3. This layer may also hinder the inward diffusion of oxygen. The fourth layer, 
adjacent to base alloy consists of a mixture of $\mathrm{Nb}_{2} \mathrm{O}_{5}$ and amorphous $\mathrm{SiO}_{2}$. Severe cracks were observed in base alloy. The cracks are believed to be due to large tensile stresses induced on the base alloy by formation of $\mathrm{Nb}_{2} \mathrm{O}_{5}$ and $\mathrm{SiO}_{2}$. XRD detected $\mathrm{Nb}_{2} \mathrm{O}_{5}$ on the surface but no crystalline $\mathrm{MoO}_{3}, \mathrm{SiO}_{2}$ and $\mathrm{B}_{2} \mathrm{O}_{3}$. When heated in air, oxidation of quaternary compositions can be described by two stages, an initial transient period followed by a region of steady state oxidation. At initial stage, $\mathrm{Nb}, \mathrm{Mo}$, and $\mathrm{Si}$ were all oxidized because of the high oxygen partial pressure. Above $700^{\circ} \mathrm{C}$, the evaporation of $\mathrm{MoO}_{3}$ resulted in a surface containing $\mathrm{Nb}_{2} \mathrm{O}_{5}$, amorphous $\mathrm{SiO}_{2}$ or and a large amount of pores. Four layered microstructure was absent in scale when heated in argon (Figure 8e). Scale mainly consists of $\mathrm{Nb}_{2} \mathrm{O}_{5}$ dispersed in glass, with a very thin layer at alloy/oxide interface, which may be internal oxidation layer. Porosity was much less for alloys heated in argon (porosity $~ 9 \%$ ) than alloys heated in air (porosity $\sim 30 \%$ ). This can be attributed to formation of $\mathrm{MoO}_{3}$ pockets during heating in air, which remains in the scale until temperature reaches the volatilization temperature of $\mathrm{MoO}_{3}$. As $\mathrm{MoO}_{3}$ volatilizes, it leaves behind large pores. Heating in argon by-passes this step and direct exposure to air at $1000^{\circ} \mathrm{C}$ vaporizes Mo as $\mathrm{MoO}_{3}$ leaving scale of $\mathrm{Nb}_{2} \mathrm{O}_{5}$ and glass. Oxide scales on $\mathrm{F}$ and $\mathrm{G}$ showed very little spallation. 


\section{Summary}

1. Powder compacts of $\mathrm{Mo}-\mathrm{Si}-\mathrm{B}, \mathrm{Nb}-\mathrm{Si}-\mathrm{B}$ and $\mathrm{Nb}-\mathrm{Mo}-\mathrm{Si}-\mathrm{B}$ intermetallics system were prepared by arc melting and sintering at $1900 \mathrm{C}$ for 2 hours. Mo-Si-B alloys were almost fully dense, while $\mathrm{Nb}-\mathrm{Si}-\mathrm{B}$ and $\mathrm{Nb}-\mathrm{Mo}-\mathrm{Si}-\mathrm{B}$ were porous. This shows that diffusion process is slower in Nb-Si-B system. Substitution of $\mathrm{Nb}$ for Mo suppresses formation of $\mathrm{Mo}_{3} \mathrm{Si}$ phase.

2. As reported previously $[11,12]$, Mo-Si-B alloys displayed excellent oxidation stability at $1000^{\circ} \mathrm{C}$ in air. The scale was found to be essentially borosilicate glass layer with minor content of $\mathrm{MoO}_{2}$ near the alloy/scale interface. $\mathrm{MoO}_{2}$ content varied according to composition and was maximum for composition $\mathrm{Mo}^{-} \mathrm{T}_{2}-\mathrm{Mo}_{3} \mathrm{Si}$

3. Substitution of $\mathrm{Nb}$ for Mo resulted in expansion of $\mathrm{T}_{1}$ and $\mathrm{T}_{2}$ lattice dimensions, where as $\mathrm{D} 88$ lattice constants were in agreement with pure $\mathrm{Nb}$-Si-B. Unit cell dimensions observed for $T_{1}$ and $T_{2}$ were between single phase $N b$ and Mo free compositions.

4. $\mathrm{T}_{2}$ alloy showed more resistance to oxidation than $\mathrm{D} 8_{8}$ alloys. Oxidation behavior of Niobium containing alloys i.e. Nb-Si-B and Nb-Mo-Si-B alloys depends on initial heating atmosphere. $T_{2}$ and $D 8_{8}$ compositions were more resistant to oxidation than when heated in argon to test temperature. Quaternary alloy containing less $\mathrm{D} 8_{8}$ phase was more resistant. Initial heating of alloys in argon displayed thinner and low porous scales formation than that of alloys heated in air. Parabolic fit for oxidation suggests that process is primarily governed by diffusion of air through porous scale containing niobium pentoxide dispersed in borosilicate glass.

5. Large rate constants indicate that scale formed from Niobium containing alloys was not protective as compared to Mo-Si-B alloys. Substitution of $\mathrm{Nb}$ for Mo drastically decreased the oxidation resistance of $\mathrm{Nb}$ free $\mathrm{T}_{1}$ alloys. The difference in oxidation stability of boron modified Mo-Si and $\mathrm{Nb}$-Si may be attributed to the non-volatile nature of oxide formed and high porosity of the scale. 


\section{Acknowledgement}

The Ames Laboratory is operated by the US Department of Energy (DOE) by Iowa State University under Contract No. W-7405-ENG-82. This work was supported by the U.S. Department of Energy (DOE) National Energy Technology Laboratory under Field Work Proposal number AL-00-360-011.

\section{References}

1. J. J. Petrovic and A. K. Vasudevan, Materials Science and Enginnering, A261, 1-5 (1999)

2. D. M. Shah, Superalloys. Ed. S. D. Antolovich et al. The Mineral, Metals and Materials Society, Warrendate, PA, 409 (1992)

3. S. Bose, "Engineering Aspects of Creep of Molybdenum Disilicide," Materials Science and Enginnering, A155, 217 (1992)

4. J. H. Schneibel, M. J. Kramer, Ö. Ưnal and R. N. Wright. Intermetallics 9, 25 (2001)

5. H. Cho, D. Chen, J. H. Schneibel and R. O. Ritchie. Intermetallics 9, 325 (2001)

6. T. G. Nieh, J. G. Wang and C. T. Liu. Intermetallics 9, 73 (2001)

7. R. Sakidja, J. Myers, S. Kim and J. H. Perepezko. Int. J. Ref. Metal Hard Mater. 18, 193 (2000)

8. M. G. Mendiratta, T. A. Parthasarathy and D. M. Dimiduk. Intermetallics 10, 225 (2002)

9. T. A. Parthasarathy, M. G. Mendiratta and D. M. Dimiduk. Acta Mater. 50, 1857 (2002)

10. C. A. Nunes, R. Sakidja and J. H. Perepezko. In: M. V. Nathal et al. Structural intermetallics 1997, TMS, Warrendale, USA, 831 (1997)

11. M. K. Meyer, A. J. Thom and M. Akinc, Intermetallics, 7, 153-162 (1999)

12. A. J. Thom, M. K. Meyer, J. J. Williams and M. Akinc, Processing and Fabrication of Advanced Materials IV, 139-49 (1996)

13. J. H. Schneibel, C. T. Liu, L. Heatherly, and M. J. Kramer, Scripta Materialia, Vol.38, No.7, 1169-1176 (1998) 
14. H. Choe, D. Chen, J. H. Schneibel, R. O. Ritchie, Intermetallics 9, 319-329 (2001)

15. H. Nowotny, E. Dimakopoulu, H. Kudielka, Monatsh. Chem., 88 , 180-192 (1957)

16. R. M. Nekkanti and D. M. Dimiduk, Mat. Res. Soc. Symp. Proc. 194,175-182 (1990)

17. M. G. Mendiratta, J. J. Lewandowski and D. M. Dimiduk, Metall. Trans, 22A, 1573-1583 (1991)

18. P. R. Subramanian, M. G. Mendiratta, and D. M. Dimiduk, , Mat. Res. Soc. Symp. Proc. Vol. 322, , 491-502 (1994)

19. H. Nowotny, F. Benesovsky, E. Rudy and A. Wittmann, , Monatch. Chem., 91, 975-990 (1960)

20. T. Murakami, C. N. Xu, A. Kithara, M. Kawahara, Y. Takahashi, H. Inui, and M. Yamaguchi, Intermetallics 7, 1043-1048 (1999)

21. Y. Liu, A. J. Thom, M. J. Kramer, and M. Akinc , Processing and Fabrication of Advanced Materials-XI, edited by T. S. Srivatsan and V. A. Ravi, ASM International, in press.

22. M. K. Meyer, Ph. D. thesis, Iowa State University, Ames (1995)

23. E. Fitzer and F. K.Schmidt, High Temperature-High Pressures, 3, 445-460 (1971)

24. H. L. Zaho, M.S. thesis, Iowa State University, Ames IA, (2001)

25. M. E.Schlesinger, H. Okamoto, A. B. Gokhale, and R. Abbaschian, J. Phase Eqil., 14(4), 502-509 (1993)

26. A. Gokhale and R. Abbaschian, J. Phase Eqil., Vol. 12, No. 4, 493 (1991)

27. H. Schachner, E. Cerwenka, and H. Nowotny, Monatch. Chem, 85, 245-254 (1954)

28. I. Barin, Thermochemical Data of Pure Substances, $2^{\text {nd }}$ ed. Weinhiem; New York: VCH (1993)

29. J. Schlichting, J. Non-Crystalline Solids, 63, 173-181 (1984)

30. F. W. Wohlbier, Diffusion and Defect data, Vol. 14, 129 (1977)

31. F. W. Wohlbier, Diffusion and Defect data, Vol. 17, 135 (1978) 
37

\begin{tabular}{|c|c|c|c|c|}
\hline \multirow{2}{*}{ Sample } & \multicolumn{4}{|c|}{ Weight \% } \\
\cline { 2 - 5 } & $\mathrm{Mo}$ & $\mathrm{Nb}$ & $\mathrm{Si}$ & $\mathrm{B}$ \\
\hline $\mathbf{A}$ & 84.0 & - & 13.4 & 2.6 \\
\hline $\mathbf{B}$ & 88.6 & - & 9.9 & 1.5 \\
\hline $\mathbf{C}$ & 94.6 & - & 4.3 & 1.1 \\
\hline $\mathbf{D}$ & - & 87.1 & 11.3 & 1.6 \\
\hline E & - & 83.7 & 14.6 & 1.7 \\
\hline F and G & 44.0 & 42.6 & 12.3 & 1.1 \\
\hline
\end{tabular}

Table 1: Nominal compositions of alloys studied

\begin{tabular}{|c|c|c|c|c|c|c|c|}
\hline \multirow[t]{2}{*}{ Sample } & \multicolumn{7}{|c|}{$\begin{array}{c}\text { Phase Composition } \\
\text { Molar } \%\end{array}$} \\
\hline & $M$ & $\mathrm{MSi}_{2}$ & $T_{1}$ & $T_{2}$ & $\mathrm{D8}_{8}$ & $\mathbf{M}_{3} \mathbf{S i}$ & MB \\
\hline A & - & 12 & 66 & - & - & - & 22 \\
\hline B & - & - & 45 & 31 & - & 24 & - \\
\hline C & 43 & - & - & 30 & - & 27 & - \\
\hline $\bar{D}$ & $3-5$ & - & - & $95-97$ & - & - & - \\
\hline $\bar{E}$ & - & - & - & - & $92-97$ & - & $3-8$ \\
\hline $\mathbf{F}$ & - & - & 42 & 38 & 20 & - & - \\
\hline $\mathbf{G}$ & - & - & 60 & 29 & 11 & - & - \\
\hline
\end{tabular}

Table 2: Phase compositions of alloys studied after Rietvield refinement of X-ray diffraction patterns 


\begin{tabular}{|l|c|c|c|c|c|c|}
\hline \multirow{2}{*}{ Sample } & \multicolumn{2}{|c|}{ T$_{1}$} & \multicolumn{2}{c|}{ T$_{2}$} & \multicolumn{2}{c|}{ D8 $_{8}$} \\
\cline { 2 - 7 } & $\mathbf{a}$ & $\mathbf{c}$ & $\mathbf{a}$ & $\mathbf{c}$ & $\mathbf{a}$ & $\mathbf{c}$ \\
\hline F & 9.816 & 5.002 & 6.138 & 11.356 & 7.480 & 5.161 \\
\hline $\mathbf{G}$ & 9.815 & 5.007 & 6.077 & 11.410 & 7.519 & 5.208 \\
\hline Mo* & 9.642 & 4.904 & 6.013 & 11.034 & & \\
\hline Nb* $^{*}$ & 10.040 & 5.081 & 6.571 & 11.887 & 7.554 & 5.247 \\
& & & & & & \\
\hline
\end{tabular}

Table 3: Lattice parameters of individual phases in Nb-Mo-Si-B system ( $\AA$ )

$\mathrm{Nb}^{*}$ : without $\mathrm{Mo}$ in composition

$\mathrm{Mo}^{*}$ : without $\mathrm{Nb}$ in composition 
39

\begin{tabular}{|c|c|c|c|}
\hline Sample & $\begin{array}{c}\text { Phase } \\
\text { Composition }\end{array}$ & $\begin{array}{c}\mathbf{K}_{\mathrm{p}} \\
\left(\mathrm{mgs}^{2} / \mathrm{cm}^{4} . \mathrm{hr}\right)\end{array}$ & $\mathbf{R}^{2}$ \\
\hline A & $\mathrm{MoSi}_{2}-\mathrm{T} 1-\mathrm{MoB}$ & 0.15 & 0.95 \\
\hline & & & \\
B & $\mathrm{T} 1-\mathrm{T}_{2}-\mathrm{Mo}_{3} \mathrm{Si}$ & 0.18 & 0.95 \\
\hline & & & \\
C & $\mathrm{Mo-T2}-\mathrm{Mo}_{3} \mathrm{Si}$ & 0.24 & 0.94 \\
\hline
\end{tabular}

Table 4: Steady state parabolic rate constants for Mo-Si-B alloys oxidation at $1000^{\circ} \mathrm{C}$

\begin{tabular}{|c|c|c|c|c|c|}
\hline \multirow[b]{2}{*}{ Sample } & \multirow[b]{2}{*}{$\begin{array}{c}\text { Phase } \\
\text { Composition }\end{array}$} & \multicolumn{2}{|c|}{ Air ${ }^{*}$} & \multicolumn{2}{|c|}{$\mathrm{Ar}^{*}$} \\
\hline & & $\begin{array}{c}\mathbf{K}_{\mathbf{p}} \\
\left(\mathrm{mgs}^{2} / \mathrm{cm}^{4} \cdot \mathrm{hr}\right)\end{array}$ & $\mathbf{R}^{2}$ & $\begin{array}{c}\mathrm{K}_{\mathrm{p}} \\
\left(\mathrm{mgs}^{2} / \mathrm{cm}^{4} \cdot \mathrm{hr}\right)\end{array}$ & $\mathbf{R}^{2}$ \\
\hline D & $T_{2}$ & 20.15 & 0.99 & 18.79 & 0.98 \\
\hline $\mathbf{E}$ & $\mathrm{D} 8_{8}$ & 114.83 & 0.99 & 54.12 & 0.99 \\
\hline $\mathbf{F}$ & $\mathrm{T}_{1}-\mathrm{T}_{2}-\mathrm{D} 8_{8}$ & 0.58 & 0.93 & 0.33 & 0.99 \\
\hline $\mathbf{G}$ & $T_{1}-T_{2}-D 8_{8}$ & 0.78 & 0.98 & 0.53 & 0.99 \\
\hline
\end{tabular}

Table 5: Parabolic rate constants for oxidation of Nb-Si-B and Nb-Mo-Si-B alloys at $1000^{\circ} \mathrm{C} . *$ Atmosphere during the heating cycle to $1000^{\circ} \mathrm{C}$ 

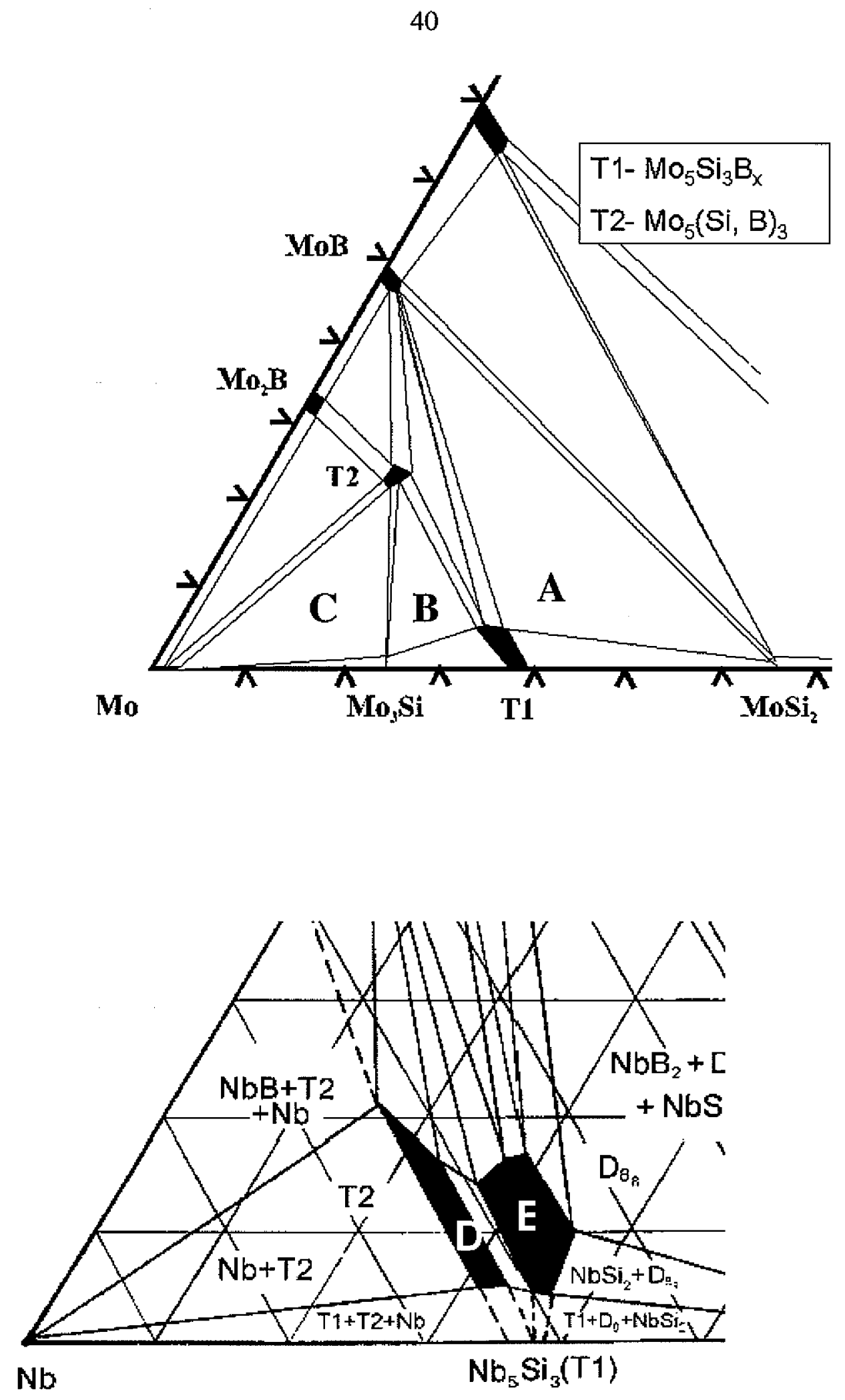

Figure 1 
41
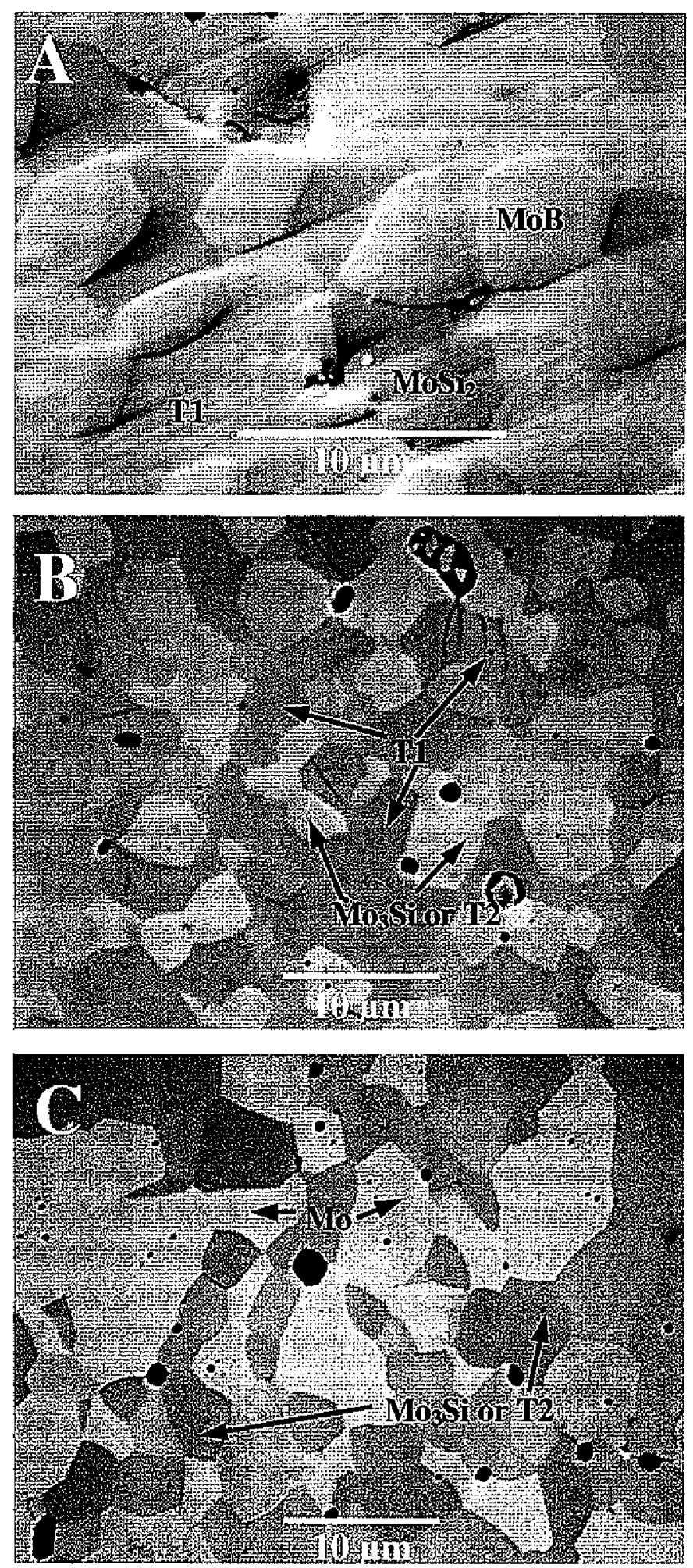

Figure 2 
42
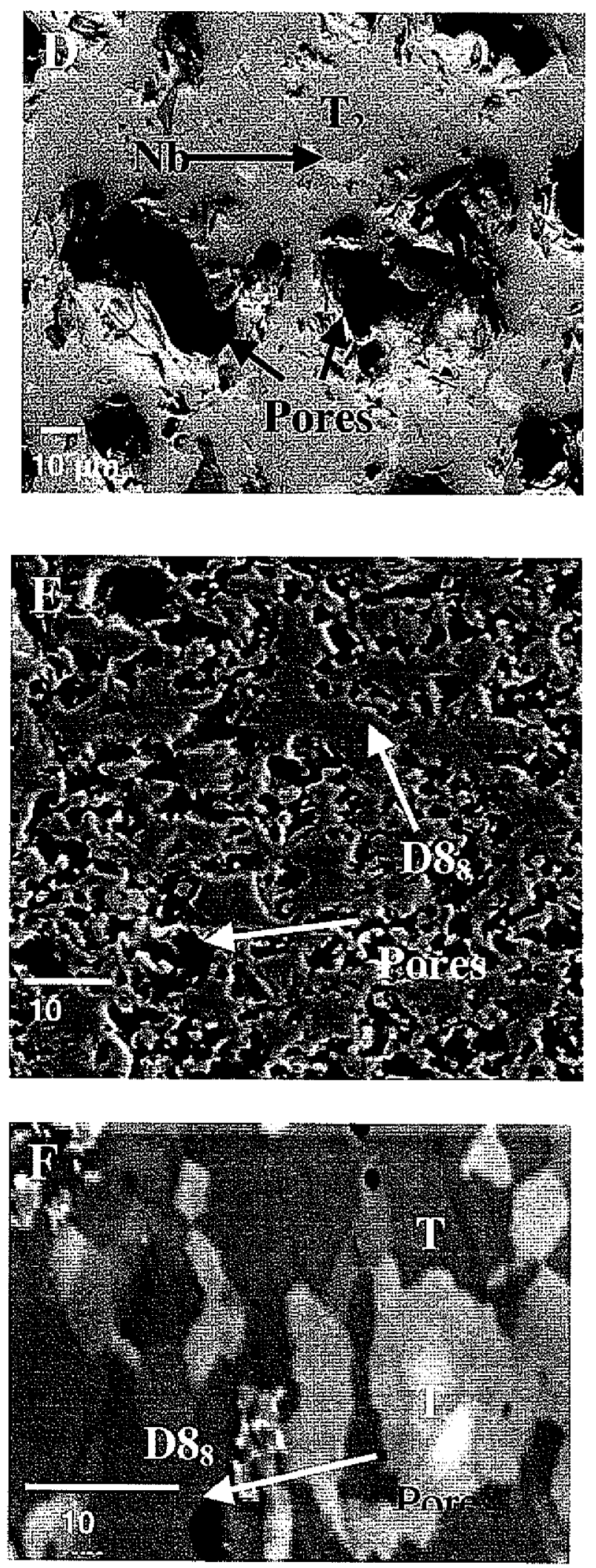

Figure 2 


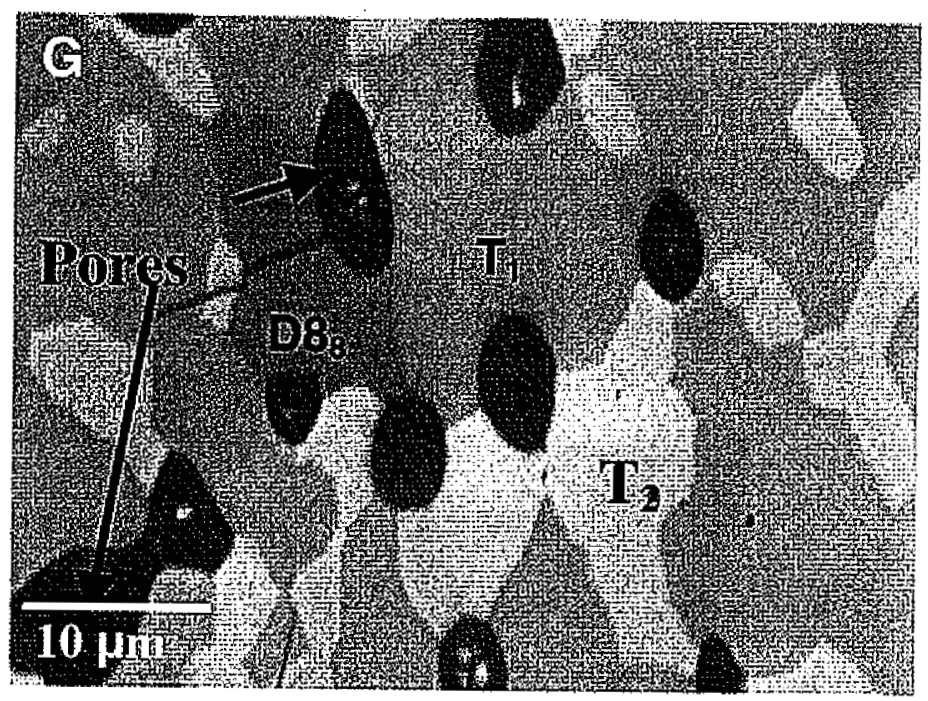

Figure 2 
44
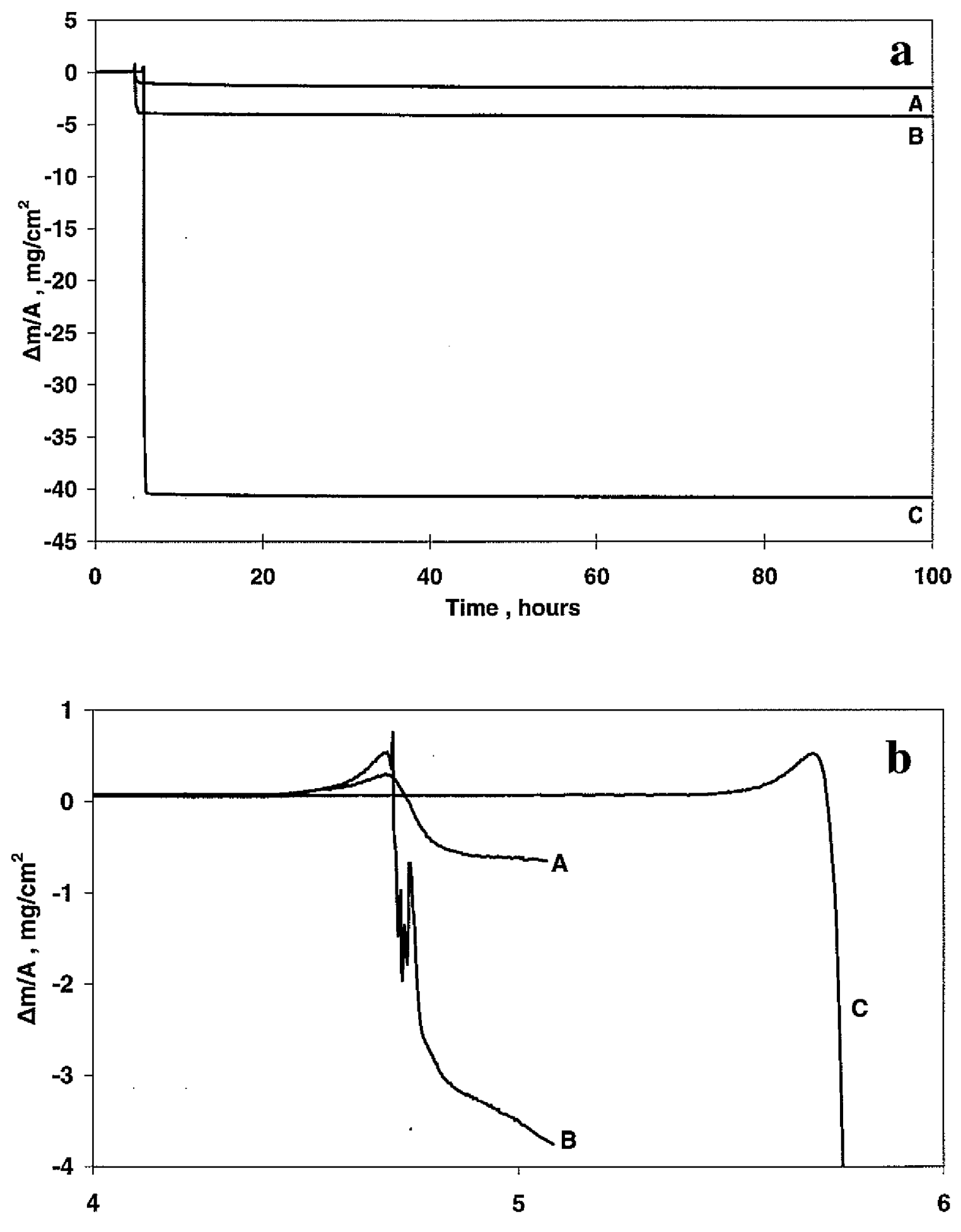

Time, hours

Figure 3 


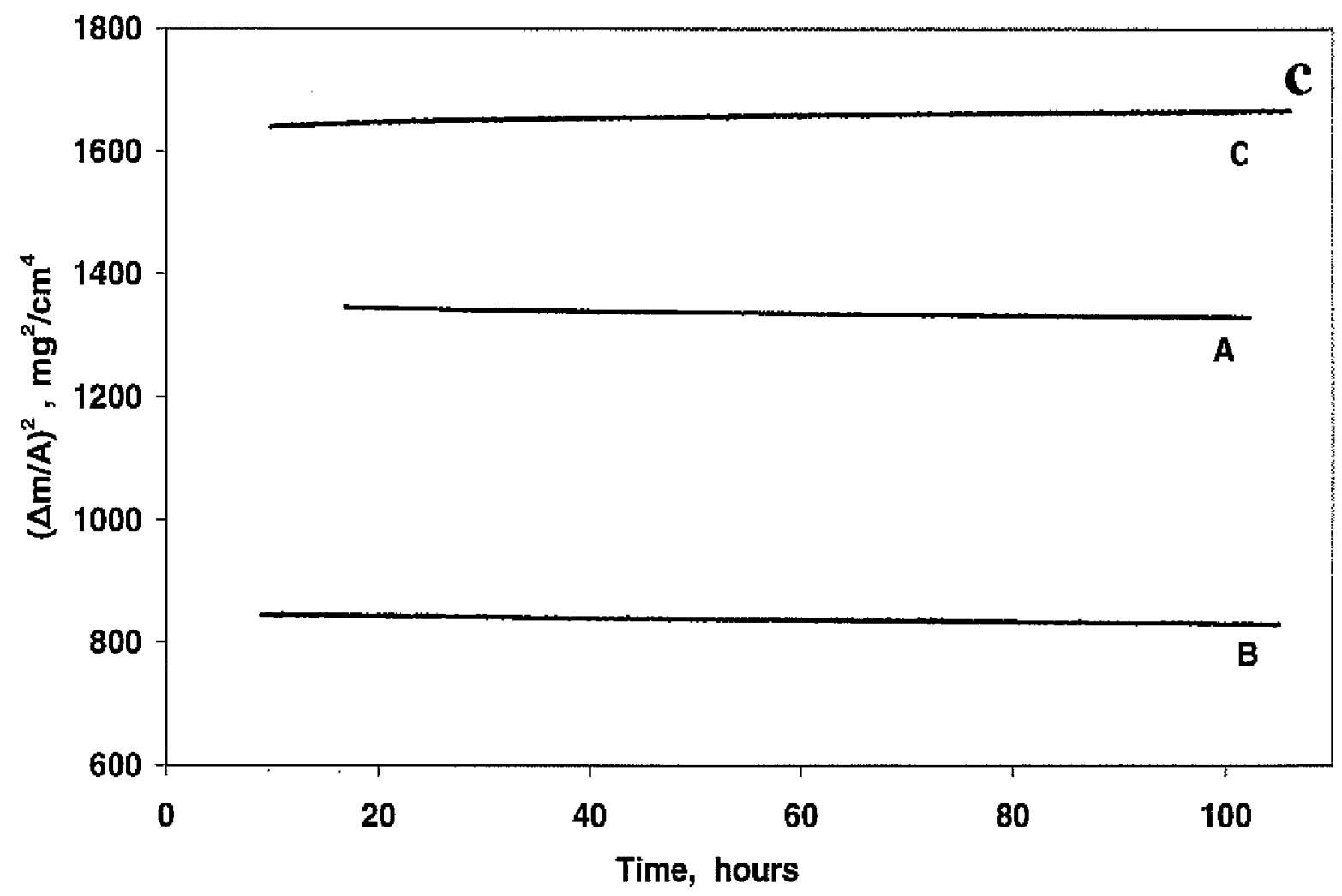

Figure 3 

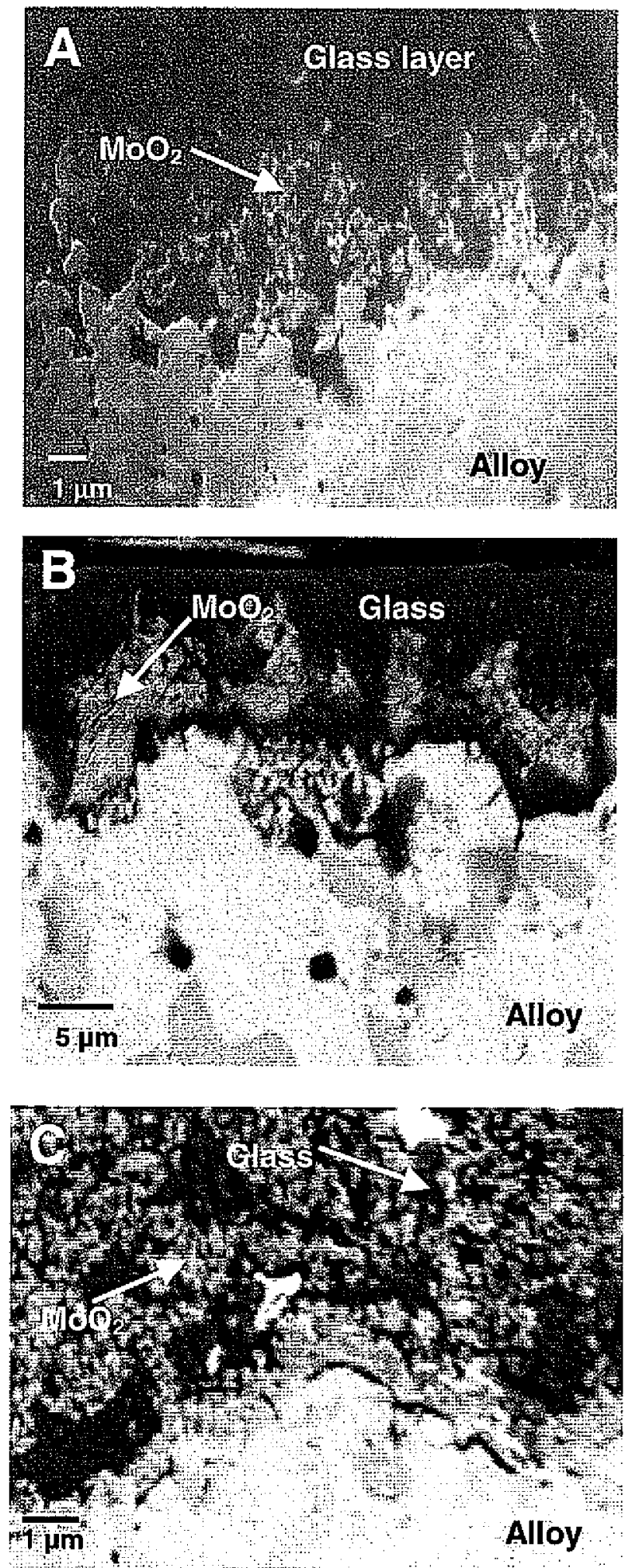

Figure 4 


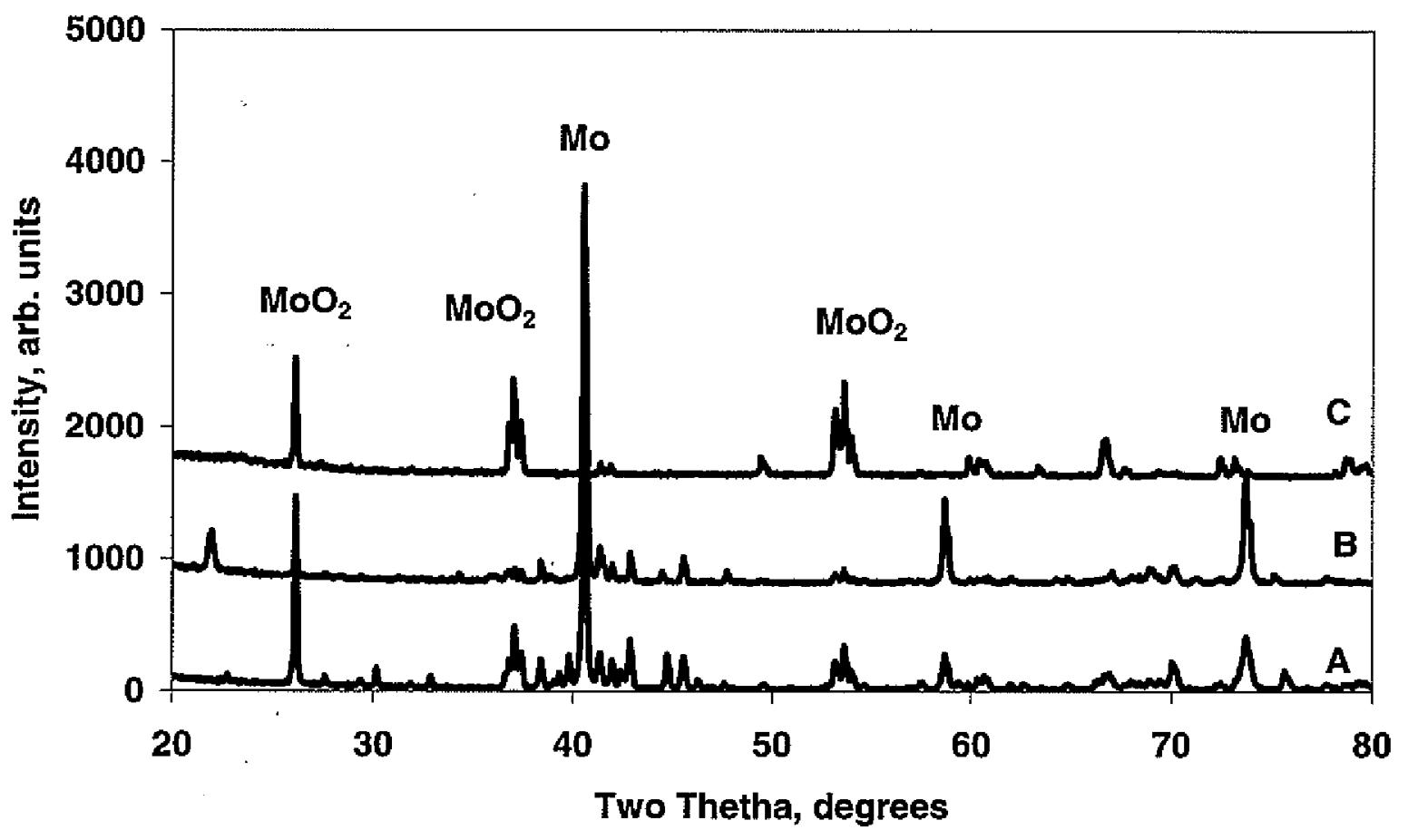

Figure 5 

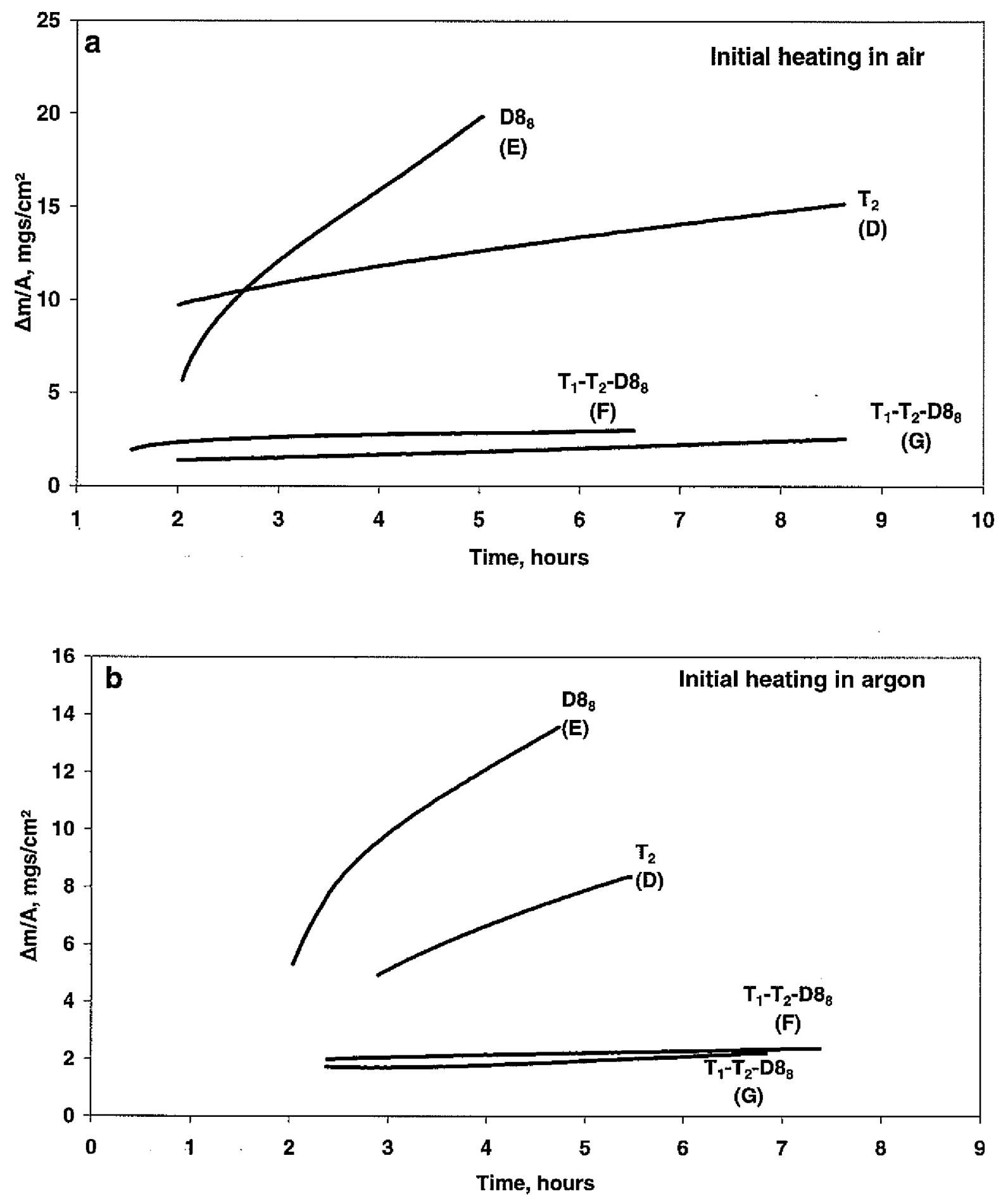

Figure 6 

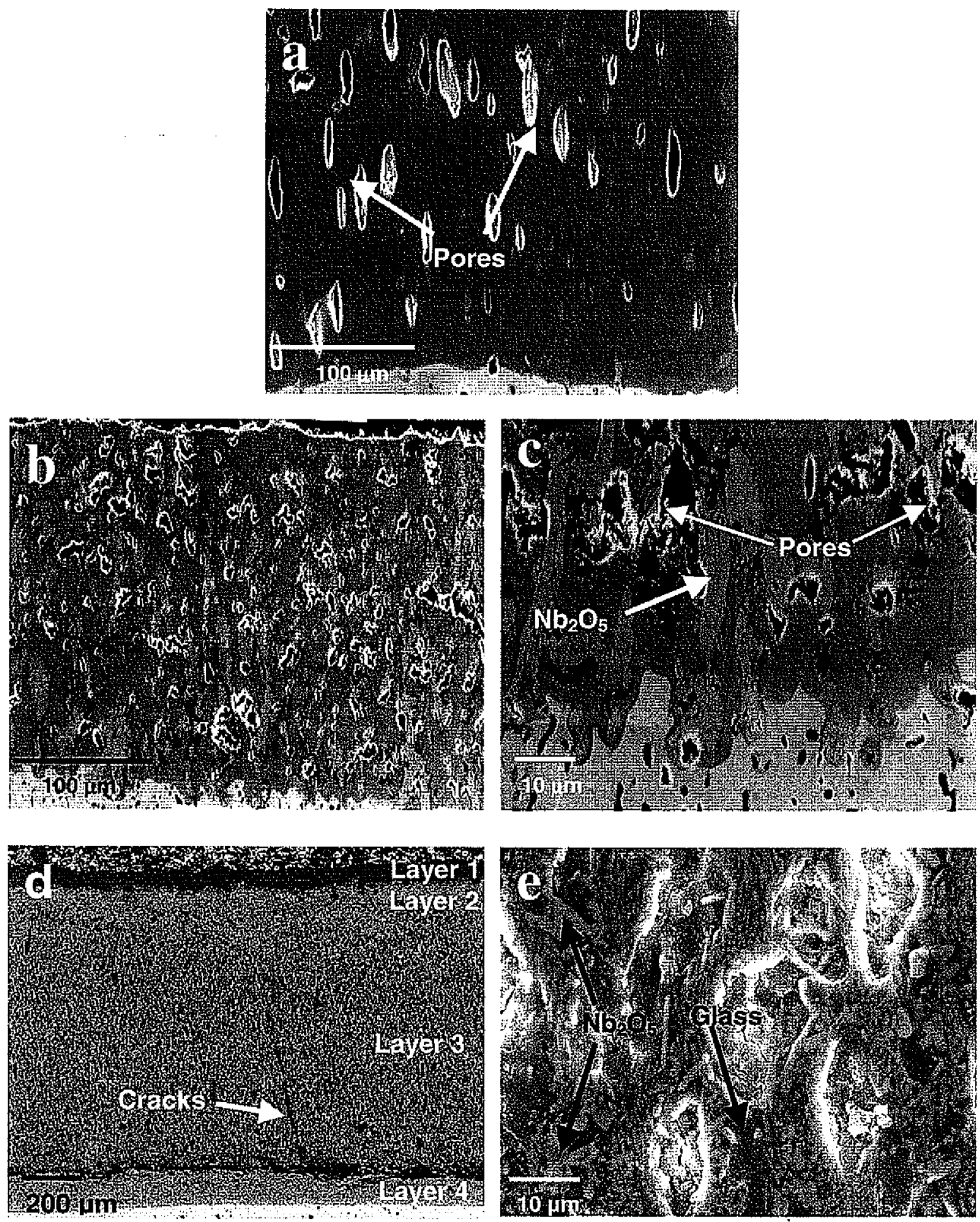

Figure 7 

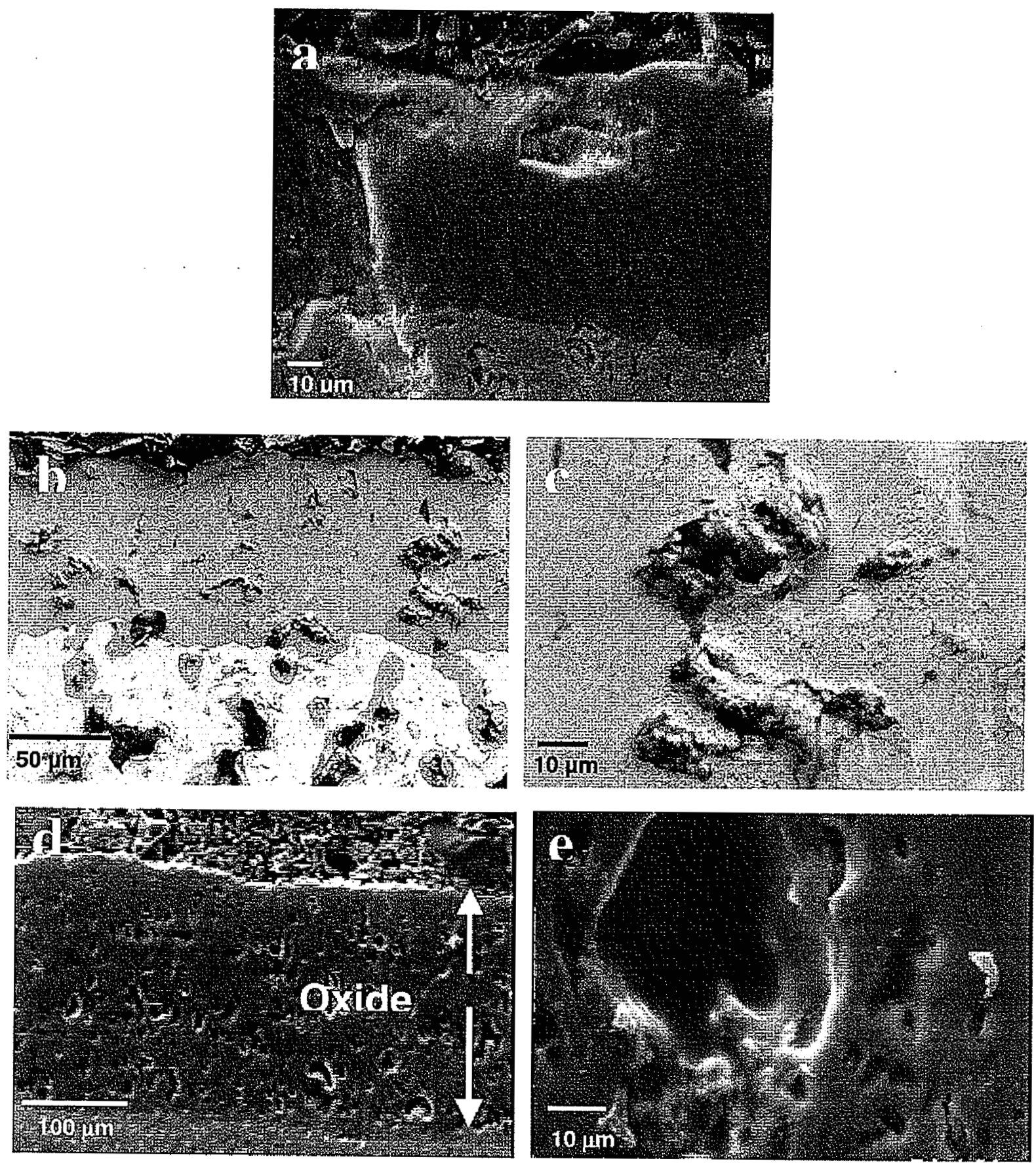

\section{Figure 8}




\section{Figure captions}

1. (a) Isothermal section of $\mathrm{Mo}-\mathrm{Si}-\mathrm{B}$ at $1600^{\circ} \mathrm{C}$; compositions studied in this work are showed as 1,2 and 3.

(b) Isothermal section of $\mathrm{Nb}-\mathrm{Si}-\mathrm{B}$ at $1600^{\circ} \mathrm{C}$; composition studied in this work are showed as 4 and 5

2. BSE images of alloy compositions studied Where, $\mathrm{T}_{1}\left(\mathrm{Mo}_{5} \mathrm{Si}_{3} \mathrm{~B}_{\mathrm{x}}\right), \mathrm{T}_{2}\left(\mathrm{Mo}_{5} \mathrm{SiB}_{2}\right)$ for $\mathrm{A}, \mathrm{B}$ and $\mathrm{C} ; \mathrm{T}_{2}\left(\mathrm{Nb}_{5}(\mathrm{Si}, \mathrm{B})_{3}\right), \mathrm{D} 8_{8}($ $\left.\mathrm{Nb}_{5} \mathrm{Si}_{3} \mathrm{~B}_{\mathrm{x}}\right)$ for $\mathrm{D}$ and $\mathrm{E} ; \mathrm{T}_{1}$ (tetragonal $\left.(\mathrm{Nb}, \mathrm{Mo})_{5} \mathrm{Si}_{3} \mathrm{~B}_{\mathrm{x}}\right), \mathrm{T}_{2}\left(\left((\mathrm{Nb}, \mathrm{Mo})_{5}(\mathrm{Si}, \mathrm{B})_{3}\right)\right.$ ,D8 8 (hexagonal $\left.(\mathrm{Nb}, \mathrm{Mo})_{5} \mathrm{Si}_{3} \mathrm{~B}_{\mathrm{x}}\right)$ for $\mathrm{F}$ and $\mathrm{G}$. Grain pullouts, silica pockets and pores are visible as dark circles.

3. (a) Oxidation kinetics of $\mathrm{Mo}-\mathrm{Si}-\mathrm{B}$ alloy compositions at $1000^{\circ} \mathrm{C}$ in flowing air

(b) Steady state oxidation kinetics at $1000^{\circ} \mathrm{C}$ in flowing air

Curves have been shifted for better comparison.

4. Secondary electron images of scale on Mo-Si-B alloys after exposure to air for 100 hours at $1000^{\circ} \mathrm{C}$

(a) Alloy A

(b) Alloy B

(c) Alloy C

Protective borosilicate glass layer is visible as dark contrast. Bright contrast phase is $\mathrm{MoO}_{2}$ formed during oxidation reaction due to low partial pressure of oxygen at alloy/scale interface. 
5. X ray diffraction patters for oxide scales after oxidation of alloy $\mathrm{A}, \mathrm{B}$ and $\mathrm{C}$ for 100 hours at $1000^{\circ} \mathrm{C}$ in flowing air. $\mathrm{MoO}_{2}$ was observed in all three compositions. Alloy $\mathrm{A}$ and $\mathrm{B}$ shows base alloy silicide peaks suggests that scale is thin whereas alloy $\mathrm{C}$ suggests thick scale as silicide peaks are absent.

6. Oxidation kinetics of Nb-Si-B and Mo-Nb-Si-B alloy compositions

(a) Initial heating to test temperature in flowing air

(b) Initial heating to test temperature in flowing ultra pure argon

7. Oxide scale after oxidation at $1000^{\circ} \mathrm{C}$, with initial heating to test temperature in flowing air

(a) Alloy $\mathrm{D}$ after 7 hrs oxidation in flowing air at $1000^{\circ} \mathrm{C}$. Thick scale on alloy $\mathrm{D}$ consists of $\mathrm{Nb}_{2} \mathrm{O}_{5}$ in glass and large pores. Scale spalled off easily.

(b) , (c) Alloy E after $7 \mathrm{hrs}$ oxidation at $1000^{\circ} \mathrm{C}$.

(d) Alloy F after 5 hrs of oxidation; four layers microstructure of scale. Layer 1 consists of $\mathrm{Nb}_{2} \mathrm{O}_{5}$ particle in silica glass. Layer 2 and 3 is coarse $\mathrm{Nb}_{2} \mathrm{O}_{5}$ in silica glass and large pores formed due to volatilization of $\mathrm{MoO}_{3}$. Layer 4 is mixture of $\mathrm{Nb}_{2} \mathrm{O}_{5}$ and amorphous silica.

(e) Layer 3 which consists of $\mathrm{Nb}_{2} \mathrm{O}_{5}$ rod shaped crystals (white) dispersed in borosilicate glass (dark matrix)

Pores are mainly left behind on the base alloy after formation of respective oxides.

8. Oxide scale after oxidation at $1000^{\circ} \mathrm{C}$, with initial heating to test temperature in ultra high pure argon

(a) Alloy $\mathrm{D}$ after $10 \mathrm{hrs}$ oxidation 
(b), (c) Alloy E after 10 hrs oxidation

(d),(e) Alloy $\mathrm{F}$ after 10 hours of oxidation. Four layered microstrucutre was absent when heated in argon. Scale mainly consists of $\mathrm{Nb}_{2} \mathrm{O}_{5}$ and borosilicate glass. 


\title{
CHAPTER 3
}

\section{CHLORINATION TREATMENT TO IMPROVE OXIDATION RESISTANCE OF Nb-Mo-Si-B ALLOYS}

Vikas Behrani, Andrew J Thom, Matthew J Kramer, Mufit Akinc

Department of Materials Science and Engineering and Ames Laboratory

Iowa State University Ames IA 50011

(To be submitted to Metallurgical and Materials Transactions A)

\begin{abstract}
Recent studies have shown that the quaternary Nb-Mo-Si-B system is not oxidation resistant. The difference in oxidation resistance between $\mathrm{Mo}-\mathrm{Si}-\mathrm{B}$ and $\mathrm{Nb}-\mathrm{Mo}-\mathrm{Si}-\mathrm{B}$ may be interpreted in terms of the volatility of the metal oxide that forms. $\mathrm{MoO}_{3}$ evaporates from the surface scale at about $650^{\circ} \mathrm{C}$, leaving an oxidation resistant borosilicate glassy scale. $\mathrm{Nb}_{2} \mathrm{O}_{5}$ persists as a rapidly growing condensed phase that overwhelms the ability of the borosilicate glass to form a protective layer. A novel chlorination processing was employed to selectively remove $\mathrm{Nb}_{2} \mathrm{O}_{5}$ from the scale of the quaternary alloy as volatile $\mathrm{NbCl}_{5}$. Present work investigated the chlorination of oxidized Nb-Mo-Si-B alloy of nominal composition 63(Nb, Mo)-30Si-7B with $\mathrm{Nb} / \mathrm{Mo}=1($ at $\%)$ comprised of a three phase microstructure of $(\mathrm{Nb}, \mathrm{Mo})_{5} \mathrm{Si}_{3} \mathrm{~B}_{\mathrm{x}}\left(T_{l}\right)$ $(\mathrm{Nb}, \mathrm{Mo})_{5}(\mathrm{Si}, \mathrm{B})_{3}\left(T_{2}\right)-\left(\mathrm{Nb}, \mathrm{Mo}_{5} \mathrm{Si}_{3} \mathrm{~B}_{\mathrm{x}}\left(D 8_{8}\right)\right.$. Oxidation behavior of these alloys in air has been studied both before and after chlorination. Results show that $\mathrm{Nb}_{2} \mathrm{O}_{5}$ can be selectively removed from the scale to leave a borosilicate rich scale. The chlorinated scale forms a dense scale after heat treatment at $1000^{\circ} \mathrm{C}$ in argon. Oxidation rate of the chlorinated alloys was about one-third that of the unchlorinated alloy under identical conditions. Alloy oxidation during heating to test temperature has been studied and a plausible mechanism for formation of porosity in oxide scale has been offered.
\end{abstract}




\section{Introduction}

The rate of oxidation depends primarily on the oxidation product formed, which in turn is determined by the combination of composition, microstructure and surface condition of alloy. Transition metal $\mathrm{M}_{5} \mathrm{Si}_{3}$ type compounds are attractive due to their high melting temperature and good creep resistance [1]. Mo-Si-B system offers a good combination of properties for high temperature applications such as excellent oxidation stability $[2,3]$ and superior creep resistance [4]. But its low fracture toughness and thermal expansion anisotropy need to be improved before the alloys can find practical applications. This was the motivation of recent studies $[5,6,7,8]$ to incorporate $\mathrm{Nb}$ into Mo-Si-B system to improve mechanical properties while retaining oxidation resistance. Nb-Si-B system offers the possibility of ductile phase toughening since $\mathrm{Nb}$ metal can coexist in equilibrium with boron containing silicides. Since there is a complete solubility between $\mathrm{Nb}$ and $\mathrm{Mo}$, the $\mathrm{Nb} / \mathrm{Mo}$ substitution can suppress $\mathrm{Mo}_{3} \mathrm{Si}$ formation, and this may enable the toughness of $\mathrm{T}_{1}\left(\mathrm{Mo}_{5} \mathrm{Si}_{3} \mathrm{~B}_{\mathrm{x}}\right)$ to be improved by ductile phase toughening. In addition, $\mathrm{Nb} / \mathrm{Mo}$ substitution may favorably affect the thermal expansion behavior of $T_{1}$ phase. Thermal expansion anisotropy of Nb-Mo-Si alloys has been studied by Fu et al [8]. They found that the CTE (coefficient of thermal expansion) anisotropy of $\mathrm{Mo}_{5} \mathrm{Si}_{3}$ can be significantly reduced through ternary alloying additions that alter interatomic distance and bonding strength along the atom chains in the $c$-direction. $\mathrm{Nb}$ was found to reduce $\mathrm{CTE}(c) / \mathrm{CTE}(a)$ ratio to a value of 1.5 for $\mathrm{MoNb}_{4} \mathrm{Si}_{3}$ from the 2.2 as reported previously[9,10,11,12]. Isothermal oxidation behavior and microstructure of Nb-Mo-Si-B intermetallic compacts with different compositions and at different temperatures has been studied recently by Liu et al [5,7]. Results show that Nb-MoSi-B alloys have poor oxidation resistance as compared to Mo-Si-B alloys. This poor oxidation resistance was attributed to the formation of the fast growing $\mathrm{Nb}_{2} \mathrm{O}_{5}$ that interferes with formation of a continuous scale of the protective borosilicate glass layer. The nonvolatile nature of $\mathrm{Nb}_{2} \mathrm{O}_{5}$ and the highly porous scale formed after evaporation of $\mathrm{MoO}_{3}$ are the proposed reasons for its poor oxidation resistance. In the Mo-Si-B system, volatile $\mathrm{MoO}_{3}$ facilitates the formation of a continuous borosilicate glass layer that acts as a barrier to oxygen diffusion and prevents further oxidation of alloy. 
We recently reported [6] that initial heating of unoxidized quaternary alloy in argon can significantly decrease the porosity of the scale $(30 \%$ to $9 \%)$. This improves the oxidation resistance but not to the limit of Mo-Si-B. The purpose of the present research is to understand the mechanism of oxidation of Nb-Mo-Si-B alloys during initial heating in air and to design a procedure to volatilize the $\mathrm{Nb}$ component from the scale. By enriching the scale of the quaternary alloy in borosilicate glass, it may be possible to affect oxidation resistance that is on par with the Mo-Si-B alloys. Although all the halides of niobium are volatile by $1000^{\circ} \mathrm{C}$, niobium pentachloride was chosen for this study, as it is relatively easy to form. Formation of niobium iodide requires iodine vapors at high pressure and temperature $\left(1300-1600^{\circ} \mathrm{C}\right)$ for complete reaction [13]. No method for preparing niobium pentabromides from niobium pentoxides is available in literature. Niobium pentafluoride reacts readily with silica or glass to form niobium oxyflouride and silicon tetrafluoride. Considering these factors, $\mathrm{NbCl}_{5}$ reaction route was selected to convert niobium pentoxide to a volatile niobium compound. The reported melting point of niobium pentachloride ranges between $205^{\circ}-210^{\circ} \mathrm{C}$ while the boiling point is only slightly higher, $254^{\circ} \mathrm{C}$. [14]

Conversion of $\mathrm{Nb}_{2} \mathrm{O}_{5}$ to $\mathrm{NbCl}_{5}$ has been studied previously $[15,16,17]$ to obtain pure niobium from impure ores. The present work will use a similar method to remove $\mathrm{Nb}_{2} \mathrm{O}_{5}$ from the scale of the oxidized Nb-Mo-Si-B samples. The direct reaction of niobium pentoxide and chlorine is not thermodynamically favorable at temperatures $<1000^{\circ} \mathrm{C}$. For this reason chlorination is performed in the presence of reducing agents like carbon [15] or carbon monoxide $[16,17]$. Inclusion of carbon in the alloy can produce undesirable phases, thus CO is chosen as reducing agent for this study. Heating $\mathrm{Nb}_{2} \mathrm{O}_{5}$ in the presence of a flowing mixture of carbon monoxide (CO) and chlorine leads to the following reaction:

$$
\mathrm{Nb}_{2} \mathrm{O}_{5}(s)+5 \mathrm{Cl}_{2}(g)+5 \mathrm{CO}(g) \rightarrow 2 \mathrm{NbCl}_{5}(g)+5 \mathrm{CO}_{2}(g)
$$

The present work investigated the extent of $\mathrm{Nb}_{2} \mathrm{O}_{5}$ removal from the oxidized scale by reaction (1). If $\mathrm{Nb}_{2} \mathrm{O}_{5}$ can be selectively removed from the oxide scale of the quaternary alloy, its oxidation resistance may also be suitably improved. Based on the previous work of Liu [7], alloys with high content of $\mathrm{Nb}$ gained mass and those with high content of Mo lost 
mass at a very rapid rate with alloys converting to oxides powder. Alloys with $\mathrm{Nb} / \mathrm{Mo}=1$ showed a small mass change in long-term oxidation tests. Thus, alloy composition from the $\mathrm{Nb}-\mathrm{Mo}-\mathrm{Si}-\mathrm{B}$ system with $\mathrm{Nb}: \mathrm{Mo}=1: 1$ was selected for the present investigation.

\section{Experimental Procedure}

Starting materials were $99.8 \%$ niobium rod (MPC of Ames Laboratory, Ames, IA), 99.9\% molybdenum rod (Mi-Tech Metals, Indianapolis, IN), $99.99 \%$ lump silicon (Alpha Chemicals, Danvers, MA) and 99.5\% lump boron (AESAR, Ward Hill, MA). Nb-Mo-Si-B samples were prepared by arc melting the starting materials on a copper hearth with a tungsten electrode under argon. Each sample was melted at least three times to ensure homogeneity. Melted buttons were then ground in a tungsten carbide lined container (Model 8000 Mixer/Mill, SPEX Industries, Edison, NJ) with 0.2 0.3 wt\% stearic acid. Powders were sieved through a -635 mesh stainless steel sieve, with a nominal opening size of $20 \mu \mathrm{m}$, and uniaxially pressed into $0.95 \mathrm{~cm}$ diameter pellets at $186 \mathrm{MPa}$. The samples were heated in a tube furnace to $550^{\circ} \mathrm{C}$ under flowing high purity argon to remove the stearic acid. Pellets were then transferred to the sintering furnace and sintered at $1900^{\circ} \mathrm{C}$ for 2 hours (Model M60, Centorr/Vacuum Industries, Nashua, NH) under flowing high purity argon. The furnace was heated at $20^{\circ} \mathrm{C} / \mathrm{min}$ and cooled at $5^{\circ} \mathrm{C} / \mathrm{min}$. Phase identification and microstructure characterization were performed using X-ray diffraction (XRD, Scintag XDS 2000, Cupertino, CA), scanning electron microscopy (SEM, JEOL, JSM 6100, Peabody, MA) and energy dispersive spectroscopy (EDS, Oxford Instruments, Valley, CA). Rietveld refinement of the XRD patterns was performed using Rietica (Lucas Height Research Laboratory, Menai, Australia) to determine the fraction of phases present and the lattice parameters. Peak profile coefficients, thermal parameters, specific atom sites, and lattice parameters were varied to obtain the best numerical fit for the X-ray data. Oxidation samples were polished using standard metallographic techniques including a final polish with $0.05 \mu \mathrm{m} \mathrm{Al}_{2} \mathrm{O}_{3}$. The oxidation coupons $(\sim 0.8 \mathrm{~cm}$ in diameter and $\sim 0.1 \mathrm{~cm}$ in thickness) were suspended from a sapphire wire in a vertical tube thermo-gravimetric analyzer using an electrobalance accurate to $0.01 \mathrm{mg}$ (Cahn-2000, Cahn Instruments,Inc., Cerritos, CA). A $0.18 \mathrm{~mm}$ diameter hole was 
drilled through coupons prior to polishing from which the coupons were suspended. The experimental setup for chlorinating the pre-oxidized Nb-Mo-Si-B alloy is shown in Figure 1. High purity argon was initially flowed through the system to purge all ambient gases. The furnace was heated at the rate of $20^{\circ} \mathrm{C} / \mathrm{min}$ to $1000^{\circ} \mathrm{C}$ under flowing argon atmosphere, and then gas flow switched to the reactive gas mixture (Chlorine, 99.5\%, Praxair, Danbury, CT and Carbon monoxide, 99.5\%, Praxair, Danbury, CT). Chlorine and carbon monoxide gas flow were both set to $25 \mathrm{ml} / \mathrm{min}$ and flowed for $30 \mathrm{~min}$. Gas flow was switched back to argon to purge the reaction tube at $1000^{\circ} \mathrm{C}$, followed by cooling to room temperature. A two-stage scrubber containing $\mathrm{NaOH}$ was used to neutralize excess chlorine exiting the tube. The gas flow was first bubbled through water to convert volatile $\mathrm{NbCl}_{5}$ carried down stream into $\mathrm{Nb}_{2} \mathrm{O}_{5}$ and $\mathrm{HCl}$. Microstructure of the oxide scale was characterized after chlorination using XRD, Auger, SEM and EDS. Treated samples were then oxidized in the TGA apparatus to determine the effect of chlorination on the alloy oxidation behavior. Parabolic rate constants were calculated to compare the effect of chlorination on alloy oxidation, where mass change during oxidation was normalized to geometrical area of sample.

\section{Results and discussion}

The starting phase composition of the as-sintered samples was determined using XRD and SEM. The detailed phase analysis and microstructure has been discussed previously [6]. The alloy composition contains three quaternary phases: $40 \% T_{1}$ (tetragonal $(\mathrm{Nb}, \mathrm{Mo})_{5} \mathrm{Si}_{3} \mathrm{~B}_{\mathrm{x}}$; $\mathrm{x}<1)$,

$40 \% T_{2}\left((\mathrm{Nb}, \mathrm{Mo})_{5}(\mathrm{Si}, \mathrm{B})_{3}\right)$ and $20 \% D 8_{8}$ (hexagonal $\left.(\mathrm{Nb}, \mathrm{Mo})_{5} \mathrm{Si}_{3}, \mathrm{~B}_{\mathrm{x}}\right)$. Phase composition of base alloy has been calculated by Rietveld refinement of XRD data. BSE image of alloy studied is shown in Figure 2. Density of alloy was measured by Archimedes method and image analysis. Alloy was $97 \pm 1 \%$ of theoretical density after sintering at $1900^{\circ} \mathrm{C}$ for 2 hours. The alloy has been tested for oxidation resistance by TGA before chlorination with different initial heating atmospheres (i.e. air, argon) and after chlorination. The effects of pre-heating and chlorination on initial mass change of the $\mathrm{Nb}-\mathrm{Mo}-\mathrm{Si}-\mathrm{B}$ alloys at $1000^{\circ} \mathrm{C}$ are shown in Figure 3A. The mass change of the alloy when heated to the test temperature in either air or argon and then subsequently exposed to air is used to establish the base line behavior of the 
alloy. A new sample is then pre-oxidized in air at $1000^{\circ} \mathrm{C}$, chlorinated, and then tested in the TGA with initial heating in air. Heating in argon establishes the effect of residual oxygen in the system on alloy oxidation. Each curve is the result of two competitive mass change processes, mass gain due to the oxidation of $\mathrm{Nb}, \mathrm{Si}$ and $\mathrm{B}$, and mass loss due to the volatilization of $\mathrm{MoO}_{3}$. XRD detected $\mathrm{Nb}_{2} \mathrm{O}_{5}$ on the surface of alloy exposed to air at $1000^{\circ} \mathrm{C}$ irrespective of initial heating atmosphere but no crystalline $\mathrm{MoO}_{3}, \mathrm{SiO}_{2}$ and $\mathrm{B}_{2} \mathrm{O}_{3}$ after 10 hours of oxidation at $1000^{\circ} \mathrm{C}$. Figure 3 shows that when heated to test temperature in air alloy (Figure 3A) gained mass during initial heating $(\sim 2 \mathrm{mg})$. At steady state (Figure 3B) mass change at the rate of $0.76 \mathrm{mg}^{2} / \mathrm{cm}^{4} / \mathrm{hr}^{2}$ was observed. After heating in argon to the test temperature, alloy gained mass at the rate of $0.53 \mathrm{mg}^{2} / \mathrm{cm}^{4} / \mathrm{hr}^{2}$. These results show that preheating atmosphere has a significant effect on oxidation resistance of alloy at test temperature. The surface morphology of the oxide scales formed at $600^{\circ}, 700^{\circ}, 800^{\circ}$ and $1000^{\circ} \mathrm{C}$ was studied to understand the initial oxidation during heating in air and argon to test temperature. Figure 4 shows SEM micrographs of scale surface formed after heating and exposure to air for $3 \mathrm{~min}$ at $600^{\circ}$, and $1000^{\circ} \mathrm{C}$ and then quickly cooled to room temperature by removing samples from the furnace. EDS detected $\mathrm{Mo}$ up to $700^{\circ} \mathrm{C}$ along with $\mathrm{Nb}$ and $\mathrm{Si}$ peaks. No Mo was detected above $800^{\circ} \mathrm{C}$ or above. Figure 5 compares the XRD patterns of the base alloy and the oxidized layer formed at $600^{\circ}, 700^{\circ}, 800^{\circ}, 1000^{\circ} \mathrm{C}$ after $3 \mathrm{~min}$. XRD patterns at $600^{\circ}$ and $700^{\circ} \mathrm{C}$ do not contain any known Nb-oxide and Mo-oxide peaks. Meyer et al $[2,3,4]$ observed needle shaped $\mathrm{MoO}_{3}$ crystals growing from the scale during initial oxidation stages of $\mathrm{Mo}-\mathrm{Si}-\mathrm{B}$ alloys. The needle shaped $\mathrm{MoO}_{3}$ crystals were not seen in the present work (Figure $4 \mathrm{a}$ ), and the XRD pattern at $700^{\circ} \mathrm{C}$ indicates that Mo is present as $\mathrm{Nb}$ Mo oxide solid-solution. $\mathrm{Mo}^{4+}(0.70 \AA)$ and $\mathrm{Mo}^{5+}(0.66 \AA)$ ions are closer in size to $\mathrm{Nb}^{5+}$ $(0.69 \AA)$ than $\mathrm{Mo}^{6+}$ ion $(0.62 \AA)$ suggesting that molybdenum may dissolve into $\mathrm{Nb}_{2} \mathrm{O}_{5}$ as $\mathrm{Mo}^{4+}$ or $\mathrm{Mo}^{5+}[18]$. Prokoshkin [19] et al studied the oxidation behavior of Mo reinforced $\mathrm{Nb}$ for different Mo content and detected presence of $(\mathrm{Nb}, \mathrm{Mo})_{2} \mathrm{O}_{5}$ in oxide scales on $\mathrm{Nb}$ reinforced with $15-50 \%$ of Mo.

As temperature increases, oxide solid-solution dissociates to $\mathrm{MoO}_{3}$ and $\mathrm{Nb}_{2} \mathrm{O}_{5}$. At $800^{\circ} \mathrm{C} \mathrm{Mo-}$ peaks disappeared from the EDS spectra, indicating dissociation of the oxide solid-solution and volatilization of $\mathrm{MoO}_{3}$ and this was further evidenced by formation of volatile $\mathrm{MoO}_{3}$ in 
the furnace at temperature $800^{\circ} \mathrm{C}$ and $1000^{\circ} \mathrm{C}$. Presence of $\mathrm{Nb}_{2} \mathrm{O}_{5}$ peaks and absence of any Mo-oxide peaks in XRD pattern after oxidation for 10 hours at $1000^{\circ} \mathrm{C}$ (Figure 5) further suggests that the solid-solution has completely dissociated.

Liu et al [7] studied the oxidation behavior of $\mathrm{Nb}-\mathrm{Mo}-\mathrm{Si}-\mathrm{B}$ alloys with different $\mathrm{Nb} / \mathrm{Mo}$ ratio. They observed that the pore size increases with the Mo content. Alloy with $\mathrm{Nb} / \mathrm{Mo}=3$ showed pores on the order of $20 \mu \mathrm{m}$ and $\mathrm{Nb} / \mathrm{Mo}=1 / 3$ showed large pore channels on the order of $150-200 \mu \mathrm{m}$. Also channel microstructure of pores suggests that $\mathrm{MoO}_{3}$ vapors coalesce to form a bubble before leaving the scale. $\mathrm{MoO}_{3}$ volatilizes from the scale leaving behind the large pores and rod like $\mathrm{Nb}_{2} \mathrm{O}_{5}$ crystals in pores as evident from the crosssectional SE images of oxide layer in Figure 6. As temperature increases to $800^{\circ} \mathrm{C}$, micro cracks emerge from the pores, which may indicate the thermal expansion mismatch between the oxides formed. These large pores then facilitate the inward diffusion of oxygen to scalealloy interface. Cross-sectional secondary electron images of alloy oxidized at $1000^{\circ} \mathrm{C}$ for 30 hours with initial heating in air are shown in Figure 6. Results show that scale consists of a four-layered microstructure of mixed oxides. The outer layer, which is called as Layer 4 , is almost pore-free and is primarily fine $\mathrm{Nb}_{2} \mathrm{O}_{5}$ with a small amount of dispersed borosilicate glass. Beneath it, layer 3 exhibited coarse rod shaped $\mathrm{Nb}_{2} \mathrm{O}_{5}$ crystals within a borosilicate glass matrix and large number of pores. Layer 4 is considerably thinner $(\sim 50 \mu \mathrm{m})$ than Layer 2 and $3(\sim 600 \mu \mathrm{m})$ and the major difference between them is primarily morphology. The Mo content of the outer two layers (layer 3 and 4) was negligible, thus most of the molybdenum oxide has evaporated. Layer 2, which is considerably enriched in molybdenum, exists beneath Layer 3. This is believed to be condensed $\mathrm{MoO}_{3}$ or $\mathrm{MoO}_{2}$ trapped in the layer. The thick layer 3 likely acts as a barrier for outer diffusion of $\mathrm{MoO}_{3}$. EDS also detected some $\mathrm{Nb}$ in layer 3.

In Mo-Si-B system, borosilicate glass is believed to contain channels at the early stages of oxidation [20]. Vaporization of $\mathrm{MoO}_{3}$ and healing of channels by viscous flow of borosilicate glass results in elimination of channels. This is not observed in Nb-Mo-Si-B system as $\mathrm{Nb}_{2} \mathrm{O}_{5}$ grains increases the viscosity of the borosilicate melt substantially. It has been reported that viscosity of lithia and soda glass increases by the factor of 10 by inclusion of $1-6 \%$ of $\mathrm{M}_{2} \mathrm{O}_{5}$, where $\mathrm{M}$ is Vanadium and Tantalum [21]. Glass scale on quaternary alloys contains 
significant amount of $\mathrm{Nb}_{2} \mathrm{O}_{5}$, so we can expect viscosity of glass to increase sufficiently to hinder the viscous flow.

For all compositions in this study, severe cracks, which were attributed to formation of $\mathrm{Nb}_{2} \mathrm{O}_{5}, \mathrm{MoO}_{3}$ and borosilicate glass during oxidation were observed only in Layer 4 . The scale formed upon heating in air was porous and spalled off, while the scale formed on heating in argon was adherent and without micro cracks.

\section{Chlorination}

Reactivity of pure $\mathrm{Nb}_{2} \mathrm{O}_{5}$ in the $\mathrm{Cl}_{2}+\mathrm{CO}$ environment was measured to ensure gas mixture and reaction time was appropriately set. Starting with $100 \mathrm{mg}$ of pure powder, $98.5 \%$ of $\mathrm{Nb}_{2} \mathrm{O}_{5}$ was removed from the reaction chamber after chlorination at $1000^{\circ} \mathrm{C}$ for $30 \mathrm{~min}$. Pure $\mathrm{SiO}_{2}$ and borosilicate glass were also tested to ensure their resistance to the chlorination process. A minimal loss of $1-1.5 \%$ at $1000^{\circ} \mathrm{C}$ during chlorination is believed to be due to vaporization of some moisture and impurities. Figure 7 compares the oxide scale microstructure before and after chlorination. EDS (not shown), XRD (Figure 8) and Auger spectroscopy (Figure 9) have been used to investigate composition of oxide scale after chlorination. After 30 hours of oxidation the scale was $700 \mu \mathrm{m}$ thick and exhibited four layers as observed previously. Layer 4 , which was primarily $\mathrm{Nb}_{2} \mathrm{O}_{5}$ rich before chlorination, showed primarily $\mathrm{SiO}_{2}$ by EDS. Layer 3 also showed more $\mathrm{SiO}_{2}$ than $\mathrm{Nb}_{2} \mathrm{O}_{5}$. Layer 2 was Mo-free but rich is $\mathrm{Si}$ and showed some $\mathrm{Nb}$, suggesting that trapped $\mathrm{MoO}_{3}$ formed Mochloride vapor and left the scale. There was no evidence of $\mathrm{Cl}$ in the oxide scale, indicating that all of the chloride phases had evaporated. Porosity comparison of the layered scale before and after chlorination suggests that glass flows to fill some of the voids but does not fill the large pores completely. This may explain why the chlorinated sample in Figure 3 showed significant reduction in mass gain. These results indicate that 30 minutes of chlorination was able to remove $\mathrm{Nb}_{2} \mathrm{O}_{5}$ from two-thirds of the scale. Remaining $\mathrm{Nb}_{2} \mathrm{O}_{5}$ is believed to be the grains that were completely covered with a borosilicate glass layer protecting them from coming in contact with the reactive gas mixture. Apparently 30 minutes of the chlorination time was not sufficient to adequately remove $\mathrm{Nb}_{2} \mathrm{O}_{5}$ from approximately $700 \mu \mathrm{m}$ thick scale. The alloy was oxidized for 5 hours to study the effect of 
chlorination on thinner scale. After 5 hours of exposure, $\sim 50 \mu \mathrm{m}$ thick scale was formed and $15 \mathrm{~min}$ of chlorination time was sufficient to remove most of $\mathrm{Nb}_{2} \mathrm{O}_{5}$ from the scale. No significant change in scale thickness was observed after chlorination. Scale after chlorination was adherent to the substrate unlike the 30 hour oxidation runs which spalled off easily. Auger analysis (Figure 9) of layer 2 shows that the scale is essentially borosilicate glass with a trace amount $\mathrm{Nb}$.

Results show that after $\mathrm{Nb}_{2} \mathrm{O}_{5}$ removal, the oxidation resistance of alloy has been improved significantly after chlorination. After 10 hours of oxidation, the untreated alloy gained 2.6 $\mathrm{mg} / \mathrm{cm}^{2}$ weight. It was decreased to $1.3 \mathrm{mg} / \mathrm{cm}^{2}$ after the chlorination. Table 1 shows the parabolic rate of oxidation for alloys oxidized before and after chlorination. Results show that the alloy oxidation rate after chlorination $\left(0.2 \mathrm{mg}^{2} / \mathrm{cm}^{4} / \mathrm{hr}^{2}\right)$ is one-third of the rate before the chlorination $\left(0.76 \mathrm{mg}^{2} / \mathrm{cm}^{4} / \mathrm{hr}^{2}\right)$. This rate is comparable to the oxidation rate of the alloy $\left(0.13 \mathrm{mg}^{2} / \mathrm{cm}^{4} / \mathrm{hr}^{2}\right)$ in argon with a residual oxygen pressure of $P_{O_{2}}=10^{-4} \mathrm{~atm}$. This suggests that oxygen diffusion through the glass layer is hindered reducing partial pressure of oxygen at alloy/scale interface.

Oxidation after chlorination occurred in three different stages. Stage 1 (Figure 3A) was a sharp gain in mass, which is believed to be due to oxidation of elements to their respective oxides. Stage 2 and 3 (Figure 3B) are small steady state mass change with linear rate on the order of $0.1 \mathrm{mg} / \mathrm{cm}^{2} / \mathrm{hr}$. This stage indicates that the after initial incubation period, the scale becomes protective in nature. Figure 10 shows the microstructure of the scale oxidized for 10 hours after chlorination of pre-oxidized alloy for 30 hours. Cracks have been observed at layer1/layer2 interface. Layer 1 is believed to be an internal oxidation layer containing silicides and layer 2 consists primarily niobium oxide. Large mismatch between thermal expansion coefficients of $\mathrm{Nb}_{2} \mathrm{O}_{5}$ and silicides is responsible for mechanical failure of scale at the interface creating cracks during oxidation. EDS shows Nb-peaks near layer 1 indicating that only $\mathrm{Nb}_{2} \mathrm{O}_{5}$ is forming. Layer 4 and 3 were mostly glass after 10 hours of oxidation shows that $\mathrm{Nb}_{2} \mathrm{O}_{5}$ formed does not diffuse to other layers.

Oxygen diffusion through non-volatile $\mathrm{Nb}_{2} \mathrm{O}_{5}$ grains and highly porous scale are the main reasons behind the oxidative instability of $\mathrm{Nb}-\mathrm{Mo}-\mathrm{Si}-\mathrm{B}$ alloys as proposed in previous works $[5,6,7,22]$. It has been shown that chlorination is able to remove most of the $\mathrm{Nb}_{2} \mathrm{O}_{5}$ from 
scale and parabolic oxidation rates of Nb-Mo-Si-B alloys have been significantly decreased after chlorination treatment. This suggests that presence of $\mathrm{Nb}_{2} \mathrm{O}_{5}$ affects the oxidation mechanism by altering the viscosity of glass melt and facilitating the diffusion of oxygen

through grains. The coefficient of oxygen diffusion in $\mathrm{Nb}_{2} \mathrm{O}_{5}\left(8.7 \times 10^{-11} \mathrm{~cm}^{2} / \mathrm{sec}\right)$ is almost 1000 times higher than in silica glass $\left(1.8 \times 10^{-14} \mathrm{~cm}^{2} / \mathrm{sec}\right)$ at $1000^{\circ} \mathrm{C}[23,24,25]$.

\section{Summary}

Oxidation behavior of Nb-Mo-Si-B alloys with initial heating in air and argon has been investigated. Alloys heated in argon showed more resistance to oxidation than the same heated in air to the test temperature. Mechanism of oxidation with initial heating has been studied. Results showed the formation of $\mathrm{Nb}-\mathrm{Mo}$ oxide solid-solution at lower temperature on exposure to air. This oxide solid-solution dissociated to $\mathrm{Nb}_{2} \mathrm{O}_{5}$ and $\mathrm{MoO}_{3}$ at higher temperature. $\mathrm{MoO}_{3}$ vapors can coalesce to form a bubble, which manifest as large pores as in the microstructure. A new processing technique of chlorination of oxidized alloys has been used to remove the non-volatile $\mathrm{Nb}_{2} \mathrm{O}_{5}$ from the oxidized scale and obtain a borosilicate glass rich layer. Chlorination was able to remove oxide from two-thirds of the scale of 30 hours pre-oxidized alloy. Oxidation rates were reduced to one-third after chlorination treatment. Steady state parabolic rate of oxidation after chlorination treatment were comparable to that of alloy oxidation in regular argon. This also suggests that oxidative instability of Nb-Mo-Si$\mathrm{B}$ alloys can be attributed to presence of non-volatile $\mathrm{Nb} 2 \mathrm{O} 5$ which increases the viscosity of the glass hence preventing the formation of a continuous glass and fast diffusion of oxygen through $\mathrm{Nb}_{2} \mathrm{O}_{5}$ grains. Low oxidation rates after chlorination indicate the formation of a protective scale. 


\section{Acknowledgement}

The Ames Laboratory is operated by the US Department of Energy (DOE) by Iowa State University under Contract No. W-7405-ENG-82. This work was supported by the U.S. Department of Energy (DOE) National Energy Technology Laboratory under Field Work Proposal number AL-00-360-011. The United States Government retains and the publisher, by acceptingthe article for publication, acknowledges that the United States Government retains a non-exclusive, paid-up, irrevocable, worldwide license to publish or reproduce the published form of this manuscript, or allow others to do so, for United States Government purposes.

\section{References}

1. Shah D. M., Superalloys, Edited by Antolovich S. D. The Mineral, Metals and Materials Society, Warrendate, PA, 1992, pp409

2. Meyer M. K., Akinc M., J Am Ceram Soc (1996),79(4):938-44

3. Meyer M. K. Akinc M., J Am Ceram Soc (1996),79(10):2763-6.

4. Meyer M. K., Kramer M. J., Akinc M., Intermetallics,(1996),4:273- 81.

5. Liu Y. H., Thom A. J., Kramer M. J., and Akinc M., Processing and Fabrication of Advanced Materials-XI, Ed. Srivatsan T. S. and Ravi V. A., ASM International, 258271.

6. Behrani V., Thom A. J., Kramer M. J. and Akinc M., "Microstructure and oxidation behavior of Nb-Mo-Si-B alloys", (To be submitted)

7. Liu Y. H., MS thesis, Iowa State University, 2001

8. Fu C. L. and Schneibel J. H., Acta Materialia (2003) 51: 5083-5092

9. Fu C. L., Wang X., Philos Mag Lett (2000) 80:683.

10. Schneibel J. H., Rawn C. J., Watkins T. R. and Payzant E. A., Phys Rev B (2002), 65: 134112.

11. Chu F., Thoma D. J., McClellan K., Peralta P., He Y., Intermetallics (1999), 7:611. 
12. Zhao H. L., Kramer M. J. and Akinc M., "Thermal expansion behavior of intermetallic compounds is the Mo-Si-B system" (Accepted in Intermetallics)

13. Fairbrother F., "The chemistry of Niobium and Tantalum", (1967) : 115-120

14. Alexander K. M. and Fairbrother F,; J. Chem. Soc., (1949) : S223

15. Fairbrother F., Cowley A. H., Scott N., J. Less-common Metals(1959) 1: 206

16. Freitas L., Ajersch F., Chem. Eng. Comun. (1984) 30: 19

17. Gaballah, I., Allain E., Djona M., Min. Met. Mat. Soc. (1992): 759

18. Argent B. B. and Phelps B., Report of a conference held in the university of Sheffield, Edited by Quarrell A. G., 198-207

19. Prokoshkin D. A., Vasil'eva E. V., Ryabshev A. M., Issled. Po Zharoproch. Splavam, Akad. Nauk SSSR, Inst. Met. (1963), 10: 233-9

20. Helmick D. A., PhD Dissertation, University of Pittsburgh, 2003

21. Bansal N. P. and Doremus R. H., "Handbook of Glass properties",1986, Academic Press, Inc.

22. Murakami T., Xu C. N., Kithara A., Kawahara M., Takahashi Y., Inui H., Yamaguchi M., Intermetallics (1999) 7: 1043-1048.

23. Schlichting J., J. Non-Crystalline Solids, (1984) 63: 173-181

24. Wohlbier F. W, Diffusion and Defect data, (1977) Vol. 14: 129 .

25. Wohlbier F. W., Diffusion and Defect data, (1978) Vol. 17: 135 


\begin{tabular}{|c|c|}
\hline Oxidation process & $\begin{array}{c}\mathbf{K}_{\mathbf{p}} \\
\left(\mathbf{m g}^{\mathbf{2}} / \mathbf{c m}^{4} / \mathbf{h r}{ }^{2}\right)\end{array}$ \\
\hline Initial heating in air & 0.76 \\
\hline Initial heating in argon & 0.53 \\
\hline After chlorination of 5 hours pre-oxidized alloy & 0.20 \\
\hline Oxidation in Argon ( $\mathrm{P}_{\mathrm{O} 2}=10^{-4}$ atm) & 0.13 \\
\hline
\end{tabular}

Table 1 : Steady state parabolic rate constants for oxidation of Nb-Mo-Si-B alloys (Data shown in Figure 3) 


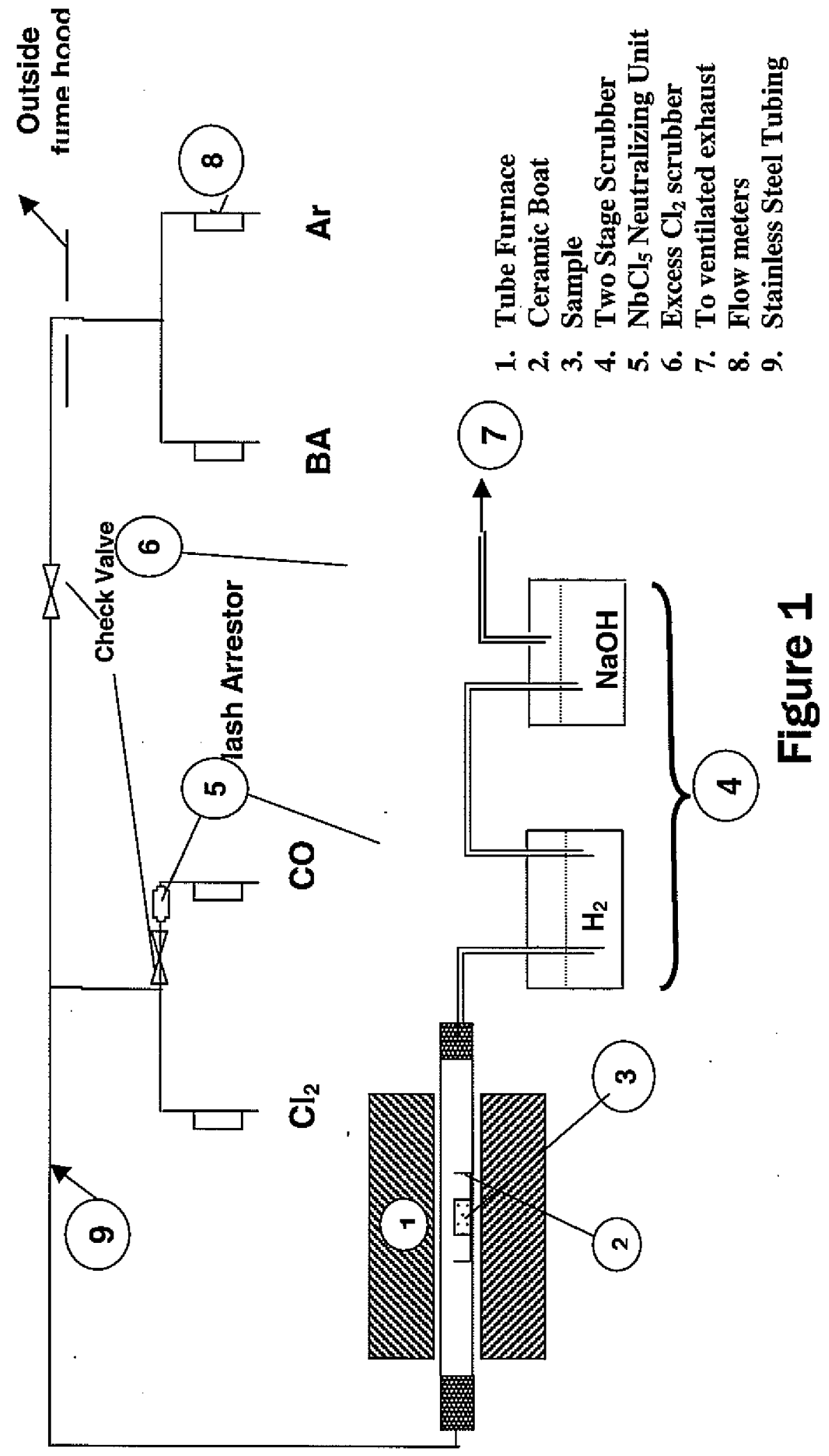




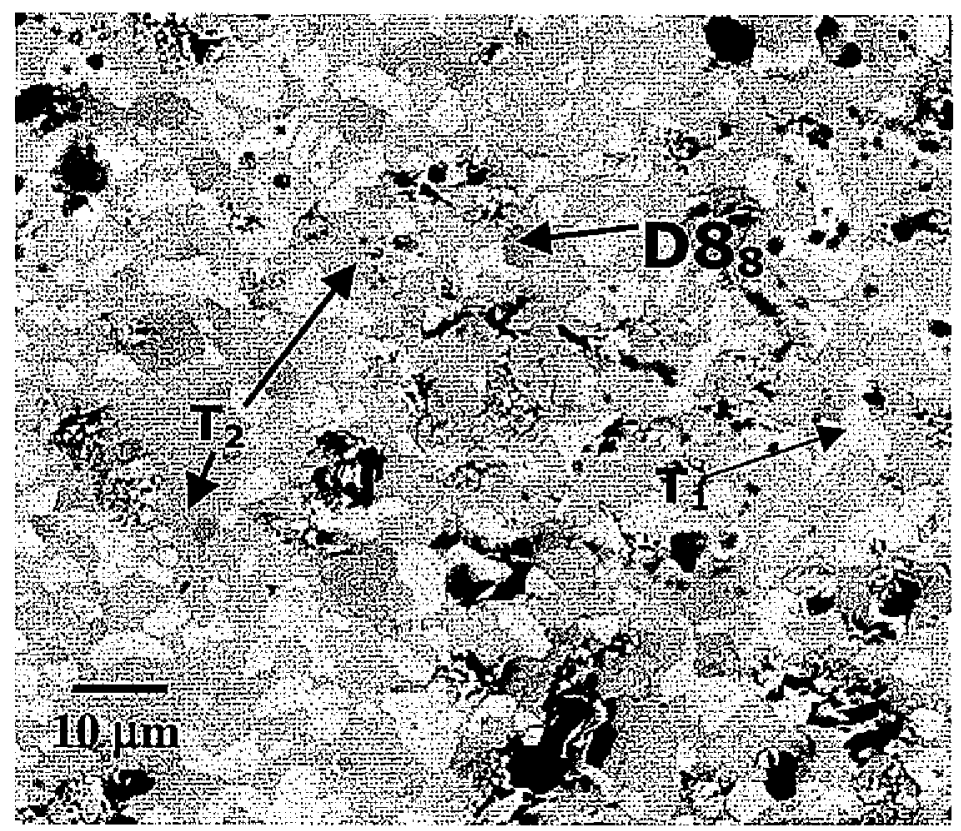

Figure 2 


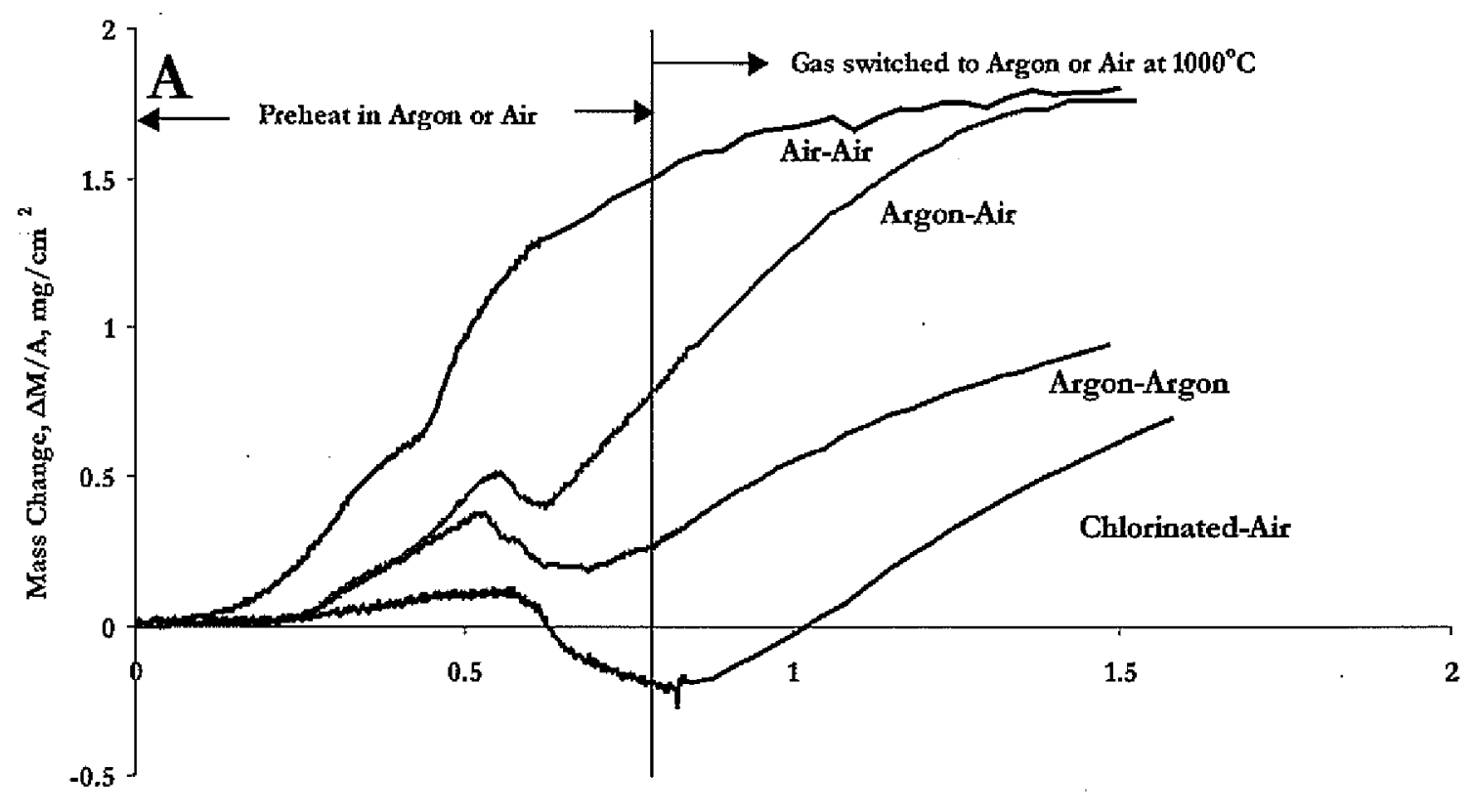

Time, hours

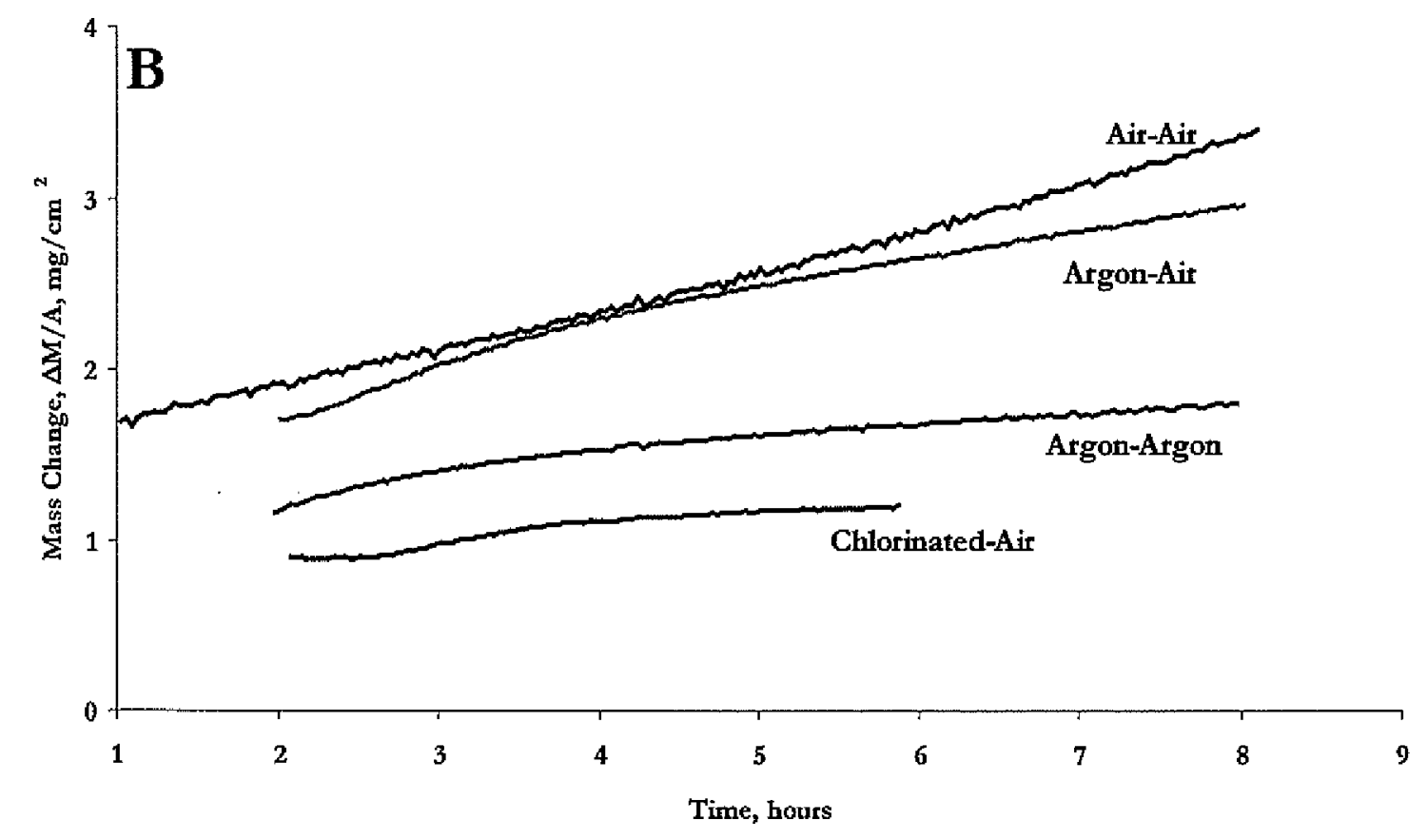

Figure 3 

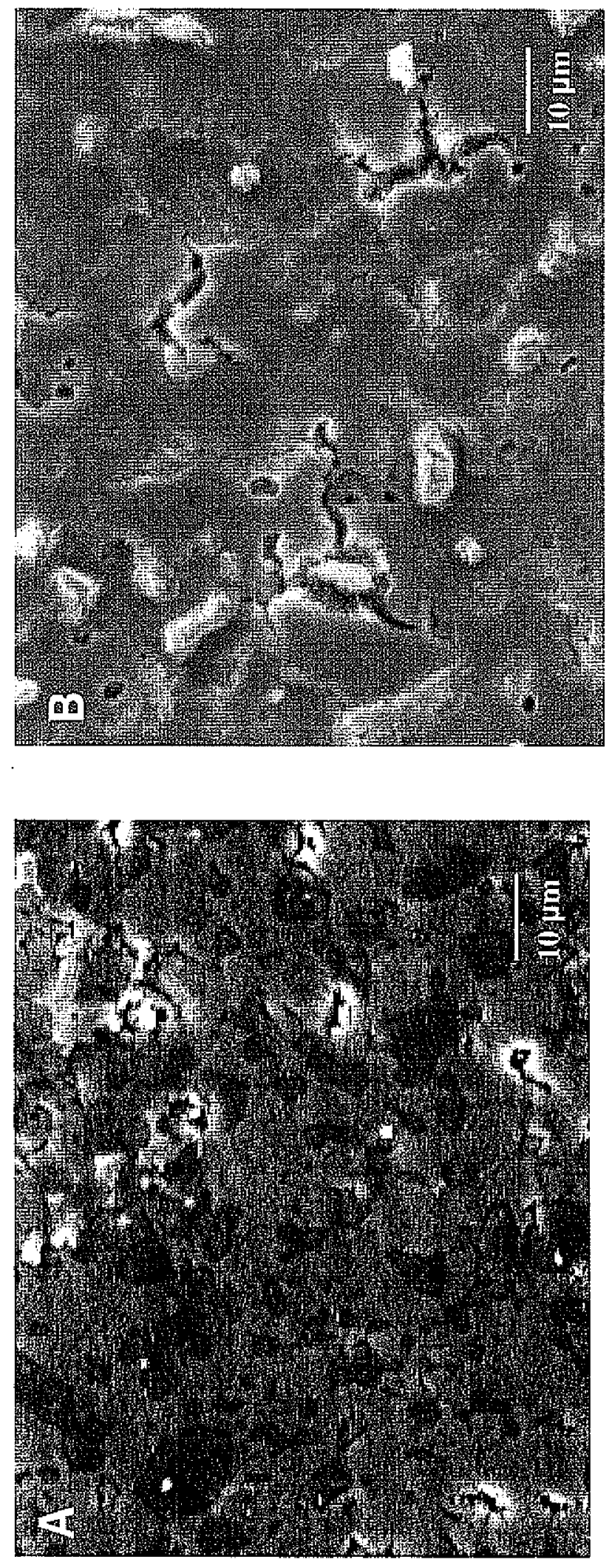

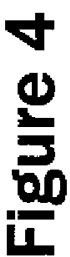




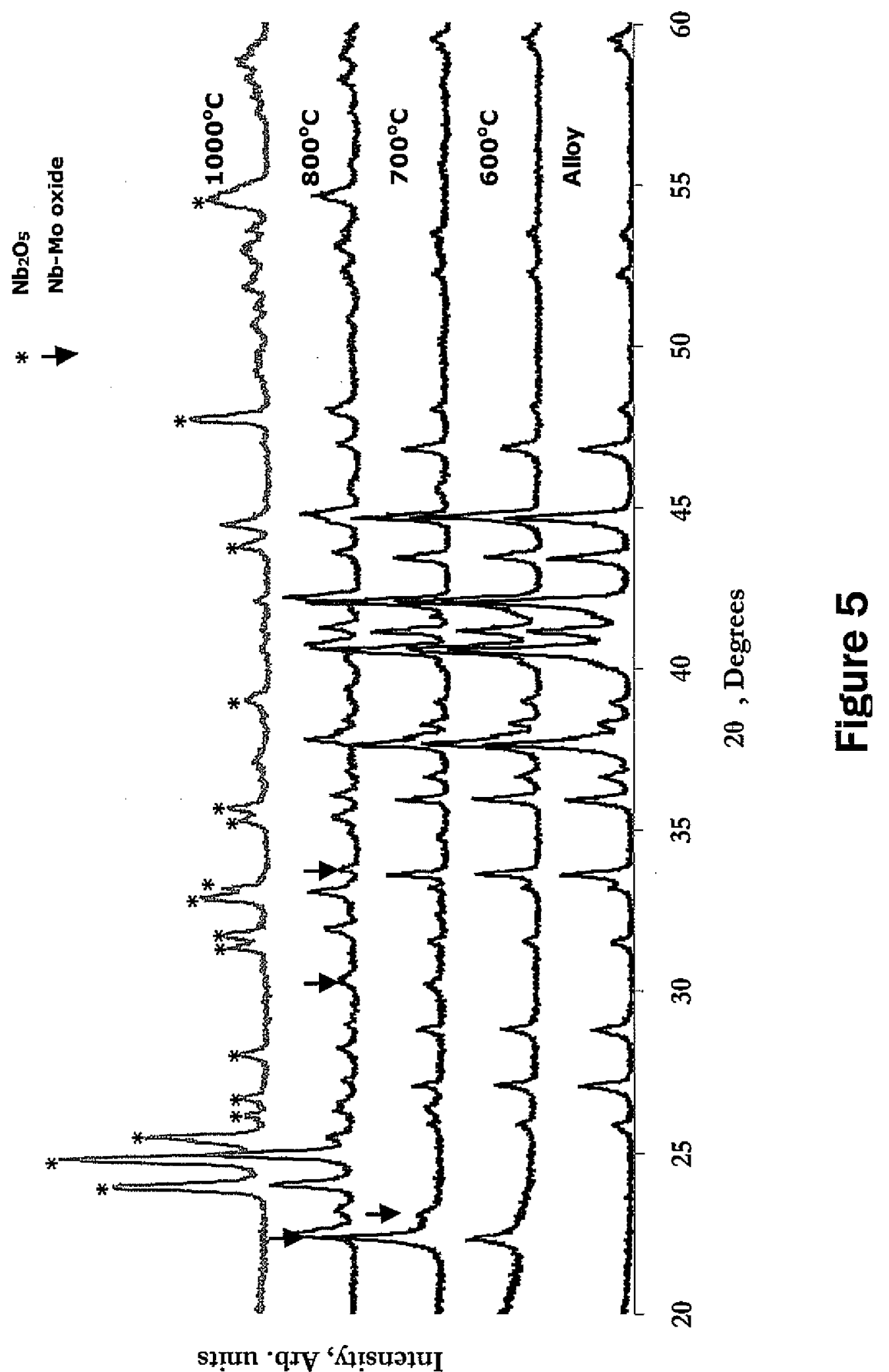



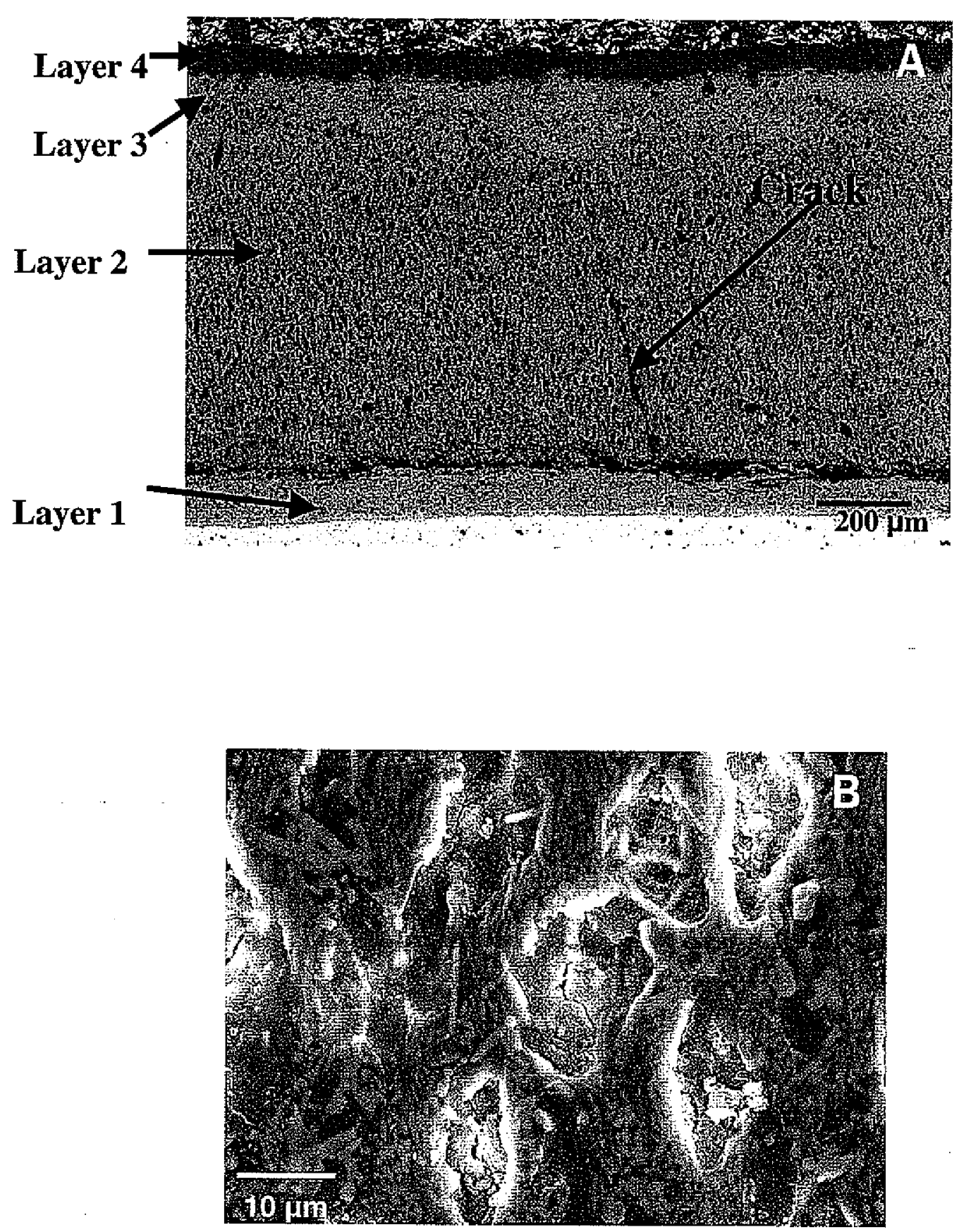

Figure 6 


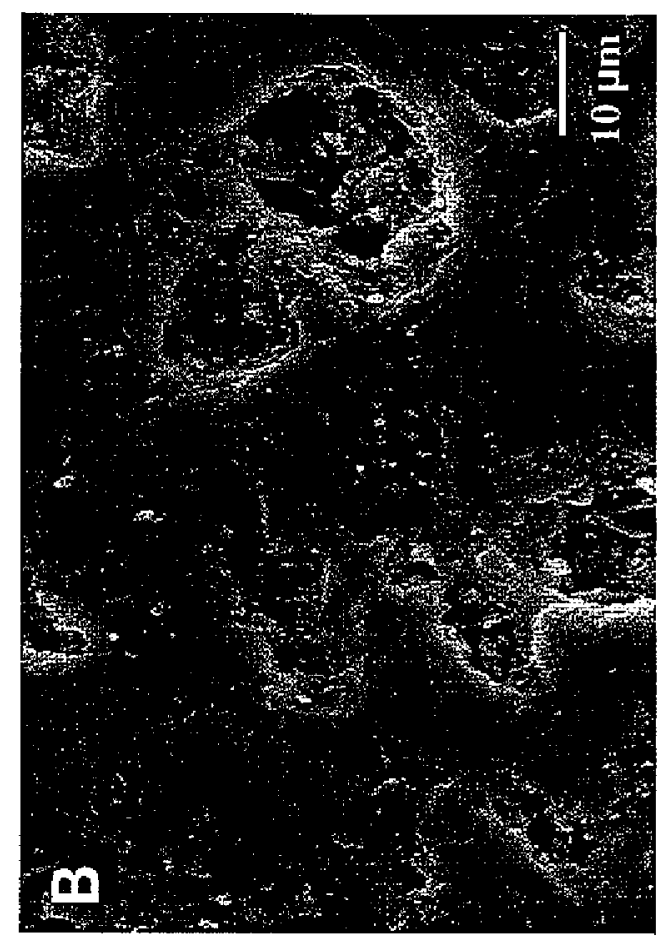

$\frac{0}{\underline{6}}$

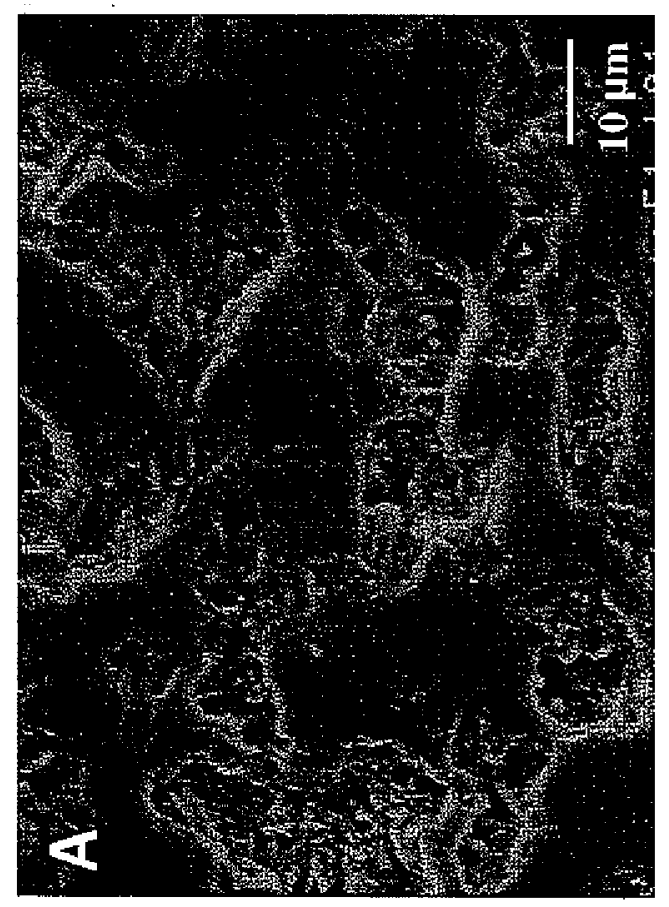




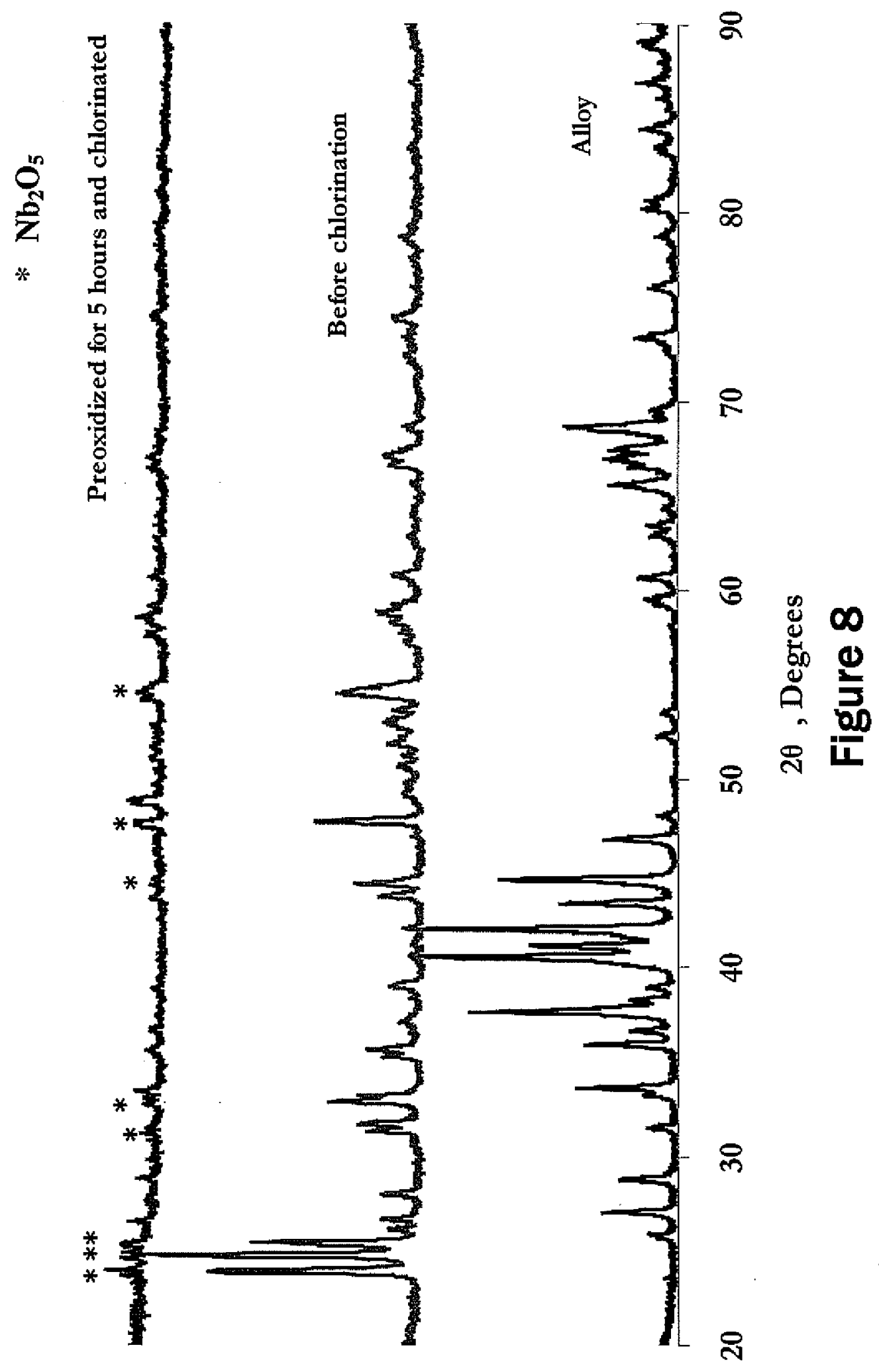




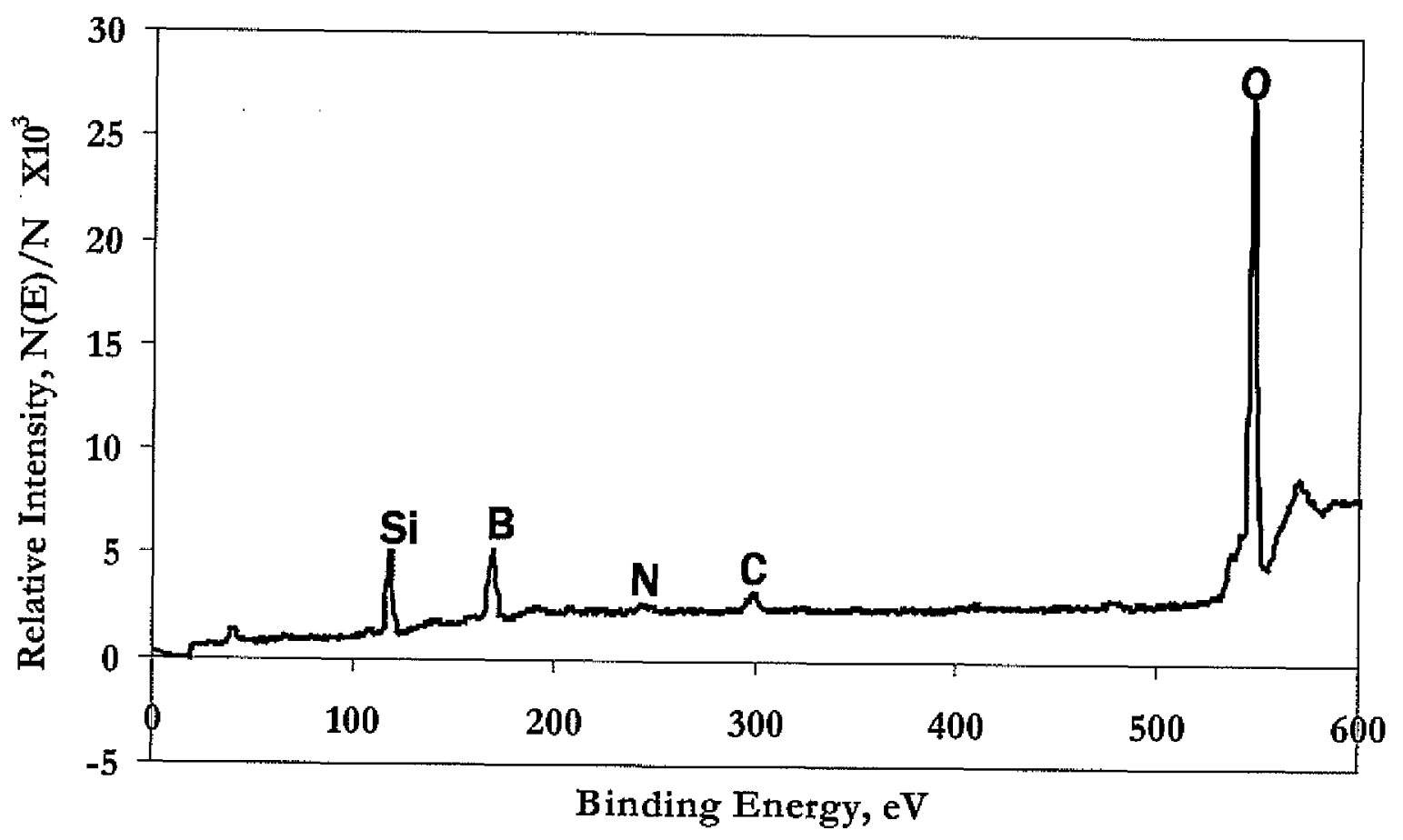

Figure 9 

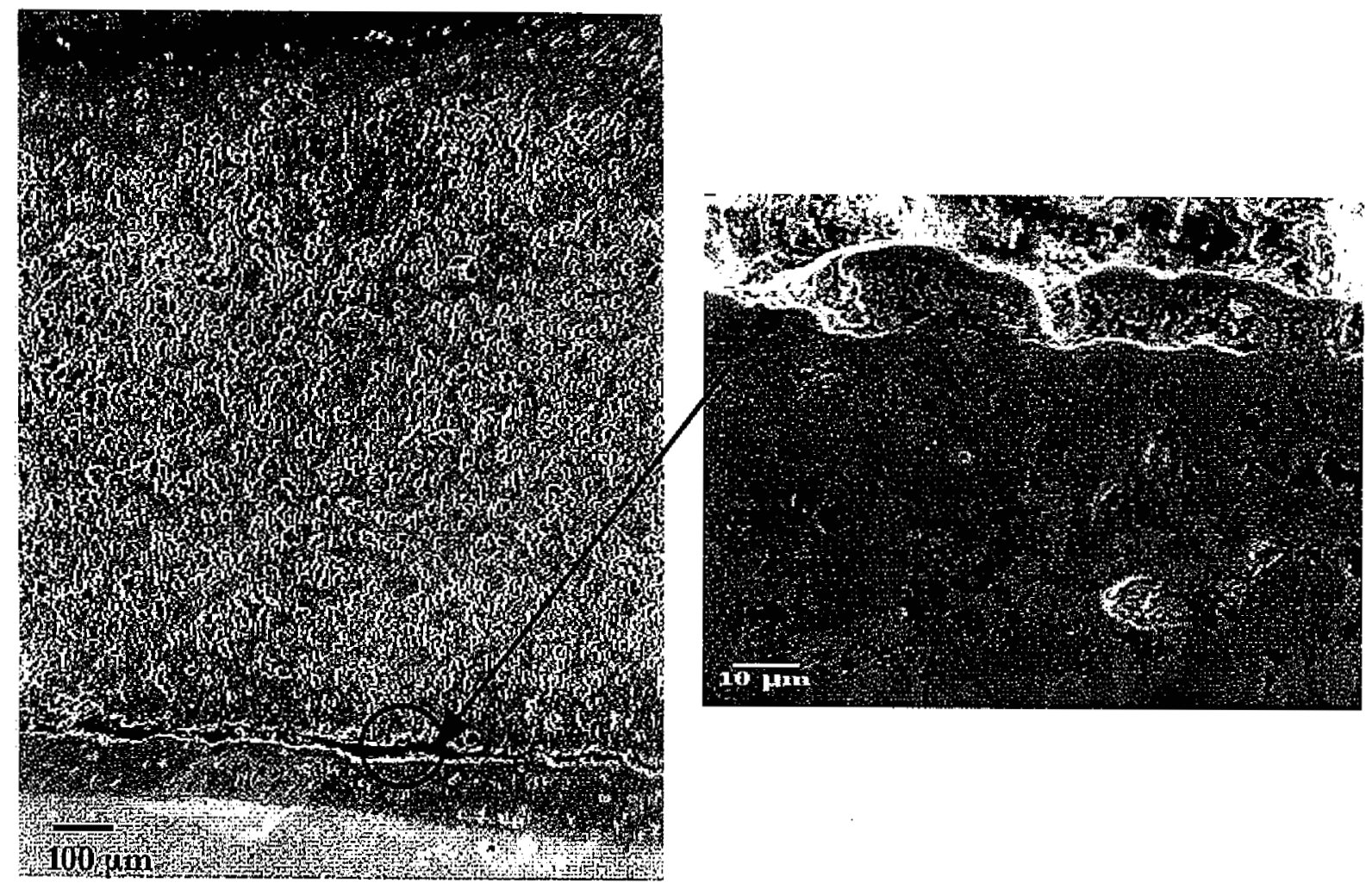

Figure 10 


\section{Figure captions}

1. Experimental setup for chlorination of $\mathrm{Nb}-\mathrm{Mo}-\mathrm{Si}-\mathrm{B}$ alloys at $1000^{\circ} \mathrm{C}$

2. BSE images of alloy studied showing phases $T_{1}, T_{2}$ and $D 8_{8}$

$\mathrm{T}_{2}$ and $\mathrm{D} 8_{8}$ have similar contrast while $\mathrm{T}_{1}$ is slightly brighter. Silica pockets and/or pores are visible as dark phase.

3. Comparison of the oxidation of the $\mathrm{Nb}-\mathrm{Mo}-\mathrm{Si}-\mathrm{B}$ alloy at $1000^{\circ} \mathrm{C}$ in flowing air. Samples were pre-heated in air or argon to $1000^{\circ} \mathrm{C}$ then exposed to air. The chlorinated sample was preheated and exposed to air, while a sample was also preheated and exposed to argon only with $P_{\mathrm{O}_{2}}=10^{-4} \mathrm{~atm}$

(A) Mass change on initial heat up

(B) Steady state kinetics at $1000^{\circ} \mathrm{C}$

4. Morphology of oxide scale of alloy after exposing alloys to air for 3 minutes to
(A) $600^{\circ} \mathrm{C}$
(B) $1000^{\circ} \mathrm{C}$

5. X-ray diffraction pattern comparison of base alloy compared to the alloy oxidized at $600^{\circ}, 700^{\circ}, 800^{\circ}$ and $1000^{\circ} \mathrm{C}$ for 3 minutes. $\mathrm{Nb}-\mathrm{Mo}$ oxide solid solution peaks are observed at $700^{\circ} \mathrm{C}$. Appearance of $\mathrm{Nb}_{2} \mathrm{O}_{5}$ peaks and absence of $\mathrm{Nb}-\mathrm{Mo}$ oxide solid solution peaks at $1000^{\circ} \mathrm{C}$ indicates the dissociation of $\mathrm{Nb}-\mathrm{Mo}$ solid solution to $\mathrm{Nb}_{2} \mathrm{O}_{5}$ and $\mathrm{MoO}_{3}$. All other peaks are from base alloy.

6. Cross-section secondary electron image of alloy oxidized for 30 hours in flowing air at $1000^{\circ} \mathrm{C}$

(a) Four-layered scale

(b) Layer 2 containing rod-shaped $\mathrm{Nb}_{2} \mathrm{O}_{5}$ dispersed in glass.

Rod shaped $\mathrm{Nb}_{2} \mathrm{O}_{5}$ is visible as bright phase dispersed in glass.

7. Comparison of oxide scale, (a) Before chlorination, (b) After chlorination $\mathrm{Nb}_{2} \mathrm{O}_{5}$ is selectively removed from the scale as $\mathrm{NbCl}_{5}$. No $\mathrm{Cl}$ peaks in EDS were observed suggesting all chlorides were volatile at the test temperature and removed from the scale. 
8. XRD patterns of base alloy, oxidized alloy for 10 hours and scale after chlorination. Disappearance of $\mathrm{Nb}_{2} \mathrm{O}_{5}$ peaks after chlorination and absence of any other peaks suggest that $\mathrm{Nb}_{2} \mathrm{O}_{5}$ has been removed from scale leaving an amorphous layer i.e. borosilicate glass

9. Auger analysis of layer 2 after chlorination and heat treatment at $1100^{\circ} \mathrm{C}$ for 1 hour Presence of Boron and Silicon peaks suggests that amorphous phase present is borosilicate glass.

10. Microstructure of alloy oxidized at $1000^{\circ} \mathrm{C}$ in flowing air for 10 hours after chlorination.

(a) Four-layered microstructure of oxide scale.

(b) Microstructure of crack and layer $1 . \mathrm{Nb}_{2} \mathrm{O}_{5}$ growth is visible as bright phase. 


\section{CHAPTER 4 GENERAL CONCLUSIONS}

Microstructure and oxidation behavior of sintered $\mathrm{Nb}-\mathrm{Mo}-\mathrm{Si}-\mathrm{B}$ alloys has been investigated at $1000^{\circ} \mathrm{C}$ under flowing air. In the Mo-Si-B system, the phase assemblies investigated were $\mathrm{T}_{1}\left(\mathrm{Mo}_{5} \mathrm{Si}_{3} \mathrm{~B}_{\mathrm{x}}\right)-\mathrm{MoSi}_{2}-\mathrm{MoB}, \mathrm{T}_{1}-\mathrm{T}_{2}\left(\mathrm{Mo}_{5} \mathrm{SiB}_{2}\right)-\mathrm{Mo}_{3} \mathrm{Si}$, and Mo- $\mathrm{T}_{2^{-}}-\mathrm{Mo}_{3} \mathrm{Si}$. Single phase $\mathrm{T}_{2}$ $\left(\mathrm{Nb}_{5}(\mathrm{Si}, \mathrm{B})_{3}\right)$ and $\mathrm{D} 8_{8}\left(\mathrm{Nb}_{5} \mathrm{Si}_{3} \mathrm{~B}_{\mathrm{x}}\right)$ were examined in $\mathrm{Nb}-\mathrm{Si}-\mathrm{B}$ system, along with three phase $\mathrm{T}_{1}-\mathrm{T}_{2}-\mathrm{D} 8_{8}$ in quaternary $(\mathrm{Nb}, \mathrm{Mo})$-Si-B system. Substitution of $\mathrm{Nb}$ for Mo resulted in expansion of $\mathrm{T}_{1}$ and $\mathrm{T}_{2}$ lattice constants. Because of $\mathrm{Nb} / \mathrm{Mo}$ substitution, the lattice parameters of $T_{1}, T_{2}$ and $D 8_{8}$ were all intermediate between corresponding $\mathrm{Nb}$ and $\mathrm{Mo}$ single-phase values.

Mo-Si-B alloys showed excellent oxidation resistance at $1000^{\circ} \mathrm{C}$. In accordance with previous work, the scale was found to be essentially a borosilicate glass layer with minor a content of $\mathrm{MoO}_{2}$ near the alloy/scale interface. $\mathrm{MoO}_{2}$ content varied depending on the Mocontent of the alloy and was maximum for composition $\mathrm{Mo}^{-} \mathrm{T}_{2}-\mathrm{Mo}_{3} \mathrm{Si}$. All $\mathrm{Nb}-\mathrm{Si}-\mathrm{B}$ compositions showed poor oxidative stability relative to Mo-Si-B alloys. In the Nb-Si-B system, $\mathrm{T}_{2}$ alloy showed more resistance to oxidation than $\mathrm{D} 8_{8}$ alloys. This can be attributed to lower porosity levels achieved in $\mathrm{T}_{2}$ (95\% theoretical density) than $\mathrm{D} 8_{8}$ ( $85 \%$ theoretical density) upon sintering under identical conditions. Oxidation behavior of niobium containing alloys, i.e. Nb-Si-B and Nb-Mo-Si-B alloys, were found to depend on initial heating atmosphere. $T_{2}$ and $D 8_{8}$ compositions were more resistant to oxidation when heated to test temperature in argon atmosphere. Quaternary alloy with lower $\mathrm{D} 8_{8}$ phase content was more resistant to oxidation, a consequence of the $\mathrm{D} 8_{8}$ phase having a lower oxidation resistance than $T_{2}$. Initial heating of alloys in argon resulted in scales that are thinner and lower porosity than that formed on alloys heated in air. Parabolic fit for mass change on oxidation suggests a process that is primarily governed by diffusion (inward diffusion of oxygen or outward diffusion of gaseous $\mathrm{MoO}_{3}$ ) through the porous scale containing niobium pentoxide dispersed in borosilicate glass. Although parabolic behavior was observed at $1000^{\circ} \mathrm{C}$, the large rate constants indicate that scale was not protective in nature. 
The mechanism of oxidation of Nb-Mo-Si-B during initial heating step was investigated. Results show the formation of $\mathrm{Nb}-\mathrm{Mo}$ oxide solid solution at temperatures below $800^{\circ} \mathrm{C}$, which later dissociates to $\mathrm{Nb}_{2} \mathrm{O}_{5}$ and $\mathrm{MoO}_{3}$ higher temperatures. The latter vaporizes to leave a porous scale with $\mathrm{Nb}_{2} \mathrm{O}_{5}$ dispersed in borosilicate glass. Evolution of $\mathrm{MoO}_{3}$ leaves large pores in the scale. Also, $\mathrm{Nb}_{2} \mathrm{O}_{5}$ presence in the scale appears to hinder the viscous flow of borosilicate glass at $1000^{\circ} \mathrm{C}$. Since the diffusion coefficient of oxygen in $\mathrm{Nb}_{2} \mathrm{O}_{5}$ is three orders of magnitude higher than of oxygen in silica glass, $\mathrm{Nb}_{2} \mathrm{O}_{5}$ can facilitate the diffusion of oxygen through grains and grain boundaries to further enhance the alloy oxidation. Severe cracks were observed in the matrix and scale presumably due to a large volume expansion associated with the formation of oxides.

The primary factor contributing to the oxidative instability of $\mathrm{Nb}-\mathrm{Mo}-\mathrm{Si}-\mathrm{B}$ alloys is believed to be the formation of $\mathrm{Nb}_{2} \mathrm{O}_{5}$ and the high scale porosity resulting from $\mathrm{MoO}_{3}$ evaporation. $\mathrm{A}$ novel chlorination technique was used to remove non-volatile $\mathrm{Nb}_{2} \mathrm{O}_{5}$ from the scale as volatile $\mathrm{NbCl}_{5}$ by flowing a mixture of chlorine and carbon monoxide over the pre-oxidized alloys. The chlorinated samples were then heat-treated to remove the scale porosity. A borosilicate glass rich layer with only minor amount of $\mathrm{Nb}_{2} \mathrm{O}_{5}$ was observed after chlorination. The oxidation rate of $\mathrm{Nb}-\mathrm{Mo}-\mathrm{Si}-\mathrm{B}$ alloys was reduced by two-thirds after $\mathrm{Nb}_{2} \mathrm{O}_{5}$ removal (from $0.76 \mathrm{mg}^{2} / \mathrm{cm}^{4} / \mathrm{hr}^{2}$ to $0.20 \mathrm{mg}^{2} / \mathrm{cm}^{4} / \mathrm{hr}^{2}$ ). The significant reduction in oxidation rate after chlorination indicates that the oxide scale became protective in nature on par with ternary Mo-Si-B $\left(0.24 \mathrm{mg}^{2} / \mathrm{cm}^{4} / \mathrm{hr}^{2}\right)$.

In order to develop Mo-Si-B as an alloy with good environmental and mechanical properties at high temperature, future work might consider adding an element, which can eliminate the formation of $\mathrm{Mo}_{3} \mathrm{Si}$ thus allowing oxidation resistant $\mathrm{Mo}_{5} \mathrm{Si}_{3} \mathrm{~B}_{\mathrm{x}}$ phase to be in equilibrium with Mo (to improve fracture toughness) and also forms a volatile oxide on exposure to air. Previous work at Ames Laboratory [1] has shown that V-Si-B forms a volatile $\mathrm{V}_{2} \mathrm{O}_{5}$ in scale, which evaporates by $1200^{\circ} \mathrm{C}$ allowing formation of passivating glass layer. In the $1960 \mathrm{~s}$, Scruggs found that powder metallurgical $\mathrm{Cr}$ is ductilized by addition of $\mathrm{MgO}$ particles that transform into $\mathrm{MgCr}_{2} \mathrm{O}_{4}$ spinel particles [2]. He determined that segregation of detrimental 
impurities such as nitrogen to the particle-matrix interface is one of the factors responsible for ductilization. Scruggs found also that Mo may be ductilized by adding $\mathrm{MgAl}_{2} \mathrm{O}_{4}$ or $\mathrm{NiAl}_{2} \mathrm{O}_{4}$ spinel particles [3]. Schneibel et al at Oak Ridge National Laboratory have confirmed the ductilizing effect of Mo by spinel particles.

Also, recent work at Oak Ridge National Laboratory [4] has shown a significant reduction in the thermal expansion anisotropy of Mo-Si alloys with ternary vanadium additions. Future work can concentrate on studying the ductalization of vanadium by spinel addition and preparing a composition rich in $(\mathrm{V}, \mathrm{Mo})_{s s}$ with spinel particles. The V-Mo-Si-B alloys with spinel particles might show a potential to form a protective glass layer with improved mechanical properties.

\section{References}

1. J. Williams, M. Akinc, "Oxidation behavior of $\mathrm{V}_{5} \mathrm{Si}_{3}$ based materials Intermetallics", 6, 269-275 (1998)

2. D. M. Scruggs, L. H. Van Vlack, and W. M. Spurgeon, "Reaction between nitrogen and spinel in chromium", J. Amer. Ceram. Soc. 51, 473 (1968)

3. D. M. Scruggs, "Ductile tungsten composition containing a spinel dispersed uniformly throughout," United States Patent 3,320,037 (1967)

4. C.L.Fu, J.H.Schneibel, "Reducing the thermal expansion anisotropy in $\mathrm{Mo}_{5} \mathrm{Si}_{3}$ by $\mathrm{Nb}$ and V additions: theory and experiment", Acta Materialia 51, 5083-5092 (2003) 


\section{ACKNOWLEDGEMENT}

The Ames Laboratory is operated by the US Department of Energy (DOE) by Iowa State University under Contract No. W-7405-ENG-82. This work was supported by the U.S. Department of Energy (DOE) National Energy Technology Laboratory under Field Work Proposal number AL-00-360-011.

I would like to dedicate this thesis to my parents, Ramesh and Rajkumari Behrani, for their moral and financial support throughout my academic career.

Thanks to Dr. Mufit Akinc, my major professor, for being a patient, wise and thoughtful advisor.

Thanks to Dr. Andrew Thom for useful discussions and advice throughout the work. Thanks to James Anderegg for discussions on XPS and Auger analysis.

Thanks to my lab mates Pranab, Heath, Chauang Ping, Wei, Tugba, and Tang for providing a healthy atmosphere in labs, and their criticism and discussion.

Finally, thanks to my graduate committee, Dr. Matthew $\mathrm{J}$ Kramer, Dr. Kurt R. Hebert and Dr. Mufit Akinc. 